\title{
Beiträge zur Geschichte der Stärke und der Verwandlungen derselben;
}

von Horace T. Brown und John Heron. (Bierza Tafol I und II.)

\section{Historisehes.}

Schon zu Anfang dieses Jahrhunderts wurde die Aufmerksamkeit der Chemiker auf jene merkwürdigen Umwundlungen gelenkt, welche die Stäke unter dem Einflusse von Hitze, Sãuren und gewissen pflanzlichen Extracten zu erleiden vermag.

Einerseits die bald in diesen Vorgãngen für die Industrie erkannte Bedeutang und andererseits die Aufklärung, welche sich aus ihnen in mancher Hinsicht für die Physialogie der Pflanzen hoffen liefs, waren der Grund, dafs die Chemie der Starke schnell ein Gegenstand allgemeiner, eifriger Forschung wurde. Und so ist seit 1811 fast kein Jahr vergangen, in dem nicht eine oder mehrere Arbeiten uber Stärke und deren Vinwandlungsproúucte erschienen wären. Aus einem Verzeichnifs, das neuerdings der eine von uns angefertigt hat, ergieht sich, dafs, wie wir beilăufig bemerken, über vierhundert solcher Abhandlungen vorliegen; unter diesen befinden sich, was wir kaum besonders za erwähnen nöthig haben, bōchst Ferthvoile und auf gedachtem Felde epochemachende. Hier mag es vielleicht geboten erscheinen, yon den unserer gesammten heutigen Kenntnifs auf diesen Gebiete zu Grunde liegenden Entdeckungen die wichtigsten aufzuführen.

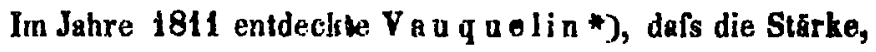
wenn etwas erhitzt, sich in eine in Wasser völlig lösliche 
166 Brown u, Heron, Beiträge zur Geschichte der

Substanz verwandelt, die viele der physikalischen Eigenschaften des arabischen Gummis besitzt. Um die gleiche Zeit fand Kirchhoff*), dafs die Stärke beim Kochen mit verdünnter Schwefelsăure einen krystallisirbaren Zucker liefert und zwei Jahre später (1814) entdeckte der gleiche Chemiker, dafs der in Korn enthalteae Pfanzeneiweifsstoff eine ähnliche Umwandlang hervorzurufen im Stande sei und dafs diese dem Eiweifsstoff innewohnende Kraft bedeutena verstärkt werde, wenn man das Getreide vorher dem Malzungsverfahren aussetze **).

Im Jahre 1812 fand Vogel $* * *$ ), dafs durch die Wirkung von heifser verdünnter Sāure auf die Stärke aufser dem Zucker noch ein gummiähnlicher Körper sich bilde. Eingehender ist diuses Gummi im Jahre 1833 beschrieben und untersucht worden $t$ ) von Biot und Persoz, welche demselben wegen seiner Eigenschaft, die Polarisationsebene beträchtlich nach rechts (dexter) abzulenken, den Namen Dextrin gaben. B i ot und Persoz legten in ihrer Abhandlung den Grund zu den heutzutage gebräuchlichen, genauen optischen Verfahren, die in den Händen von B ond on e a u, M uscul us, o'Sullivan u. A. so wichtige Ergebnisse zu Tage gefördert haben.

Dafs Stärke ein Reagens auf Jod ist, wurde schon 1813 von Stro m e yer ti) entdeckt, und die reducirende Wirkung der Stärkeproducte auf eine alkalische Kupferlōsung wurde zuerst von $T$ r o $m \mathrm{~m}$ er $f++$ ) untersucht. Pa y e $\mathrm{n}$ und $P$ e r soz stellten im Jahre 1833*) fest, dafs die Wirkung eines Auf-

\footnotetext{
*) Schweigg. Journ. 4, 108.

**) Daselhst 1815, 14, 389.

**) Daselbat E, 80.

t) Ann. chim. phyw [2] 58, 72.

†) Schwigg. Journ. IA, 349.

tf) Diese Annalen $89,360$.

*) Ann. chim. phys. 58, 73.
} 
gusses von gemalztem Getreide auf die Stärke von der Gegenwart eines besondersartigen Verwandlungsagens herrührt, welches sie wegen der ihm innewohnen sollenden Eigenschaft, das Innere der Stärkekörnchen von deren Hülle zu scheiden, Diastase benannten.

Die wirkliche Zusammensetzung des Stärkekörnchens wurde zuerst von Fritzsche in einer werthvollen, von demselben im Jahre 1834 *) veröffentlichten Abhandlung nachgewiesen, welche einige Jahre darauf die Grundlage gebildet hat zu $\mathrm{C}$. Nàg e li's klassischen Untersuchungen über die Morphologie des Stürkemehlkorns; letztere finden sich in der vortrefflichen Monographie desselben, betitelt „Die Stärkekörner" (Zürich 1858) zusaminengefafst.

Die im Jahre 1860 verōffentlichten Untersuchungen von Muscalus liefsen die Binwirkung der Schwefelsäure und der Diastase auf die Stärke in ganz neuem Lichte erstheinen. Bis dahın war man nănlich in dem Glauben, dafs der bei dieser Reaction gebildete Zucker ein durch Wasserbindung aus Dextrin hervorgegangenes Product sei, und dafs somit das Dextrin, isomerisch mit der Stärke, in der Mitte zwischen dieser und dem Zucker stehe. Musculus kam jedoch auf experimenteller Grundlage zu dem unabweisbaren Schlusse, dafs diese Auffassung eine irrige sei, indem die durch Wasseraddition bewirkte Spaltung des Stärkemoleculs die gleichzeitige Bildung von Dextrin und Zucker ergebe **).

Ob zwar diese Anschaung zur Zeit starken Widerspruch fand und viele Chemiker, insbesondere $\mathrm{Pay}$ en und $\mathrm{Sch}$ war$z e r$, derselben entgegentraten, so hat sulche doch Stich gehalten und wird heutigen Tages im Grofsen und Ganzen als richtig anerkannt.

*) Pogg. Ann. 8\%, 128.

**) Ann. chim. phys. [3] 10, 203 i Compt. rand. 54, 194. 
168 Brown u. Horon, Beiträge zur Guschichte der

Es wũrde uns za weit führon, wollten wir auch nur im Umrisse die vielfăltigen, auf den genannten Entdeckungen forsenden Nachforschungen anzudeuten versuchen; wir bogaủgen uns also damit, den Gegenstand bei einem verhëltnifsmấsig neueren Datum aufzunehmen.

In einer Reihenfoige bemerkenswerther und höchsı werthvoller, in der Zeitschrift der englischen chemischen Gesellschaft z zwisclen 1872 und 1876 erschienener Abhandlungen hat 0 'Sullivan nachgewiesen, dafs der durch die Einwirkung von Diastase oder Säure aú die Stärke erzeugte Zucker nicht, wie bis dahin allgemein angenommen war, Dextrose, sondern ein sacsharinartiger Zucker ist, mit bedeutend gröiserer optischer Thätigkeit als Dextrose und von weil geringerer reducirender Wirkung auf Fehling 'sche Lösung.

Dieser Körper war vordem schon von de Saussure im Jahre 1819 ) isolirt worden, doch hatte dieser nur die krystailinische Beschaffenheit desselben und zwar mit grofser Genavigkeit beschrieben. Der gleiche Körper wurde hinwiederum 1847 von Dubrunfais **) dargestelit, und letzterer erkannte denselben an seinen optischen Eigerischaften als eine besondere Znckerart und benannte ihn Maltose. Doch hlieben Dubrunfaut's Beobachlungern zur damaligen Zeit ziemlich unbeachtet und scheinen, bis $O^{\prime} S u l l i$ y a n viele Jahre später die Maltose neu entueckte, gànzlich in Y'ergessenheit gerathen zu sein.

Nachdem $0^{\prime}$ Sulli i an die Haupteizenscheften der Maltose und des Dextrins, welehe nebst Dextrose die einzigen aus Stärke zu gewinnenden Producte sind, festgestellt, suchte und

*) Journ. Chem. Soo. [2] 10, 579. Dawellut [3] 2, 125. Daselbst [8] $\mathbf{2}, 478$.

**) Ann. chim. phys. 11, 879.

***) Daselbat [3] 21, 178. 
fand er, in welcher besonderen $W$ eiss die Stärke unter der Wirkung von Malzextract und der variirenden Temperaturverhältnisse gespalten wird. Die Ergebnisse seiner Untersuchungen lieisen ihs in Vebereinstimmung mit M usculus darauf schliefsen, defs die Verwandlung der Stärke in Dextrin und Maltose nicht einer stufenweisen Zersetzung durch Wasseraufnahme gleichriomun, bei welcher Dextrin zuerst und alsdann Maltose gebildet wird, sondern dafs die beiden Kórper durch Spaltung des Stärkemoleculs gleichzeitig und in äquivalenten Mengen entstehen.

Die Zersetzung der Stärke lăfst sich, je nach der Temperatur, bei welcher sie vor sich geht, durch eine der drei folgenden Gleichungen zur Anschauung bringen :

$$
\begin{aligned}
& \text { (A) } \mathrm{C}_{18} \mathrm{H}_{80} \mathrm{O}_{16}+\mathrm{OH}_{3}=\mathrm{C}_{15} \mathrm{H}_{22} \mathrm{O}_{21}+\mathrm{C}_{0} \mathrm{~B}_{20} \mathrm{O}_{3} \\
& \text { Maltoso Dextrin. }
\end{aligned}
$$

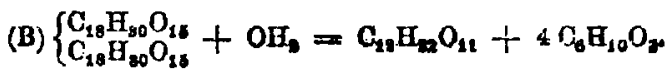

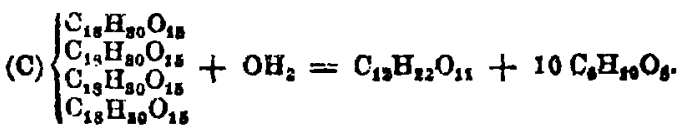

Die Verwandlung entspricht der Gleichung (A), wepn Malzextract auf Stärkekleister bei einer Temperatur von unter $63^{\circ} \mathrm{C}$. einwirkt, der Gleichung (B) bei einer Temperatur ron $64^{\circ}$ bis $68^{\circ}$ oder $70^{\circ}$ und der Gleichung (C) von 68 bis $70^{\circ}$ bis zu der Ternperatur, bei der das Verwandlungsagens zu wirken auf hört.

Obigen Gleichungen entspricht das specifische Rotationsvermōgen und das Kupferoxydreductionsvermögen der gemischten Verwandlungsproducte, wie folgt :

$\begin{array}{ccc} & & \text { Kopferoxydreductionsrormbgen } \\ \text { in Procenten } & (\alpha) & 44,1 \\ \text { (A) } & 170,6^{\circ} & 22,4 \\ \text { (B) } & 191,8^{\circ} & 2,4 \\ \text { (C) } & 202,5^{\circ} & 11,3 .\end{array}$


170 Brovn u. Heron, Beiträge zur Geschichte der

Die aus den obigen Verwandlungen sich ergebenden Dextrinurten gelten sämmtlich als identisch and sind fähig, bei fortgeführter Digestion der Lösung mit Malzextract durch langsame und allmălige Wasserbindung in Maltose überzugehen. Bel mehrstündiger Fortfuhrung der Digestion fand sich, dafs die Moltose anscheinend eine geringe Menge Dextrose oder eine Dextrosenmischung mil dem optischen Gesammtdrehungsvermōgen von $(\alpha)+67^{\circ}$ abgab. Diese Erzeugung von Dextrose wurde dem Umstande zngeschrieben, dafs in dem zur Verwendung kommenden Malzextract stets ein geringes Quantum Sãure sich vorfand.

O'Sulli ya n hălt dafür, dafs die in den drei Gleichungen dargestellten Ergebnisse von gewissen, durch die Hitze in der Natur des Verwandlungsagens hervorgebrachten Veränderungen, nicht aber von irgend welchem Unterschiede in der Gröfse des Stärkenoleculs herzaleiten sind.

Nach Mãroker*) geben vier Stãrkemolucule bei $60^{\circ} \mathrm{C}$. drei Maltose und ein Dextrin; bei $65^{\circ}$ geht das Quantum Maltose etwas herunter und bei noch höherer Temperatur liefern zwei Stärkemolecule ein Maltose und ein Dextrin. Hieraus schliefst Marcker, dafs vielleicht zwei diastatische Fermente vorhanden sind, von welchen das eine viel Maltose und wenig Dextrin erzeugt and bei verbältnifsnñufsig niederer Temperutur erlischt, während das andere mehr Dextrin und weniger Maltose hervorzubringen vermag und bei einer höheren Temparatur zerstört wird. Das letztere Verwandlungsagens wirkt nicht ouf das Dextrin, während eine frische, unerhitzte Diastase dasselbe rasch in Zucker rerwandelt.

Im Juli vorigen Jahres haben $\mathbf{L}$ u s c u lus und Gruber **) die Ergebnisse einer neuen Reihe von Versuchen mit Stärke

") Landw. Venuchsstat. D9, 69 und Ber. der Naturfor. München 1877.

**) Bull. soa. chim. 80, 54. 
beschrieben. Dieselben betrachten die Stärke als ein die Gruppe $\mathrm{C}_{18} \mathrm{H}_{80} \mathrm{O}_{10}$ fünf bis sechs Mal enthaltendes Polysaccharid. Unter der Einwirkung der Diastase oder verdūnnter Säuren finden in diesem Koblehydrat eine Reihe Wasserbindungen und darauf folgender Zersetzungen statt, als deren Resultat Maltose und ein neues Dextrin von geringerem Moleculargewicht sich ergeben. Dieser Procefs geht schrittweise vor sich bis zum $\boldsymbol{\gamma}$-Achroodextrin, welches dann, wabrscheinlich durch einfache Wasserbindung, in Maltose verwandelt wird. Die Verfasser stellen drei besondere Achroodextrine (d. h. Dextrine, die nicht von Jod gefärbt werden) auf, die durch ihre optische Thătigkeit und durch ihr Kupferoxydreductionsvermögen von einander unterschieden sind; es sind diefs folgende :

$(\alpha)_{j} \quad$ Kupfexoxydrednctioneverzuögen

$\Delta$ chroodextrin a $210^{\circ}$

12

Achroodextrin $\beta 190^{\circ}$

12

Aohroodextrin $\gamma 150^{\circ}$

28.

Aus den Ergebnissen unserer eigenen Versuche wird es sich, sobald wir an die Beschreibung derselben gelangen, erweisen, dafs auch wir triftige Gründe dafür haben, die Achroodextrinarten als nicht identisch hinzustellen. Wir haben dieselben in einigen ihrer Eigenschaften so verschieden von einander gefunden, dafs diefs nur durch die Annahme einer mehr oder weniger complicirten Natur ihrer Molecule zu erklären ist. Unsere Ergebnisse wurden einige Monate vor dem Brscheinen der M usculus und Gruber'schen Abhandlung erzielt : Diese Thatsache erwähnen wir nicht etwa, um einen Streit über Prioritātsanrechte an diese Entdeckung zu veranlassen, sondern nur, weil dieselbe der gedachten Theorie ejne grörsere Wabrscheinlichkeit verleiht. Die optischen und übrigen Eigenschaften unserer Dextrinarten entsprechen indeßs nicht denen der von Musculus und Grubor beschriebenen. 
172 Brown u. Heron, Beiträge zur Geschichte der

Musculus and Gruber gebrauchten bei ihren Versuchen aus Malz hergestellte, gefältte Diastase. Wir selber haben mit der nach $\mathrm{H}$ ü $\mathrm{n}$ \& $\mathbf{r}$ 's Glycerinverfahren *) bereiteten sogenannten Diastase einige Versuche angestell, jedoch gefunden, dafs die Wirkung derselben sich je nach der Herstellungsweise bedeutend ändert. Durch wiederholte Lösung in Glycerin und Fällung mit Alkohol und Aether wird die Thätigkeit des Körpers stetig verringert, bis derselbe schliefslich den Stärkekleister dúnnfüssig macht, jedoch ohne irgend welche weitere Verwandlung 20 erzeugen. Bei anseren sãmmtlichen nachfolgenden Untersuchungen haben wir uns deshalb eines kalten wàsserigen Malzaufgusses als Yerwandlungsmittels bedient, da derselbe bei gehöriger Vorsicht den höchsten Grad von Gensuigkeit zuläfst.

\section{Versuchsmethode.}

Reinigung der Kartoffelstärke. - Sämmtliche im Gegenwärtigen beschriebenen Versuche sind mit Kartoffelstärke angestellt worden, welche zuerst tüchtig in Wasser gewaschen und dann nacheinander mit einer sehr verdünnten Lõsung von Folihydrat und einer einprocentigen Losung von Salzsäure behandelt wurde. Die Stärke wurde darauf zuerst vollständig in Wasser gewaschen, bis jede Spur von Säure verschwunden war, und dann bei einer $25^{n}$ C. nicht übersteigenden Temperatur getrocknet. Die derart zugerichtete Kartoffelstärke wird unter günstigen Verhältnissen vorn Malzextract so vollständig verwandelt, dats dieselbe eine fast absolut durchsichtige Lōsung ergiebt, denn der Rackstand von ungefahr acnt bis zehn Starkekörnchen fallt fast gar nicht in's Gewicht. Derart behandelte Stärke lăfst nicht mehr als 0,15 pC. Asche zurück. Feinkörnigere Stärke, wiu z. B. die aus Welschkorn oder Reis

*) Joumal fur prakt. Chemie [2] 6, 872. 
dargestellte, lifst sich nach dem obigen Verfahren nur schwierig rein erhalten und ist demgemärs zu den in dem Nachfolgenden zu beschreibenden Versuchen weniger geeignet.

Herstellung des Stärkekleisters. - Bei der Herstellung des Stärkekleisters ist wohl Bedacht zu nehmen, dafs die Verwandlung in Gallerte vollständig vor sich gehe und dafs die Masse durchaus homogene Besehaffenheit zeige, sonst ist es unmöglich, eine vollkommene Gleichartigkeit in den Ergebnissen zu erzielen. $\mathrm{Zu}$ diesem Behufe ist es am Besten, die Stärke mit einer genügenden Menge kalten Wassers zu mengen, bis dieselbe zu einem dūnnen Brei wird und letzteren alsdann anter beständigem und schnellem Umrühren in Wassor von $100^{\circ}$ einzugiefsen. Am Besten nimmt man 3 bis $5 \mathrm{Grm}$. Stärke per 100 CC. Der Kleister mufs nicht za dickflüssig sein, insbesondere wenn nur kleine Mengen Malzextract zur Anwendung kommen sollen.

Bereitung und Analyse des Malesatracts. - Das Malzextract wurde stets in folgender Weise zubereitet : $100 \mathrm{Grm}$. fein gemahlenes helles Malz wurden mit $250 \mathrm{CC}$. destillirtem Wasser gemischt. Die Mischung wurde wohl umgerührt, dann 6 bis 12 Stunden stehen gelassen und alsdann völlig klar filtrirt. Die so gewonnene filtrirte Lösung hat, je nach der verwendeten Malzgattung, ein specifisches Gewioht von 1036 bis 1040 (Wasser $=1000)$; wir nennen dieselbe das normale Malesxtract, und letzteres baben wir, soweit es nicht anders angegeben ist, durchgāngig bei unseren Versuchen angewendet. Das specifische Gewicht, die optische Thätigkeit und das Kupferoxydreductionsvermögen des Malzextracts ist entweder in der ursprünglichen Flūssigkeit, the irgend welche Behandlung stattfindet, zu bestimmen, oder aber nach dem Erhitzen und Filtriren; es hängt dlefs von den Umstānden ab, unter denen der Versuch ausgefuhrt wird. 
174 Brown u. Heron, Beiträge eur Geschichte der

Vorsichtsmaísregoln beim Einwirkenlassen von Malzextract auf Starke. - Vom Malzextract wird eine bestimmte Quantität aus eíner Bürette oder einer genau graduirten Pipelte in den Stärkebrei getropft, welcher inzwischen in einem Wasserbad auf die für die Verwandlung erforderliche Temperatur gebracht worden ist. Das Wasserbad wird mittelst eines Thermostats auf gleichförmiger Temperatur erhalten. Hierfür haben wir Page's Regulator ganz besonders zweckdienlich gefunden.

Sobald der Versuch zu Ende ist, läfst man die Flüssigkeit bis auf $15,5^{\circ} \mathrm{C}$. erkalten, dann mifst man den Raumgehalt derselben, oder aber wiegt, wenn besondere Genauigkeit erforderlich ist, die Lösung and bestimmt das Volum nach dem specifischen Gewicht. Sollen, während der Verwandlungsprocefs vor sich geht, Proben zur Untersuchung mit Jod herausgenommen werden, so sind solche mit einer Pipette sorgfältig abzumessen und spāter bei Bestimmung des Gesammtranmgehalts der Flüssigkeit in Abrechnung zu bringen.

Falls die Zeit der Verwandlung über 15 bis 20 Minuten binausgeht und das zur Verwendang kommende Malzextract mehr als 2 bis $3 \mathrm{CC}$. per 1 c0 CC. Stárkekleister beträgt, sollte ein wenig ron dem Malzextract in einer besonderen Flasche wâhrend der gleichen Zeitdauer und unter denselben Wärmeverhältnissen wie die Verwandlungsflüssigkeit digerirt werden; in einem solchen Falle hat die Analyse des Malzextracts nach der Einwirkung stattzufinden. Die Gründe für diese Vorsichtsmafsregel werden von selber klar werden, sobald wir zur Betrachtung der von der Hitze in Malzextract bewirkten Verānderungen gelangen.

Analyse der Stärkeverwandlungsproducte.

a) Berechnung der festen Substanx. - Die Lösung der Stärkeproducte ist nun zu analysiren. Zuerst wird das speci- 
fische Gewicht derselben bei $15,5^{\circ}$ (Wasser bei $15,5^{\circ}$ als 1000 angenommen) bestimm! und mit dessen Hülfe die gesammte feste Masse per $100 \mathrm{CC}$. dadurch annihernd festgestellt, dafs man das specifische Gewicht minus 1000 (Wasser $=1000$ ) mit der Constanten 3,86 theilt *). Von der Summe des derart erzielten festen Stoffs ist das in je $100 \mathrm{CC}$. Malzextract an festen Körpern Enthaltene abzuziehen. Die Differenz ergiebt, wie viele Gramme Stărkeproducte per $100 \mathrm{CC}$. Flüssigkeit vorhanden sind.

b) Bestimmung des Kupferoxydreductionsvermögens. Demnächst ist das Kúuferoxydreductionsvermōgen der Flüssig-

") Diese Conatante ist far Robreuckerlösungen rom specifinchen Gowichte 1050 absolut richtig. Wir wimen wohl, dafs der wirkliche Theilungseozffecient für Doxtrin- und Maltowolösungen von oraterer otwas abweicht, doch hat diefs anf unsere in Procenten ansgodriekten Rosultate keinen Einfluf, da den im Gegenwurtigon gebrauchten 2ablen, die des speoifischo Rotationsvermögen ron Maltose, Doxtrose and Doxtrin, sowie des Kupferoxydreductionsvermïgen dex Maltose und Dextrose darstellen, slmmtlich dio gleiche Conutante 8,86 zu Grundo liegt. Obzwar diener Theiler auch noch für Rohrzuckerlösungen von 1 bis $10 \mathrm{pC}$. als ziemlich richtig betrachtet werden kann, so erweint sich dersolbo doch rar Lösungen ron gröfeorom apecifuchen Gewricht als za boch, da das Volumen, welches eine Gewichtseinheit Zucker in Lbungen ron bohem specifischen Gewichte einnimmt, gröfser ist, als dasjenige derselben Gowich tseinheit in Lbsungen ron niedorem upecifischon Gewichte; oder in anderen Worten : wenn oin gegebenes Volumen einer concentrirten Rohrauckerlösnng mit einem gegebenen Tolumen Wasser oder specifisch leichterer Zuckeriobsung rersefat wird, so ist das sich ergebende Volnmen geringer, als dis Summe der beiden Vulumina.

Die Ergabnisse unserer in dieser Richtong mit Rohruacker angestellten Versuche aind in Tafel I, Figur 1 in Carvenform dargestellt. Diese Curvo setzt uns in den Stand, auf den orsten Blick den fär Lönangen rom specifschen Gewiobt 1000 bis 1070 erforderlicken Theilor sn erkennen, mit Hälfe dessen nich die Qnantitat Zuokex in Grammen por $100 \mathrm{CC}$. Flüssigkeit bosfimmen lafst. Dis Curvo ist nahezu eine Parabel. 
176 Brown 4. Horon, Beiträge zur Geschichte der

heit zu bestimmen. Dasselbe wird gravimetrisok mit Fehling'scher Kupferlösung ermittelt. Ba mufs hier vorsichtshalber die 20 arialysirende Flüssigkeit gewogen werden, denn da die zur Verwendung kommende Mengo sellen 5 bis 6 CC. ubersteigt, so würde der geringste Fehler im Messen der Genauigkeit Einlrag thun. Man findet das Volumen der Flisssigkeil dadurch, dafs man das Gewicht in Grammen durch das specifische Gewicht theilt. Man nimmt von der Flüssigkeit ein Quantum, genügend, um 0,2 bis $0,3 \mathrm{Grm}$. Kupferoxyd zu liefern. Die Reduction mit Fehling'scher Lösung geschieht auf die Dauer von 12 bis 15 Minuten in einem Wassarbade. Wenn irgend welche von den höheren Dextrinarten vorhanden sind, so ist es nicht rathsam, die Erhitzung lānger wāhren zu lassen, da diese beim Erhitzen mit Kalilösung etwas verändert werden. Der Kupferoxydulniederschlag wird filtrirt und getrocknet, dann durch Glühen oxydirt und hierauf gewogen.

Nunmehr ist das Gewicht des ron 100 CC. der behandelten Flüssigkeit reducirten Kupferaxyds $z u$ berechnen. Bezeichnet $\mathbf{x}$ dieses Gewicht, $\mathbf{v}$ den Raumgahalt der Flüssigkeit in Cubikcentimetern und w das Gewicht des Kupferoxyds, so ist :

$$
x=\frac{100 \pi}{\nabla} .
$$

Vom Werthe für $x$ ist abzuziehen das Kupferoxyd, welches der in $100 \mathrm{CC}$. der Verwandlungsflussigkeit enthaltenen A nzahl Cubikcentimeter Malzextract entspricht *).

*) Durch dieses Verfahren, zuckerartige d. b. reduoirende Substanzen zu bentimmen, lassen sich bel Beobachtung gehöriger Vorsicht tiberaus gengne und thbereinutimmende Ergebnisse erzielen und die neuerdings ron Soxblet (Chom. Centralblatt, 8. Folge, 9. Jabrgeng, B. 219) aungesprochene. Verurtheilung des gravimotrischen Vorfubrens lot durchaus nubegretndet. Wir halten un ta dienur Bohauptang um to mehr berechtigt, als wir durch oine drejjuhrige Praxis die Zavorlässigłeit jener Methodo za orproben Golegenhelt hatten. 
v) Bestimmung der optischen Thätigkeit. - Es verbleibt nun noch die optische Thătigkeit der gedachten Substanz zu bestimmen. Alle optischen Beobachtungen wurden mit einem von $\mathrm{Sch}$ in id $t \mathrm{Haensch}$ in Berlin angefertigten Soleil-Venizko-Scheibler'echen Apparat ansgefübrt. Der Analysator, Polarisator und Compensator sind so gestelit, dals dieselben auf dem Nulipunkte einen Lichtkreis ergeben, der gleichförmig von der sogenannten Neutraltinte erleuchtet wird, welche an Brechbarkeit dew mittleren gelben Strahl des Sonnenspectrums entsprichz. Die Lösungen der Stärkeverwandlungsproducte, die beinahe immer forblos waren, wurden fast durchgängig in einer 200 MM. langen Sāule untersucht. In keinem einzigen Falle ist Thierkohle zur Entfärbung der Flüssigkeiten verwendet worden.

Untersuchung gefürbter Lösungen. - Um die geringe Schwierigkeit, welche die Farbe des Malzextracts bei der Untersuchung jener Flüssigkeit mit sich bringt, zu beseitigen, wurdo eine $100 \mathrm{MM}$. lange Säule verwendet, welihe dem am Yorderende des Apparats befindlichen überzïhligen Nicol'schen Prisma eine geringe Drehang beibrachle, so zwar, dals dadurch einer etwaigen leichten Färbung der Lösung entgegengewirkt wurde. Vermēge dieses drinen Nicoi'schen Prismas wird der Soleil-Yentake-Scheibler'sche Apparat für derartige Beohachtungen un so geeigneter, als bei feiren Untersuchungen die Entfärbung tnittelst Kobie nicht als zldverlāssigg betrachtet werden kann; denn wenn auch heim Filtriren das zuerst Durchlaufende beseitigt wird, kormmt es doch selten vor, dais das Filtrat einer viele linksdrehende Albuminoïde enthaltenden Lösung genau dieselbe optische Thätigkeit besilzt, wie die ursprüngliche Flüssigkeit.

Bei dem von uns verwendeten Instrumente firden wir, dofs 100 Th. der Scala 38,22 Bogengraden gleichkommen. Ist das Licht recht gut und die Lösung recht durchsichtig, so 
abersteigt die Abweichung in der Gradbestimmung für ein geübtes Auge nicht $1 / 10$ eines Scalenthciles $\leftarrow 2,3$ Minuten der Kreiseintheilung *).

- Verhalten des Auges aur Neutraltinte. - Bai diener Gelegenheit wollen wir einer eigenthümlichen, beim Gobrauche des Polariskops sich einstellenden und unueres Winsens bisiang noch unbeschtet gebliebenen Erscheinung ororkmen. Wenn der Apparat ron Einem von uns Boiden gonau auf Null gestellt ist, d. h. wonn die beidon Halbsobeiben von der wabron Noutraltinte gleich orleuchtet sind, so finden wir, dafs der Andere, um ejne pöllig gleiche Neutralitat zu erzielen, den Compansator um ${ }^{2} / 10$ einer Eintheilung nach Rechts vorrücken mufs. Zuerat glaublen wir, diese "persönlicho Bogleichung ", wenn wir es so nennen dürfen, habe ihren Grund darin, dafs etwa Einer ron uns Beiden für verschwindend kleino Farbenunterschiede oin besseres Empfindungevermōgen habe; wire dem aber so, so müfate des weniger empindlicho Auge durch zwei auf je einer Seite des wabren Nullpunkta befindlicho und von letzterem gleich woit abstehendo Punkte sich befriedigen lassen, denn an diesen beiden Punkten waren dann die Farben in Tiefe einauder gleich, jedoch on ihrer Stellung an einander umgekehrt. Thatsuchlich ist diefs jedoch nicht der Fall, dor Boobscbtunganterschied ist bei beidon stets in einer und derselben Bichtung und bloibt sich stetm numerisch gleich. Zur Zeik vermögon wir für diese Erscheinung noch kuine befriedigende Erklarung au geben, glauben jodooh, dafs oine solche im Bereich der physiologischen Optik gefonden werden durfte. Die Untersuchang der Augenfuchtigkeit (im Ocbenenge) durch Einen von uns Beiden bat die Thatsaohe offenbart, daff whorend die whsserge und die Glasfouehtigkeit keinerlei Wirkung anf das planopolarisirte Licht hervorbringen, die Krystallinse selber ein markirtes Linksdrehungsvermögen besitzt. Wir finden, dafe ein 4,5 MM. dicker Linsendurchschuitt die Polariantionsebene für die Neutraltinte um $1,34^{0}$ nach Links za drehen rermag. Diese Linkedrehung ist oben so grofs, wie die Bechtsdrehung einer 14 procentigen Rohrzuckerlöвung in einer gleich dicken Schicht. Diese Figenschaft der Krystallinse dürfte rägglicherweise mit der "persönlichen Bogloichung" des Polariskops in Verbindung stehen, kann jedoch nicht den directen und auscchliefslichen Grund der Erscheinung abgeben, da eine circularpolarisirende Substanz, wonn volcho zwischen das latzate Nicol'sohe Prisura und das Auge tritt, keineswogs dio relativen Nanoen der beiden Soiton dor erleuohteten Schoibe an undern rermeg. 
Die auf dem 200 MM. langen Rőhrchen abgelesene Ziffer wird durch 2 getheilt, und durch Correctur wird der durch das Malzextract verursachten $\mathbf{A b w e i c h u n g ~ R e c h n a n g ~ g e t r a g e n . ~}$

Nun haben wir drei unter Berücksichtigung des zur Verwendang gekommenen Malzextracts corrigirte Factoren für die Stärkeumwandlungsproducte erhalten, nämlich :

1) Die gesammten festen Bestandtheile, in Grammen per $100 \mathrm{CC}$. ausgedrückt (corrigirt);

2) das durch $100 \mathrm{CC}$. der Lösung reducirte Quantum Kupferoxyd (corrigirt);

3) die (corrigirte) optische Thátigkeit der Lōsung in dem 100 MM. langen Rohre, in Scalentheilen des Soleil'schen Instruments ausgedrückt.

Yon diesen Daten haben wir das specifische Drehungsvermögen der festen Masse sowie deren Kupferoxydreductionsvermōgen in Procenten abzuleiten.

Das absolute specifische Drehungsvermogen eines Steffs ist die Winkelabweichung eines Strahls von planopolarisirtem Lichte von bestimmter Brechbarkeit, der durch eine Schicht von dessen wásseriger Lősung geht, welche $1000 \mathrm{MM}$. dick ist und $10 \mathrm{Grm}$. von dem Stoffe per $100 \mathrm{CC}$. enthält. Wenn die dem mittleren gelben Strahl des Sonnenspectrums entsprechende Neutralfarbe zur Anwendung kommt, so wird dus specifische Umdrehungsvermögen mit dem Symbol [a] bezeichnet, wăbrend $[\alpha]_{D}$ das specifische Drehungsvermōgen für das dem weifsglübenden Natriumdampfe entstrōmende Licht darstellt *).

Bei Versuchen, wie wir sie hier beschreiben, mufs das Quantum der in Lösung befindlichen Masse nothwendigerweise mittelst des specifischen Gewichts bestimmt werden, und da

*) Das Vorhältnif ron $[\alpha]_{j}$ en $[\alpha]_{D}$ int fur Kohlehydrato $=24: 21,54$. 
180 Brown u. Heron, Beiträge zur Geschichte der

die Dichtigkeit der verschiedenen Kohlehydrate in Losung elwas variirt, so leuchtet es ein, dafs wenn zwei oder mehr solch» Kõrper neben einander anwesend sind, die Feststellung der festen Masse viel zu complicirt wird. Aus diesem und dem noch triftigeren Grunde, dafs die Lösungsdichtigkeit der versehiedenen Kohlehydrate bisher nur sehr unvollkommen hestimmt ist, entschlossen wir uns, einen constantei und nicht variirenden Theiler zur Bestimmung der festen Masse snzunehmen, auf den sämmtliche specifische Rotationskräfte zu beziehen sind. Dieser Theiler ist, wie schon oben bemerkt, $=3,86$, und so oft derselbe zur Bestimmung der Constanten verwendet wird, fügen wir ihn dem gewöhnlichen Symbol für das specifische hotationsvermögen folgendermarsen bei : $[\alpha]_{j}, 3,86$. Um $[a]_{j, 68}$ in das absolute specifische Drehungsvermögen 2 a verwandeln, braucht nur die Winkelgröfse in dern Verhältmisse von 3,86 zum absoluten Theiler, sobald dieser ermittelt ist, vergröfsert oder verringert zu werden.

Aenderung des Drehungsvermögens mit der Concentration. - Die jüngsten Versuche von trollens und von Schmitz wher Dextrose und Rohrzucker * deuten darauf hin, dafs das specifische Drehungsvernögen dieser Körper nicht ein und dasselbe in concentririen und in verdünten Lossungen ist. Fur Rohrzucker fand sownhl Tollens wie Schmitz, dafs bei stark concentrirten Lossngen der $W$ erth von $[\alpha]_{n}$ marklich geringer war als bei verdünnteren, während betreffs der Dexirose jener Beobachter bei stark inncentrirten Lösungen eine merkiche Erhöhung im specifischen Drehungsvermögen wahrnabm.

Fernere Untersuchungen werden wahrscheinlich ähnliche Anomalien bei alien Kohlehydraten mit optischer Thãtigkeit

*) Bericate dex deutuchan chemischen Gesellschaft 5,$1331 ; 10$, 1403,$1414 ; 21,1807$. 
ergeben; da jedoch die beregten Rrscheinungen nur bei stark concentrirten Lösungen beobachtet worden sind, so können unsere sämmtlich mit verdünnten Lösungen angestellten Versuche in ihrer Genauigkeit hiervon nicht berührt werden.

Der Werth von $[\alpha]$ s,8 wird folgendermafsen ermittelt : Es sei :

$x=$ die rom pecifischen Gowicht hergeleitete und fur Maizextract corrigirte Grammenzahl (per 100 CC.) der slammtlichen Btirkererwandlungsproducte,

$y=$ der auf dem 100 MM. Rohr abgelesene und bextglich des Malzextracts corrigirte Stand der Lösung in Scalentheilen; so ist :

$$
[\alpha]_{\mathrm{s}, \mathrm{ss}}=\frac{3,822 \mathrm{y}}{\mathrm{x}},
$$

wo 3,822 eine Constante für das in Anwendung kommende Instrument, da 100 Scalentheile $=38,22^{\circ}$.

Kupferoxydreductionsvermögen ( $x$ ) auf Dextrose als Norm bezogen. - Bei Ermittelung des Kupferoxydreducirungsvermögens eines Körpers hat 0 'Sullivan die Dextrose als Vergleichungsnorm angenommen. Das Kupferoxydreductionsvermögen definirt or als „das als Dextrose berechnete Quantum Kupferoxyd, welches 100 Th. reduciren * *) wenn also das von $1 \mathrm{Grm}$. Dextrose reducirte Quantum Kupferoxyd bekannt ist, so stellt das nach dieser Zabl als Norm in Procenten berechnete, von $1 \mathrm{Grm}$. irgend eines anderen Stoffs reducirte Quantum Kupferoxyd das Kupferoxydreducirungsvermögen dieses Stoffs dar und wir bezeichnen dasselbe mit dem Symbol $x$. Hier hinwiederam, wie beim specifischen Drehungsvermōgen, wird die Constante 3,86, wenn dieselbe zur Ermittelung des Werthes von $x$ gedient hat, letzterem angefügt $\left(x_{3,88}\right)$.

Das von $1 \mathrm{Grm}$. Dextrose reducirte Quantum Kupferoxyd ist als $=2,205 \mathrm{Grm}$. ermittelt worden. Wir haben uns von

*) Journ. Chem. Soo. 1876, a, 180.

Annelen der Chemile 109. Bd. 
182 Brown u. Geron, Beitröge zur Geschichte der

der hichtigkeit dieses Coëficientert durch wiederholte Versuche mil Dexirose viserzeagt, welch' letziere sowohl durch Invertirung des Rohrzuckers, wie auch durch Binwirkung von Süure auf Stärke dargestellt worden war. Der Werth von $\boldsymbol{x}_{3, \mathrm{~N} 6}$ wird bestimmt durch die formel :

$$
x_{3,36}=\frac{100 y}{2,205 x},
$$

wobei :

$y=$ Granmgewicht der, von $100 \mathrm{CC}$. des Lösung reducirsen Kupferrayds mit Be:ichtigung fir Malzextract und

$x=$ Granngewicht der sulumtlichen Sturheproducte per $100 \mathrm{CC}$, von spocitischan Gowicht lergeleitet und für Malzextract borichtigt.

Verhalten der Stärke gegen Malzextract. Wirkung a.er Wärme auf Italzextract.

Aenderung kalter Maizaufgüsse. - Bei frūheren Versuchen mit Stärke, bei deuen Malzextract zur Anwendung kam, war angenommen worden, dafs die optische Thätigkeih, das Kupferoxydreductionsvermogen und der Procentsatz von festen Bestandtheilen im Extract nur geringem W.echsel unterworion sei, und dafs man nur diese Factoren für ein gegebenes Volum kaiten Malzaufgusses oder für eine bestimmte, mit kaltem Wasser erschöpfte Gewichtsinenge Malz zu ermitteln brauche, um die für das Gemisch der Verwandlungsproducte nōthige Correction zu erhahen. Thatsāchlich aber findet sich, dafs frisch zubereitetes und filtrirtes Malzextraci selbst bei gewöhnlichın Temperaturverhältnissen einer beständigen Veränderung anterliegt. Mit dieser Verānderung geht Hand in Hand eine almälige Erhohung des specifischen Gewichts und des Kupferoxydreductionsvermögens und eine Verringerung in der optischen Thätigkeit. In der Kälte und bei Temperaturen unter $45^{\circ}$ ist es nicht möglich, den Fortgang dieser Veränderungen 
in seinen einzelnen Stadien lange zu beubachten, und zwar wegen der raschen Gührung, der kalte Malzaufgüsse besonders Rusgesetzt sind.

Gährung kalter Malzaufgülsse. - Diese Gährıng entspringt gewöhnlich dem Vorhandensein von Baciilus subtilis und dem bisweiligen Erscheinen von ein oder zwei kleinen Arten Saccharomyces. Wenn das Malzextracr bei 40 bis $45^{\circ} \mathrm{C}$. digerirt wird, so erscheint Saccharomyces nicht näufig, und die mit keinem anderen Organismus vermischten *) Bacilli machen in 48 Stunden ihren Kreislauf von Wachsthum und Entwickelung durch, welcher in Sporenbilidung und elmer gänzlichen Zersetzung der sporentragenden Reiser endet. Gleichzeilig werden Ströme von Kohlensäure und Wasserstufif in gleichen Verhältnissen arzeugt und Butiersäure erscheint in der Flüssigkcit. Wird hohrzucker und kohlensaurer Kalk oder Zirkoxyd einern Kaltwassermaizextract hinzugefügt, so gewährt die auf 40 bis $45^{\circ} \mathrm{C}$. gebrachte Mischung ein vortreffliches Mittel zur Gewinnung von Buttersäure und ermöglicht ein bequemes Studium der bei dem Procels haatigen Organismen. In solchen Fällen bildet sich wenigr oder gar keine Milchsãure, oder aber wird, wenn sie sich bildet, alsbald in Buttersäure verwandelt.

Einflufs der Wärme. - Die im Obigen besprochenen optischen und chemischen Verãnderungen im Malzextract hängen in keinerlei Weise von dem Vorhandensein organisirter Fermente ab, da dieselben noch fortwähren, wenn das Malzextraot einer Temperatur ausgeseizt worden ist, die hoch genug wäre, um der Gährthätigkeit solcher Organismen Einhalt zu gebieten. Bei $50^{\circ}$ C. treten die Veränderungen sehr rusch und vollständig ein. Wird Malzextract einige Minuten lang über $50^{\circ}$ erhitzt und nach den Filtriren und Analysiren einige Zeit bei $50^{\circ}$ digerirt,

†) Mitanter tritt Sapoina auf. 
181 Brown u. Heron, Beiträge zur Geschichte der

so gehen die vorerwăhnten Verānderungen im specifischen Gewicht, der optischen Thätigkeit und dem Kupferoxydreducirungsvermōgen um so weniger rasch und vollständig vor sieh, je höher die Temperatur war, auf welche die Flüssigkeit erhitzt worden ist; woraus sich ergiebt, dafs die Hitze eine entschieden schwächende Wirkung auf das specielle Verwandlungsagens ausübt. Malzextract, welches üluer $76^{\circ}$ erhitzt worden ist, erleidet bei nachfolgender mehrstūndiger Digestion bei $50^{\circ} \mathrm{C}$. wenig oder gar keine Verānderung; ein Beweis dafür, dafs die Säuren des Malzextracts an den erwähnten Varänderungen keinen Antheil haben.

Das in dem Obigen Ausgeführte findet sich in den folgenden, einer langen Reihe von Versuchen entnommenen Beispielen erläutert.

Beispiels sur Veranschaulichung der Wirkung der Warme auf filtrirtes Normalmalzextract.

\begin{tabular}{|c|c|c|c|c|}
\hline & $\begin{array}{c}\text { Beroitung und Behandlung des Malz- } \\
\text { extracts }\end{array}$ & 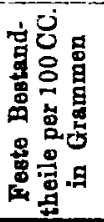 & 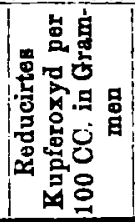 & 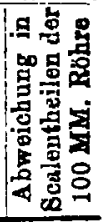 \\
\hline 1 & 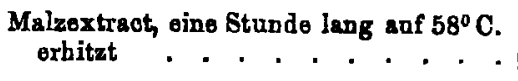 & 9,888 & 9,261 & 8,5 \\
\hline 2 & 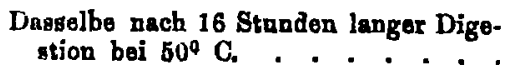 & 10,025 & 11,798 & 6,8 \\
\hline $\mathbf{3}$ & $\begin{array}{l}\text { Malzextract, schnell zubereitet (in oiner } \\
\text { Stunde) . . . . . . . . . . . . }\end{array}$ & 9,129 & 4,857 & 8,8 \\
\hline 4 & $\begin{array}{l}\text { Dasselbe } 20 \text { Minuten lang auf } 60^{\circ} \mathrm{C} \text {. } \\
\text { urbitat } \\
\end{array}$ & 9,295 & 6,200 & 8,8 \\
\hline $\mathfrak{\mathbf { j }}$ & $\begin{array}{l}\text { Dasselbe } 20 \text { Minuten lang auf } 60^{\circ} \mathrm{C} \text {. } \\
\text { erhitet, filtrirt and dann } 15 \text { Standen } \\
\text { lang bei } 56^{\circ} \mathrm{C} \text {. digerirt } \quad . \quad . \quad .\end{array}$ & 8,453 & 9,208 & 6,7 \\
\hline 6 & Malzextrach frisch beroitet . . . . & 7,758 & 4,657 & 7,7 \\
\hline 7 & 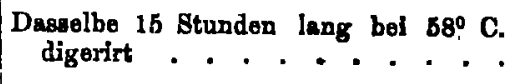 & 7,979 & 7,454 & 6,3 \\
\hline 8 & 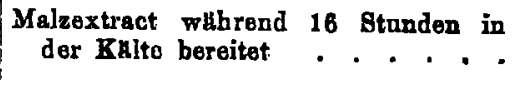 & 9,956 & 8,653 & 8,5 \\
\hline
\end{tabular}




\begin{tabular}{|c|c|c|c|c|}
\hline & $\begin{array}{l}\text { Beroitung und Behandlung des Malz- } \\
\text { oxtracts }\end{array}$ & 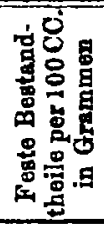 & 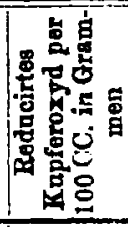 & 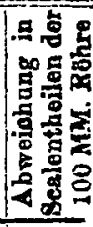 \\
\hline 9 & 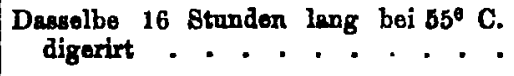 & 10,152 & 11,263 & 7,2 \\
\hline 10 & Nr. 820 Minuten lang anf $62^{\circ}$ erhitat & 10,849 & 9,562 & 8,8 \\
\hline 11 & Nr. 1016 Btunden lang bei $85^{\circ}$ dîgerirt & - & 11,002 & 7,5 \\
\hline 12 & $\begin{array}{l}\text { Malnextract } 20 \text { Minuten lang } a u f 70^{\circ} \mathrm{er} \\
\text { hitet . . . . . . . . . . . }\end{array}$ & 9,677 & 6,282 & 9,4 \\
\hline 13 & Daselbe 16 Stunden lang bei $55^{\circ}$ digerirt & 9,849 & 6,146 & 9,2 \\
\hline 14 & $\begin{array}{l}\text { Malzextract, sohnell zubereitet und } \\
15 \text { Minuten lang gekocht . . . . }\end{array}$ & 7,562 & 5,257 & 8,0 \\
\hline 15 & $\begin{array}{l}\text { Dassulbe nach dem Kochen } 16 \text { Stunden } \\
\text { lang bei } 55^{0} \text { digerirt. . . . . . }\end{array}$ & 7,523 & 5,020 & 8,3 \\
\hline 16 & 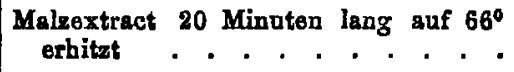 & $\theta, 836$ & 6,185 & 8,8 \\
\hline 17 & $\begin{array}{l}\text { Dasselbe nach dem Erhituen auf } 66^{\circ} \\
16 \text { Btunden lang bei } 55^{\circ} \text { aigerirt }\end{array}$ & 9,401 & 7,633 & 8,5 \\
\hline
\end{tabular}

Die beobachtetermafsen bei der Digestion des Malzextracts In einer gemäfsigten Wärme stattfindende Erhöhung des specifischen Gewichts spricht dafür, dafs der Aufgufs eines oder mehrere der durch Wasseraufnahme zersetzbaren Kohlehydrate enthält.

Im Jahre 1875 entdeckte Kühnemann *) unter deı löslichen Bestandtheilen des Gerstenmalzes den Rohrzucker; daraus folgerten wir, es sei mōglich, dafs die von der Zeit und der erhöhten Temperatur im Maizextract hervorgrebrachten Veränderungen eine Invertirung dieses Kōrpers. zum Grunde haben könnten.

Wenn die Verănderung in der Zusammensetzung sich insgesammt auf diesen Umstand zurückführen lāist, so leuchtet es ein, dafs dann die beziehungsweise aus der Dichtigkeits-

*) Berichte der dentschen chemischen Gesellgchaft 8, 202, 887. 
trhohiung der Lösung und aus der Erhöhung des Kupferoxydreductionsvermōgens unabhängig von einander berechneten Mengen yon Rohrzucker mit einander übereinstiminen müssen, abgesehen von Ungenauigkeiten in den Versuchen. Diefs ist aher thatsāchlich nicht der Fall, wie aus den nachfolgenden Zahlen hervorgeht:

\begin{tabular}{|c|c|c|}
\hline $\begin{array}{l}\text { Nr. der in der } \\
\text { yorauigehedien } \\
\text { Tabeils arige- } \\
\text { gebonen Ver- } \\
\text { ocche }\end{array}$ & $\begin{array}{l}\text { Rohrzucker in Grammen } \\
\text { per } 100 \text { CC., aus der darch } \\
\text { die Inrertirung bewirkten } \\
\text { Vergrofsernng des spec. } \\
\text { Gewichts bertennet }\end{array}$ & $\begin{array}{l}\text { Rohrzucker in Grammen } \\
\text { per } 100 \text { CC., nach der Er- } \\
\text { böhupg in dem Knpfor- } \\
\text { oxydreductionsvermogen } \\
\text { berechnet }\end{array}$ \\
\hline 1 und 9 & 2,441 & 1,156 \\
\hline 1 und : & 8,058 & 1,864 \\
\hline 16 und 17 & 1,250 & 0,656 \\
\hline
\end{tabular}

Bei den obigen Versuchen land wahrend der Digestion kein Niederschlag fester Bestanditheile statt. Die Aenderungen in der optischen Thätigkeit waren zu gering, um zuverlässige Daten für die Berechnung abzugebea; allein in allen den genannter Fällen war die Verminderung des Drehungsvermögens bedeutend geringer, als der Invertirung eines Quantums Rohrzucker, yeich dem in einer der obigen Rubriken vernerhien, entsprrichen hātte.

Fs ist demgemãfs ein!euchtend, dafs die im Vorstebenden crwähnten Yeränderungen in den Eigenschaften des MalzExtracs.j sich jedenfalls micht vollständig auf das Vorhanden-sein ron Rohrzucker zurückführen lassen. Wir haben uns inders von der Richligkeit der Kühnemann'schen Beobachtungen überzeugt. Kin kailer wässeriger Malzaufguls enthält sicher eine sehr bemerkliche Menge Rohrzucker, und dafs dieser letztere unter solchen Verhältnissen und durch Wärme begünstigt allmälig Wasser aufnimmt und dadurch eine Umsetzung erleidet, ergiebt sich aus den nachfolgenden Versuchen durch welche utherhaupt wohl jetzl zum ersten yale 
klar erwiesen wird, dafs Malz ein den Rahrzucker zu invertiren fühiges, unorganisirtes Ferment enthült.

Wirking des Normaimalzextractes auf Mohraucker.

\section{Serio 1.}

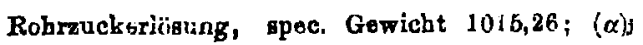

$72,8^{\mathrm{n}} ; 75$ CC. Zuokerlosung mit 25 CC. Malzextract.

1. Rohrauckerlbsung 16 Standen lang bei $55^{\circ}$ ohne Hinzuftigung von Malzextrast digerirt

2. 16 Stunden lang mit Malsextract in dex Kulte in Berührung gelassen

B. 16 Stunder lang dar Einwirkung des Maly. uxtracta hei $55^{\circ}$ aussgesutzt

Serie II.

Rohrzuckexlösang, spec. Gewicht 1015,78; 7500. mit 25 CC. Malzextract ensammengeiracht Duszer der Einwirkung stets 16 Sinndam

4. Boi $45^{\circ}$ mit Malzeztract digaxirt, wulohes vurhor 20 Minuton lang auf $60^{\prime \prime}$ erisitat wordon war

5. Bei $45^{\circ}$ mit Malzextract digezirt. welch es rorher 20 Minuten auf $63^{\circ}$ erbitzt pordan $x$ or

6. Boi $46^{\prime \prime}$ mit Maizextract digerirt, weletses yorher 15 Minuten lang zun Korhen erhitst worden nar

\author{
Mengo \\ dos inver- \\ tirten \\ Zuckers \\ in Procen- \\ ton
}

$72,8^{\circ} \quad 0$

$69,3^{\circ} \quad 3,6$

$32,6^{0} \quad 20,4$

Bei Versuch (2) war eine geringe Bacterienbildung bemerkbar, welche auf die Ergebusse nicht ohne Einflufs gebliehen sein mag. Bei den übrige: Versuchen lieis sich die ganze Zeit über keine Spur orgarischen Lebens bemerken, so dafs dieselben also nicht den gleichen Einvand zulassen.

Aus den oben angeführten Versuchen ergiebt sich, dafs das invertirende Ferment des Malzextracts seine höchste Wirkung bei ungefähr $55^{\circ}$ zu äufsern vermag; bei $60^{\circ}$ ist diesolbe betröchtlich garinger und bei $66^{\circ}$ hört sio beinahe auf Durch Kochen wird das Invertirungsvermögen gänzlich vernichtet. Die im Malzextract rorhandenen organischen Säuren 
188 Brown u. Heron, Beiträge zur Geschichte der

besitzen keine invertirende Wirkung, denn die geringe anscheinende Invertirung in Nr. 6. liegt vielleicht an einer Versuchsungenauigkeit.

Grund der Unbeständigkeit des Kaltwassermalzextracts. - Die unbeständige Natur des gewöhnlichen Kaltwassermalzextracts rührt unserer Ansicht nach hauptsächlich davon her, dafs ein kleines Quantum Stärkeverwandlungsproducte in Lösung vorbanden ist, und diefs hinwiederum entspringt der Wirkung des Verwandlungsagens auf jene Körnchen, die theilweise desorganisirt worden sind, a) während des Keimens, b) während des Darrens, c) während der Zerkleinerung des Malzes. Unter allen diesen Verhältnissen, wie weiter unten nachgewiesen wird, werden die Stärkekörnchen von dem Verwandlungsagens angegriffen, und daraus ergiebt sich die rasche Erzeugung von Maltose und des niedrigsten Achroodextrins in der Reihe, welch letzteres dann vermöge der fortdauernden Wirkung des Malzextracts eine weitere Veränderung unter Addition von Wasser erleidet. Die bei fortgesetztem Digeriren des Malzextracts sich ergebenden Resultate lassen sich durch die gleichzeitige Wasseraufnahme von ein wenig Dextrin und die Invertirung des Rohrzuckers erklären. Sehr wohl möglich ist es, dafs ein kalter wãsseriger Malzaufgufs andere der Wasseraufnahme fähige und direct dem $\mathrm{Malz}$ entstammende Kohlehydrate enthält, doch müssen wir uns die Erörterung dieses Punktes vorbehalten.

Wir haben von den im Malzextracte durch die Wärme erzeugten Veränderungen nur deshalb so eingehend gesprochen, weil es uns darum za thun war, es klar zu machen, wio wichtig es bei allen Stärkeverwandlumgsversuchen ist, eine zweite Probe des Malzextracts unter genau denselben Temperaturverhãltnissen und eben so lange wie die VerwandlungsGussigkeit selber za digeriren und die bei Prüfung des Du- 
plicats erhaltenen Werthe zur Correcction an jener zu verwenden.

Natur und Eigenschaften der Stärke und Stärkecellulose.

Die Stărkekörner sind aus scharf geschichteten Lagen aufgebaut, welche hauptsăchlich aus einer von C. Nãgeli Granulose genannten Substanz bestehen. Die äufseren Lagen sind in der Regel dichter als die dem Kerne näheren und der Wassergehalt derselben steigt von Aufsen nach Innen zu. Jeder Theil des Körnchens enthält aufser Granulose noch kleine Quantitäten eines anderen, der Granulose nahe verwandten Körpers, dem neuere Beobachter den Namen Stärkecellulose beigelegt haben. Diesen Stoff finden wir vorwiegend in den Aufsenschichten des Stärkekorns, wenn nicht überhaupt das gesammte Aeufsere desselben daraus besteht. Diese ăufsere Lage ist im Wachsthum die älteste, denn das Stärkekörnchen wächst von Aufsen nach Innen mittelst Intussusception, d. h. das während des Wachsthunıs der Körnchen innerhalb des Protoplasmas der Pflanzenzelle von Aufsen aufgenommene Bildungsmaterial wird zwischen die bereits bestehenden Pertikeln in der Richtung der Oberflāche der Schichten abgelagert (C. Nāgeli, die Stärkekörner).

Der Gegenwart dieser schützenden Cellulosenhülle ist es zuzuschreiben, dafs auf die noch unversehrten Stärkekōrner kaltes Wasser absolut keine Wirkung ausübt. Obgleich Wasser in hohem Grade von der Granulose selbst absorbirt wird, so kann sich doch von diesem letzteren, überaus colloïdalen Stoffe Nichts in das ihn umgebende Mittel verbreiten. Wenn die äufsere Hùlle des Körnchens beim Abreiben durchbricht, so schwill das Innere durch Aufnahmouvon Wasser stark uuf, und ein kleines, alle Kigenschaften der löslichen Stärke besitzendes Körperquantum geht in Lösung über. Durch wicderholte Behandlung der durchbrochenen Stärkekörner mit kaltern 
190 Brown u. B̈eron, Beiträge \&u Geschichte der

Wasser lälst sich der grölste Theil der Granulose entiemen, während der gröfste Theil der Celuinge in Gestait überaus dünner Schichten zurückbleibt, welche, ungleich der Granalose, von Jod nur schmutzig-gelb gefärbt werden. Die Granulose selber und das Wasser, das mil derseiben nur kurze Zeit in Berührung gewesen, werden mit Jodlösung tief Indigoblau. Fr. Schulze*) hat Stärkecellulose dadureh erhalten, dafs er Stärke mehrere Tage lang bei $60^{\prime \prime}$ mit einer $1 \mathrm{pC}$. Salzsăure enthaitenden gesättigten Kochsaizlosung digerirte.

Die gleiche Substanz hat anch C. Nägeli dadurch gewonnen, dafs er Stärke bei 45 bis $55^{4} \mathrm{C}$. mit Speichel behandelte, welch' letzterer ein nur dis Granulose angreifendes nud auflösendes Agens (das Ptyalin) enthält **).

Schliefslich hut it $z^{*}$ *) beotachiet, dafs gewisse Schizomyceten die Granulose des Surheliteisters leich zum Gähren bringen, saber die Stärkeceilulose dabei whberishrt lussen.

Darstellung der Stärkecellulose - - Wir haben gefunden, dafs die Wirkung des Malzextracis au' den Starkekleister ohne Hitze ein einfaches Mittel abgieltt, die Celluluse des Stärkekörnchens in grofsen Quantitäten als gewinnen. Ein 5 bis $6 \mathrm{Grm}$. Stärke per $100 \mathrm{CC}$. enthallend Stärkek!eister wird, wenn völlig kalt, mit ungefähr einum Zehntel seines Volumens an frisch bereitetem Normalmalzextracl hehandelt. In etwa 4 bis 8 Minuten wird die Mischung völig klar und lälst sich dann leichi filtriren. Wenn der auf ưm Filser zurückbleibende nockige Körper durch Waschen mit kaltem Wasser vom Malzextract und den Verwandlungsprociucten der Grunulose befreit ist, so besteht derselbe nur noch aus sogenannter Stärkecellulose. Das Filtrat ist zuerst vollkommen klar, wird jedoch in

\footnotetext{
7) Honneberg's Journ. Landw., Feue Folge 8, 214.

-e) Dio Starkelörner, 8. 113.

N*y Beriohto der doatschen chemischon Gesolischaft 10, 289.
} 
wenigen Xinuten trübe, in Folge der Abscheidung eines weiteren Quantums einer flockigen Substanz, welche, abgesehen von threr äufseren Struciur, in keiner Weise von der eben abfiltrirten verschieden zu sein scheint. Diese weitere Abscheidung von Cellulose rührt davon her, dafs die lōsliche Stärke und die höheren Dextrinarıen, die sich als erste Prodacte aus der Einwirkung des Malzextracts auf Granulose ergeben, von der Cellulose Einiges in Lösung za erhalten verinögen; sowio jedoch die lösliche Stärke und die höheren Dextrinarten sich weiter verändern, scheidet sich der gröfste Theil der Cellulose in unlöslicher Form aus. Die auf dem Filter zurückbleibende Masse besteht aos feinen Blättchen, welche die Form der geschwollenen Stärkekörner noch beibehalten haben, während der Niederschlag naturrlich amorph ist.

Die derart abgeschiedene Starkecellulose ist sowohl in salten Wasser, wie auch in Wasser von 70 bis $80^{\circ} \mathrm{C}$. völlig. unlöslich und wird von Lösungen !ōslicher Stärke oder höherer Dextrinarten uicht aufgenommen. Dofs dieselbe jedch unter geswissen Verhăltnissen făhig ist, in Lösung zu gehen, ergiebt sich aus den oben gemeldeten Thatsachen und aus der Unnöglichkeit, sie mit setr verdünntem Stärkekleister (d. h. 1 bis 1,5 Grm. per 100 C.) darzustellen *).

Veruasidluing der uniöslicken Starkecellulose und Abscheidung eincs zuceiten Körpers. - Auf unlöstiche Stärkecellulose übt Mulzextract weder in der Kälte, noch bei $60^{\circ} \mathrm{C}$. eine Einwirkung aus; wir haben indefs Gründo zur Anahme, dafs auf die lösliche Modification in der Kälte zwar nur lang-

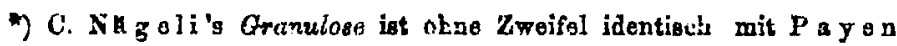
nu:d Persoz's Amidone (Aun. chim. phys. 56, 837, 1834) and

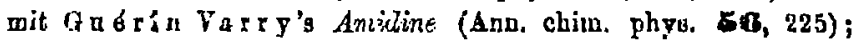
des latzteren Vertassers amiciine tégumentaire und amidine soluble ist mit den iüylichen und anlöglichen Varietlten der Stur'sectllalose identisoh. 
192 Brown u. Heron, Beiträge zur Geschichte der

sam, bei 50 bis $78^{\circ} \mathrm{C}$. jedoch sehr rasch, eine Einwirkung vor sich geht. Beweise hierfür werden weiter unten beigebracht werden.

Durch Kochen mit Wasser verwandelt sich die Stärkecellulose grofsentheils in lösliche Stärke; diese Lösung hat alle optischen Eigenschaften jenes Körpers und zeigt durch Jod die charakteristische Indig ofarbe. Bei wiederholtem Kochen mit Wasser und häufigem Waschen bleibt schliefslich ein Körper zurlick, welcher durch eine Portsetzang des Verfahrens keine weitere Aenderung mehr erleidet. Dieser Körper ist ungefähr gleich einem Fünftel des ursprünglich behandelten Stoffes und ist leicht löslich in Kalilauge, unter deren Einwirkung er sich, bei höherer Temperatur digerirt, langsam in lösliche Stärke verwandelt.

Es foigt hieraus, dufs unlösliche Stãrkecellulose aus min-destens zwei Körpern besteht, von welchen der eine schnell von siedendem Wasser afficirt wird, der andere aber nicht. Diese beiden Körper müssen der Granulose sebr nahe verwandt sein, da die sămmtlichen drei Körper unter günstigen Verhältnissen lösliche Stărke als ihr erstes Verwandlungsproduct abgeben.

Das von uns aus gut gewaschener Kartoffeistärke mittelst des obigen Yerfahrens gewonnene Quantum Stärkecellulose beläuft sich auf 2,0 bis $5,3 \mathrm{pC}$. je nach der Behandlung, welche die Stärke vorher beim Reinigungsprocefs erfahren hat. Eine Kartoffelstärkeprobe, die durch lang anhaltendes Waschen mił stark verdūnnter Kalilauge gereinigt worden war, ergal bei dem obigen Proceis 2,46 Célulose, während eine andere Probe der gleichen Stärke, die nur einer ganz leichten Behandlung mit Alkali unterworfen worden war, volle $5,54 \mathrm{pC}$. lieferte.

Wenn die Stārkecellulose in verdūnnter Kalilauge aufgolōst worden ist, so kunn der groofsere Theil derselben durch Essigsăure oder durch Eirleiten von Kohlensäure wieder niedergeschlagen 
werden. Wird die alkalische Lösung auf gewöhnlicher Temperatur erhalten und alsbald mit Sāure wieder gefällt, so findet man, dafs ungefähr $30 \mathrm{pC}$. in lösliche Stărke verwandelt worden sind. Wird die Lōsung in mấsiger Wărme digerirt, so wird mehr lōsliche Stärke gebildet; in einem Falle konnten wir nach halbstündiger Digestion bei $60^{\circ}$ nur $57,3 \mathrm{pC}$. der ursprünglichen Menge Cellulose durch Sãure wieder ausfällen.

Das specifische Drehungsvermögen einer alkalischen Stärkecelluloselösung scheint sehr zu schwanken, steigt jedoch immer, wenn dieselbe einer höheren Temperatur ausgesetzt wird. Wir fanden das specifische Rotationsvermõgen einer frisch bereiteten Lösung, nach dem Quantum des darin vorhandenen Kohlehydrats berechnet, kaum höher als $(\alpha)_{3} 146^{\circ}$, und dasselbe stieg bei einige Minuten langem Erhitzen auf $60^{\circ} \mathrm{C}$. bis $(\alpha)_{\mathrm{d}}, 173,6^{\circ}$. Die Vergröfserung des Drehungswinkels unter solchen Umständen entsteht aus der Verwandlung der Cellulose in lösliche Stärke. Die gesammte optische Thätigkeit der Lōsung kann indefs nicht allein in dem Vorhandensein dieser letzteren Substanz ihren Grund haben; die Cellulose selber mufs, wāhrend sie von der Kalilauge gelöst ist, auf das polarisirte Licht einigen Einflufs ausüben.

Wenn Kartoffelstärke unter der Wirkung des Malzextracts bei mehr als $45^{\circ} \mathrm{C}$. verwandelt wird, so scheidet sich die Cellulose nur aus, insofern der Kleister schr dickflüssig und das Malzextract in ungenügender Quantităt vorhanden ist; daher ist es klar, dafs die Stärkecellulose im Augenblicke ihrer Abscheidung von der Granulose unter diesen Umständen leicht lōslich sein mufs.

Auf dieser Thatsache fofsend haben wir versucht, die auf dem oben beschriebenen kalten Wege gewonnene Stärkecellulose dadurch wieder aufzulösen, dafs wir dieselbe in kleinen Cuantitäten in einem dünnen Stärkebrei vertheilten und das Gemenge mit Malzextract bei $65^{\circ}$ behandelten. Es ist uns 
194 Brown u. Heron, Beiträge zur Geschichte der

aber niemals gelungen, auî diesem Wege eine Lösung auch nur eines kleinen Theiles der Collulose zu erzielen. Unserer Anschauung nach sind awischen den löslichen und unlöslichen Arten Stärkecellulose eben so markirte Unterschiede vorhanden, wie zwischen geronnenem und nicht geronnenem Eiweifs.

\section{Stärkelcleister.}

Verschiedene Klebrigkeit. - Wenn Stärke mit heifsem Wasser behandelt wird, so schwillt der Inhalt der Körnchen vermöge der starken Aufnahme von Wasser beträchtlich an und bildet schliefslich in Folge des Durchbruchs der Hülle eine sehr klebrige Flüssigkeit, die als Stärkekleister bekannt ist.

Durch geringe Schwankungen in der Behandlung der Stärke, wăhrend des Reinigungs- und Trocknungsprocesses, entstehen merkliche Unterschiede in der Klebrigkeit dieses kileisters. Ist die Stärke mit Kali und Säure behandelt worden, so entsteht unter sonst gleichen Umständen ein weniger klebriger Kleister, als wenn ein anderes Verfahren befolgt wird. Auch haben wir sehr grofse Schwankungen in der Consistenz des sich ergebenden Kleisters bei nur geringer Abänderung der Art und Weise, wie die Stärke getrocknet wird, beobachtet. Langsam und in niederer Temperatur getrocknete Starke liefert stets eine klebrigere Lösung, als eine in höherer Temperatur rasch getrocknete. Die nachfolgenden an verschiedenen Partien einer und derselben Kartoffelstärkeprobe angestellten Versuche werden das Gesagte erlăutern. Als Maafs für die relative Klebrigkeit des Kleisters diente das Gewicht, das erforderlich war, um in denselben jeweils eine dünne Glasscheibe von $5 / 8$ Zoll im Durchmosser einsinken zu machen. In jodem einzelnen Falle war der Brei aus $3 \mathrm{Grm}$. Stärke auf $100 \mathrm{CC}$. Wasser hergestellt; da jedoch die Stärkeproben nicht sămmtlich das gleiche Quantum Feuchtigkeit enthielten, so sind die 
Beobaclitungen auf gleiche Gewichtsinengen von trockener Stärke umgerechnet.

1. Zuerat, wohr fwisht, bei $50^{\circ} \mathrm{C}$. und dann bei $100^{\circ} 24$ Etunden long getrichnet.

11. Zucrut, gehr feticht, bei gewøinlicher Temperatur unter der Luftpumpe uyd dann bei $100^{\circ} 24$ Stunden lang im Luftbade geworkuet.

III. Unter der Luftpumpe und sohliofslich bei einor Temperatur von nioht ther $30^{n} \mathrm{C}$. Eetrocknet.

Kolativo Klobrigkcit des ans den obigen Proben hergestellten Kleistars, I als Einhoit angenommen :

$$
\begin{array}{r}
\text { I. } 1,000 . \\
\text { II. } 2.306 . \\
\text { III. } 3,288 \text {. }
\end{array}
$$

Die Unterschiede in dem Grad der Klebrigkeit sind überaus merkwürdig und waren kaum porauszusehen. Wenn die neuerdings von Whewell *) gemachte Angabe richtig ist, dafs der gewerbliche Werth der Stärke je nach ihrer Fähigkeil, einen mehr oder minder klebrigen Kleister zu liefern, variirt, so haben wir hier eine für den Stärkefabrikanten höchst bedeutungsvolle Thatsache, welche unseres Wissens bisher noch ganz unbemerkt gebliebon ist.

Bpecifisches Gevoicht der Stärke in Kleisterform. - Die nachfolgenden Versuche sind angestellt worden zur Firmittelung des specifischen Gewichts der Stärke (Granulose plus Stărkecellulose) in Kieisterform.

Versuch $I$ 2,250C Grm. vollkommon wasserfreier 8thrke warden mit kochendem Wasser in Gallerte verwandelt und den Volumen anphatud bis auf $100 \mathrm{CC}$. bei $15,5^{\circ}$ gobracht. Das absoluto Gewicht den Kleisters Tar 100,78 ond soin npecifiebes Gowicht bei 15,5 ' 1008,95 , folglich war das Volumen $=82,88 \mathrm{CC}$. and $100 \mathrm{CC}$. von dieser Flürsigkeit würden 2,2527 Grm. trockene Starke onthrlton. Das ans dieson Zablen berechnote mpecifische Gowicbt der Bturke in Kleisteriorm tot $=1,658$ bei $18,5^{\circ}$. Ein andurer Ahnlicher Vernuch ergab 1,662.

*) Chem. Nowr 88; 97. 
196 Brown u. Heron, Beiträge zur Goschichte der

Das Mittel dieser beiden nahezu übereinstimmenden Versuche ergiebt 1,66 als das specifische Gewicht der Stärke in schwachen Lösungen.

Aus dieser Zahl läfst sich der Theiler berechnen, der für Stärkekleister erforderlich ist, um specifische Gewichte in Gramme der trockenen Substanz per 100 CC. zu verwandeln. Die allgemeine Formel ist :

$$
x=10\left(1-\frac{1}{y}\right)
$$

wo $x$ den orforderlichen Theiler und $y$ das apec. Gewicht des Kobrpers in Lossung bei $15,6^{\circ}$ C. im Vergleich sa Wasser von gleicher Temperatur besoighnet. Im obigon Fallo int $x=3,976 *$.

Lösliohkeit der Granulose. - Es haben sich von Zeit zu Zeit grofse Meinungsverschiedenheiten darúber bemerkliob gemacht, ob Granulose in dem Stärkekleister in einer wirkliohen Lösung, oder aber in feine Partikelchen vertheilt vorhanden ist. Die Moglichkeit, einen grofsen Theil der Granulose von einem märsig dicken Kleister mit den gewōhnlichen Filtrirmethoden zu scheiden, scheint auf den ersten Blick für die letztere Anschauung zu sprechen, doch ist dieselbe damit noch keineswegs erwiesen, wie sich aus dem Nachfolgenden orgiebt.

Bs ist keinem Zweifel unterworfen, dafs lösliche Stärke făhig ist, mit Wasser eine vollkommene Lösung zu bilden, trotzdem haben wir gefunden, dafs eine Lösung dieses Körpers beim Filtriren durch eine dủnne poröse Thonwand unter geringem Drucke das Meiste von ihrer festen Masse einbüfst : eine poröse Zwischenwand dieser Art läfst das weniger collaỉdale Dextrin und sămmtliche Krystalloìde frei durchgehen.

*) Ist $x$ die bekannto und $y$ dio gesuchto Grofere, vo nimmt dio Formel die Gestalt an :

$$
y=\frac{1}{1-\frac{x}{10}}
$$


Diese und ähnliche Eirscheinungen lassen sich unserer Ansicht nach folgendercatsen erkläs : Wir haben Grand zur Annahme, dafs die chemischen Molecule der Colloïde in der Regel viel zusarnmengesetzter sind, als diejenigen der Krystalloìde. Dss Giejche lärst sich wainrscheinlich von dem Verhältnisse zwischen den Lōsnngsmoleculen der beiden Körperarten saggen; denn das Lösungsmolecul ist un so grölsur, je vollkommener colloidal ein körper ist. Sind die Foren des Filters im Vergleich zur Grófse des Lösungsmoleculs eines Körpers entsprechend eng genug, so wird dieses auf seinem Wege durch das Filter aufgehaiten, während andere Körper mit kleineren Lösungsmoleculen mit Leichtigkeit durchkommen können.

Stărkekleister (zum grōfsten Theil aus Granulose bestehend] ist eines der vollkommensten Colloide, welche man kennt, und da das Lösungsmolecul desselben sehr grofs ist, so dringt dasselbe nur schwer durch die engen Poren von gewöhnlichem Filtrirpapier. Andererseits hat des weniger vollkommene Colloĩd, die lösliche Stärke, ein bleineres Lösungsmolecul ais die Gramulose und dringt leicht durch gewöhnliches Filtrirpapier, jedoch nicht durch die sehr kleinen Poren einer Thonwand; diese wird indefs von den minder colloìdalen Dextrinarten und mit besonderer Leichtigkeit von allen Krystalloìden durchdrungen.

Unserer Ansicht nach läfst sich die Frage, ob die Granulose in dem Stärkekleister in Lòsung oder nur suspendirt vorhanden ist, auf eine andere Weise anfhellen. Wir wissen, dafs in den meisten Fallen das aus Körper und Flüssigkeit berechnete Volumen einer Losung gröfser ist, ols das beobachtete, oder unit anderen Worten, dafs das specifische Gewicht eines Körpers in Lōsung grörser ist, als wenn er nur in einer Flüssigkeit suspendirt sich befindet. Wir haben gezeigt, dais das specifische Gewicht der Stárke in Kleisterform $=1,66$ ist. Nun hat aber Stärke, wean mit Wasser in Gallerte verwan- 
delt und dann mit Weingeist gefüllt, nach vollkommenem Trocknen ein specifisches Gewicht von 1,513. Daher ist es uberaus wahrscheinlich, dafs die Granulose im Stärkekleister in Form einer wahren Lösung existirt.

Optische Thatigkeit des Stärkelcleisters. - Die Ermitlelung der optischen Thätigkeit des Stärkekleisters bietet bodeutende Schwierigkeit dar wegen des Mangels an Durchsichtigkeit bei der Flüssigkeit und der Schwierigkeiten, die sich dem Filtriren einer so klebrigen Lōsung entgegenstellen. Gute Beobachtungsdaten lassen sich mit Stärkekleister bei mehr als $1 \mathrm{Grm}$. fester Substanz auf $100 \mathrm{CC}$. nicht erzielen, und auch bei weniger als $1 \mathrm{Grm}$. nur dann, wenn die Stārke vorher mit verdünnter Kalilauge zur Entfernung eines Theils der Cellulose behandelt worden ist.

Die folgenden Ergebnisse sind mit in Gallerte verwandelter Stărke erzielt worden. Das Quantum fester gelōster Substanz betrug im ersteren Falle 1,054 Grm. per $100 \mathrm{CC}$., in zweiten 1,00 Grm.

$\begin{array}{ccc} & {[\alpha]_{1} 8,46} & {[\alpha]_{\text {abboldot }}} \\ \text { I. } & 202,1^{\circ} & 208,8^{\circ} \\ \text { II. } & 201,1^{\circ} & 207,3^{\circ} .\end{array}$

Bei halbstündigem Kochen von II. warde die Flüssigkeit weit durchsichtiger und ihre optische Thätigkeit merklich erhöht.

$$
\begin{array}{r}
\text { IL. (nach dem Koohon) }[\alpha] \text { s, 10 } \\
21 \mathrm{~B}, 3^{\circ}
\end{array}
$$

Diese Vergrōfserung des Winkels entsteht daraus, dafs die Stärkecellulose in lösliche Stärke verwandełt wurde.

W. $\mathrm{N}$ ăg eli fand das specifische Drehungsvermōgen eines dünnen gekochten Stärkekleisters $[\alpha]=190^{\circ}$. Da indefs dio betreffenden Lösungen nur 0,16 Grm. feste Substanz auf 100 CC. enthielten, so kỏnnen wir diese annähernde Genauigkeił nur als zufallig ansehen. 
Wirkung von KHO auf Stärkekleister. Btdirke-Kaliverbindung. - Wenn dem Stärkekleister eine etwas starke Kalilōsung hinzugefügt wird, so wird die vorher buntschillernde Flassigkeit vollkommen durchsichtig, ohne dafs in der Klebrigkeit derselben eine Verinderung stattfände. Diese Erhöhung in der Durchsichtigkeit hat die Lōsung der vorher suspendirt gewesenen Cellalosehüllen zum Grunde. Die optische Thätigkeit der Losung wird gleichzeitig durch don Zutritt der ersten Theile der Kalilauge bedeutend verringert, steigt jedoch wieder bis zu ihrer ursprünglichen Höhe und bisweilen etwas hōher, wenn das Alkali mit Essigsäure oder Kohlensāure neutralisirt wird. Diese Erscheinungen sind lurch die Bildung einer bestimmten Verbindung von Stärke mit dem Kalihydrat bedingt. Ein derartiger Körper ist von Sch midt*) und von Ventzke **) beschrieben worden; der letztere Beobachter behauptet jedoch irrthümlich, dafs derselbe auf polarisirtes Licht nicht wirke, was unrichtig ist.

Die nachfolgenden Zahlen haben wir for das specifische Drehungsvermögen der Stärke-Kaliverbindung ermittelt; dieselben sind nach dem in der Yerbindung vorhendenen Stärkequantum berechnet :

Stïrko mit KHO

[a]; 8,26

1.

2.

3.

4.

Bei einem anderen Versuche, in dem die Kaliverbindung mit Kohlensāure zerselzt ward, wurden die folgenden Ergebniswe erzielt :

7) Diese Annalen 51, 31.

-) Journul fur prakt. Chemie $25,65$.
Nech dem Ansäuern mit Essigetinre.

$[\alpha]$,, 18

$188,8^{\circ}$

$200,3^{\circ}$

206,89. 
200 Brown w. Heron, Beiträge eur Geschishte der

Bukjo $\pi$ it KHO

$[a] j$, s.e6

5. $166,0^{\circ}$
Nach Zarsotrung wit $\mathrm{CO}$,

[a] 8,86

$216,0^{\circ}$.

Bai diesen Versuciten entstand nicht eine Spur von Xupferoxyd reducirendew Zucker, noch auch wurcic eino irge!ndwie beträchtliche llenge löslicher Stärke erzeugt, sofern niclit das Digeriren mit Kaliluuge eine Zeit lang bei hoher Tomperatur fortgesetzt wurde. Nach dem Ansäuern verblieb die läsung durchsichtig und besafs die gleiche oder nahezu die gleiche Klebrigkeit wie der ursprüngliche Stärkekleister.

Wenn lōsliche Stårke mit Kalilange behandelt wird, so ist die optische Thātigkeit der sich ergebenden Verbindung $[\alpha]_{j}, 0182,6^{\circ}$, während die der löslichen Stärke solber $[a]_{j}$ s,so $=216^{\circ}$ ist. Durch sorgfältige partielle Pällung unit Alkohol Iafst sich aw einem gekuchten Starkekleistor in kleinen Quantitaten ein mit genau diesen Bigenschaften ausgestatteter and in heifsem Wasser vollkommen löslicher Körpes absctreiden. Derselbe ist in verdünntem Weingeist löslicher als Granulose und wird demgemäfs, wean letztere durch Weingeist schon gefallt iut, noch in Lösung vorgefunden. Dem wechselnden Mengenverhältnifs zwischen lōslicher Stärke and Stærkecellulose ist unzweifelbaft der Mangel un gröfserer Uebereinstimmung in den obigen Winkelgrôfsen für Stärkekleister zuzuschreiben. Der Werth ron $[a]$ für die reine Kaliverbiadang der Granulose int wahrscheinlich 165 bis $168^{\circ}$.

Eigenschafion der Maltosa.

Bejm Bestimmen der in einer Lösung von Stärkeverwandlungsproducten vorhandenen Maltose mittelst der gravimetrischen Kapferoxydmethode haben wir durchgängig den für die Mischang berechneten Werth von $[a]_{j}$ höher gefunden, als das specifischo Drehungsvermögen beobachtet wurde. Diesen Mangel an Uebereinstimmung wofsten wir uns eine Zeitleng durchaus nicht 
zl erklären. Durselbe war sowohl in Bezug auf Richting als auch Betrag so beständig, daifs or gewirs nicht in Versuchsungenauigkeiten, noch aurh allem Anscheine nach in der Erzenugung von etwas Dextroze seinen Grand haben kounte, sonst hätte der Uaterschied eine stols aufwärts stejgende Tendenz erkennen lossen mússen, was nicht dey Fall war. Die einzig mögliche Sirklärnng schien zu sein : Bntweder dafs das specifische Rotationsvernögen von Maltose und Dextrin zu hoch angenommen, oder der von 0 'Sullivan för das Kupferoxydreducirungsvermögen der Maltose aufgestellte Coëfficient $65 \mathrm{zu}$ hoch gegriffen war. Letzteres schien weitaus das Wahrscheinlichere, da wir bemerkten, dafs der Unterschied zwischen den beobachieten und den berechneten Zahlew mit dem Procentsatz der Maltose Schritt hielt, also bei den vollständigsten Verwandiungen am Gröfsten war und beinahe verschwand, wenn die Maltose 10 bis $15 \mathrm{pC}$. nicht überstieg.

Um diesem wichtigen Punkte uuf den Grund 20 kommen bereiteten wir zu verschiedenen Malen nach dem von 0 'S u llivan empfohlenen Yerfahren Maltose, d. h. es wurde die syrupartige Masse, die durch Verdampfang einer aus Stārke bereiteten Lösung von Dextrin und Maltose gewonnen wird, mit Weingeist ausgezogen. Hierbei wurde auf eine möglichst vollständige Umwandlung unter den weiter unten angegebenen Verhältnissen geachtet. Die Maltose wurde nach dem Auskrystallisiren mit Alkohol gewaschen und wieder krystallisiren gelassen, bis die Eigenschaften derselben sich constant erwiesen. Mit geschicktem Operiren läfst sich dieser Punkt nacb der zweiten Umkrystallisirung erreichen.

Löoungsdichtigkeit. - Wasserfreie Maltose hat unserer Beobachtung nach ein etwas höheres specifisches Gewicht in Lösung, als Robrzucker in einer Lösung von gleicher Dichto. Eine auf $100 \mathrm{CC}$. 5,0655 Grm. wasserfreier Maltose enthaltende Lösung hat bei $15,5^{\circ}$ ein specifisches Gewicht von 
202 Brown u. Horon, Beilräge zur Geschichte der

1319,915 , demgemlifs ist der bei einer Fünfgrammlösung zur Berechnung der Grammenzahl auf 100 CC. anzuwendende Theiler $=3,9314$.

Specifisches Drehwngsvermögen. - Das specifische Drehungsvermõgen stellte sich bei mehreren verschiedenen Versuchen folgendermafsen heraus :

$\begin{array}{lcc}\text { Bpecifisches Botationsrermbgen der Maltoso : } \\ {[a] 8,86} & {[\alpha] \text { absolat }} \\ \text { 1. } & 150,7^{\circ} & - \\ 2 . & 150,9^{\circ} & - \\ \text { 8. } & 150,1^{\circ} & - \\ \text { 4. } & 150,0^{\circ} & - \\ \text { Mittol } & 154,0^{\circ} & 158,1^{\circ} .\end{array}$

Das specifische Drehungsvermōgen nach O'Sullivan ist $[a]_{3} 8,85=150,0^{\circ}$, und die von ihm angeführten Versuche orgeben $150,2^{\circ}$ als Durchschnittswinkel, was einen mit dem unsrigen beinahe genau übereinstimmenden Werth ergiebt.

Kupferoxydreducirungsvermögen. - Wir haben das Kupferoxydreducirungsvermögen von mehreren Proben reiner Maltose sorgfältig bestimmt und unabänderlich einen geringeren Werth als den gewöhnlich angenommenen von 65 erhalten. Nachstehend einige unserer Resultate.

Kupforoxydreducirungovermogen der Maltose :

$\begin{array}{ccc} & 2 \mathrm{~s}, \mathrm{se} & x \text { sbrolat } \\ \text { 1. } & 61,0 & - \\ \text { 2. } & 61,68 & - \\ \text { 8. } & 60,2 & - \\ \text { 4. } & 60,67 & - \\ \text { 5. } & 61,11 & - \\ \text { 6. } & 61,28 & - \\ \text { Mittlexer Worth } & 60,8 & 61,9 .\end{array}$

Die Zahlon kõnnen möglicherweise etwas zu niedrig ausgefallen sein, jedoch gewifs nicht um mehr als 0,5. Wir haben 61,0 als den wahren $W$ erth von $x_{s, 86}$ für Maltose angenommen und finden, defs, wenn dieser Werth statt 65,0 in 
unseren Versuchen gebraucht wird, die berechneten und beobachteten Ergebnisse so nahe wie nur irgend möglich miteinander übereinstimmen.

Einwirkiung verdünnter Schwofelsäurs auf Maltose. Wir haben die Einwirkung der verdūnnten Schwefelsäure auf Maltose genau untersucht.

Nach O'Sullivan ist das Ergebnifs der Wirkung der verdünnten Săure die Entstehung von Dextrose oder einer Mischung von Dextrosen mit einer gesamnten optischen Thätigkeit von $[\alpha]_{j}+67,0^{\circ}$ ).

Tollens **) hat von den Endproducten der Wirkung verdünnter Sảure auf Stärke eine Dextrose abgeschieden, welche alle Eigenschaften der beim Invertiren des Rohrzuckers gewonnenen hat. Das specifische Rotationsvermögen war nach Tollens $[\alpha]_{D} 53,1^{\circ}=[\alpha]_{b} 59,1^{\circ}$. Wir haben dieselbe Stärkedextrose bereitet und finden deren specifisches Drehungsvermögen bei 5 - bis 10 procentigen Lösungen $[\alpha]_{j, 89}=$ $58,65^{\circ}$. Unsere Versuche deuten diese Dextrose als einzigos Endproduct der durch Wasseraufnahme bewirkten Zersetzung der Maltose an.

Die besten Verhăltnisse für einen günstigen Erfolg dieses durch Säure eingeleiteten Verwandlungsprocesses der Maltose werden nach unserer Erfahrung dadurch erzielt, dafs man die Lōsung eine lange Zeit hindüch bei einer Temperatur von nicht über 80 bis $90^{\circ} \mathrm{C}$. digerirt. Wenn man über diese Grenze nicht hinausgeht, so lāuft man keine Gefahr, die Dextrose in uncharakterisirbare Substanzen zu verwandeln, welche die Lösung mehr oder minder farrben.

Die ersten Stufen der Wasserbindung finden siemlich rasch aufeinander statt. Das specifische Gewicht der Lōsung

-) Journ. Chem. Boc. 1876, D, 189.

-) Bariohte der deutschen chemischon Gesollschan D, 1682. 
204 Brown u. Eeron, Beiträge zur Gerchichte der

steigt mit dem Niederžehen ihrer optischen Thàtigkeit. Bedarf es eines weiceren Beweises als des bureits von O'SuJlivan gegebenen defür, dais Wiaitose ein Zucker ron der $\mathrm{C}_{29} \mathrm{II}_{22} \mathrm{O}_{11}$-Gattung ist, so ergieht sich solcher ays diesem bedeutenden Steigen des specifischen Gewichts und der damit verbundenen Raumverminderıng - ein für die Wasserbincung unirügliches Zeichen. In uitsser Reziehurig finden bei Maltose die gleichen Erscheinungen stuth, welche bei Invertirung des Rohrzuckers beobachlot werden, der Prucentsatz dur Gesanmtvermehrung der festen Masse ist am Ende der beiden Keactionen anscheinend ein und rerselbe. Der Anfangs rasche Niedergang in der optischen Thatigkeit wird nach und nach, je mehr sich das Kupferoxydreducirungsvermögen der Zahl 100 nähert, langsamer und weniger markirt. Letzterer Werth von $x$ wiru indefs nie erreicht, bevor nicht der Werih vơn $[\alpha]_{j}$ für die Lösungsmasse auf $58,59^{\circ}$ heruntergeggngen ist.

Die nachfolgenden Versuche fanden mit einer reinen Maltoselösang statt, die nach Zusatz der Săure $4.8510 \mathrm{Grm}$. Zucker per $100 \mathrm{CC}$. enthielt; es wurden dabei $5 \mathrm{CC}$. verdünnter Schwefelsäure (Ein-Fünftel-Säure) für die Reaction verwendet.

\begin{tabular}{|c|c|c|c|c|}
\hline Dauer de & Digastion & Temperstur & {$[c]$ is,\& } & $\times 3,86$ \\
\hline & tundo & $70^{\circ}$ & $147,2^{\circ}$ & - \\
\hline 8 & tunden & $n$ & $142,4^{\circ}$ & - \\
\hline 8 & & $80^{\circ}$ & $114,7^{\circ}$ & - \\
\hline 16 & . & . & 98,90 & - \\
\hline 20 & $n$ & $85^{\circ}$ & $83,9^{\circ}$ & - \\
\hline 26 & » & ๓ & $73,2^{*}$ & 87,4 \\
\hline 82 & . & $n$ & $66,6^{3}$ & - \\
\hline 38 & $n$ & $n$ & $63,6^{\circ}$ & - \\
\hline 47 & . & ॥ & $61,3^{\circ}$ & 99,7 \\
\hline 53 & ״ & 90 & $58,6^{\circ}$ & - \\
\hline 58 & $n$ & n & $68,6^{\circ}$ & 100,2 \\
\hline
\end{tabular}


Obzwar der letzte Theil der Reaction sehr tràge verläufh, so kommt dieseibe doch nicht zam Stillstande, beyor nicht der Schlufswirkel von 58,6 und das Kupteroxydreducirungsremögen yon 100 erreicht ist. Diefs sind die Eigenschaften der gewöhnlichen Dextroglusose.

Wirkting des Mrlzextracts auf Btaltose. - Zum Yerständniiłs der durch eine anhaltende Binwirkung von Malzextract auf die Stärkeverwandlungrsproducte erzieiten Ergebnisse war es erforderlich, die Wirkung zu ermitteln, welche dureh langanhaltende Digestion einer Malloselōsung mil einetn Ueberschu?s von Malzextract an ersierer hervorgebrach! werden würde.

Bei dieser Untersnchang wurde die gleiche Vorsicht beobachtet, wie bei gewöhnlichen langunhaltenden Stärkeverwaudlungen; d. h. alle zur Verwendung kom!nender. Lösungen wurden sorgfãttig gewogen und ihr Yolumen aus dem specifischen Gewicht berechneh, wàhrend Duplicatproben von Malzextract eben so lange wie dis Maltoselösung selber digerirt wurden und die Correctionen wie gewöhnlich stattfanden.

Forauch I. 75,47 CC. Maltoselisnng rom speo. Gewicht $=1020,94$ warde wit 24,58 CC. xicht orhitztem Normalmalesextrast boi $85^{\circ}$ C. digarirt.

\begin{tabular}{|c|c|c|}
\hline & [ajy 2,80 & $x 8,4$ \\
\hline Urup̃tingliche Lösung & $151,4^{0}$ & 60,1 \\
\hline Naob \& Stunden bei $55^{\circ}$ & $148,8^{\circ}$ & - \\
\hline 16 & 10000 & 57,8 . \\
\hline
\end{tabular}

Versuch IL $71 \mathrm{CC}$. Maltoselosung wurdon boi $6 \mathrm{~B}^{\circ}$ mit $29 \mathrm{CC}$. Normslextract digerirt, welches sorher 20 Minuten lang auf $6 b^{0}$ orkitzt worden war. Nech 20 atöndigor Digestion [a]j 8,86 $=3001,5^{\circ}, \times 8,84=60,07^{\circ}$.

Fersuch III. 75,00 CC. Maltoselöbung vom apec. Gewichto 1027,00 mit 25,00 CC. vorber boi $55^{\circ}$ exhitatem Normalmaleaxtract gemisebt. Digestion bei 50 ? $\mathrm{C}$.

\begin{tabular}{|c|c|c|}
\hline & {$[\alpha]_{j} s, s d$} & 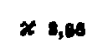 \\
\hline Uraprüngliche Libsung & $150,7^{0}$ & $60,67^{\circ}$ \\
\hline Nsoh 16 Głundon bai $60^{\circ} \mathrm{C}$. & $150,5^{0}$ & $60,7^{\circ}$ \\
\hline
\end{tabular}


206 Brovn u. Heron, Beiträge zur Geschichte der

Aus obigen Yersuchen ist es klar ersichtlich, dafs Malzextract keine Agentien enthälth die im Stande wären, Wasseradditionen an der Maltose zu bewirken. Selbst die stets in geringer Menge vorhandene Säure vermag keinerlei Yerānderung hervorzubringen.

Obzwar die Maltose der Saccharosegruppe angehört, ist sie doch offenbar weniger wandelbar, als Rohrzucker, welch' letzterer, wie wir gesehen, rom Malzexiract schon bei einer niederen Temperatur invertirt wird.

Wirkung des Malecxtracts auf dis Stärke.

Wirkung auf nicht in Gallerte verwandelte Stärke. O'Sullipan*) hat nachgewiesen, dafs Malzextract auf unveränderte Stărke nicht einwirkt. Nach wiederholten Versuchen können wir diese Angabe vōllig bestãtigen. Sogar wenn Malzextract und Stárkekörner eine beträchtliche Zeit hindurch mit einander in Berührung gewesen, haben wir bei gewoohnlicher Temperatur fast niemals eine Einwirkung wahrzunehmen vermocht.

Es scheint diefs auf den ersten Blick dem bekannten Verschwinden der Stārke im Samen während des Keimungsprocesses zu widersprechen, das fast durchgehends der Wirkung diastatischer Gährstoffe zugeschrieben worden ist. Wir hielten es daher für angezeigt, die mit der Metastase der Stārke unter solchen Umständen verbandenen Erscheinungen eingehender zu prüfen.

Unsere Versuche fanden mit Weizen, Gerste und Hafer im Keimungszustande statt. Um unsere Ergebnisse verstandlicher zu machen, wollen wir die wesentlichen Theile der Frucht dieser Cerealien in kurzen Worten beschreiben.

") Journ. Chem, Soe. 1876, in, 188, 
Frucht und Keimungovorgang der Cerealien. - Die Frucht besteht aus dem stärkereichen zelligen Endosporm, welches von einer Schicht rechtwinkeliger Zellen umgeben ist, die die sogenannten zumeist aus Proteiden bestehenden A leuronkiorner enthält. Unmittelbar um die Aleuronzellenschicht herum liegt die Tosta oder eigentliche Samenhülle, und aufsen scbliefst sich dicht an dieselbe die Fruchthülle (Pericarpium). Diese Verbindung ron Frucht and Samen ist als Caryopsis bekannt, und bei den meisten Arten Gerste ist letztere mit einer dicken, autseren, aus sich fest anschliefsenden Hülsen (Paleas) bestehenden Haut bedeckt. Beim gewöhnlichen Weizen schliefsen sich diese Hülsen der Caryopsis nicht fest an, sondern sind als Spelzen vom Körnchen getrennt. Der Embryo oder der Keimling ist in einen Zellenmantel gehüllt, welcher nach hinten zunächst dem Endosperm eine dicke schildförmige, als Köpfchen (Boutellum) bekannte Epidermis bildet.

Wenn der Weizen zu keimen anfängt, so befindet sich das Blattfederchen des Embryos beim Durchbrechen seiner Holle in unmillelbarer Berūhrung mit der inneren Fläche des Pericarpiums, welche in diesem Palle nicht widerstandsfähig ist, sondern durchbrochen wird, so ewar, dafs das Blattfederchen aufserhalb des Kornes fortwächst. Bei der Gerste ist das Pericarpium stark genug, um das Blattfedercher in sich festzuhalten (diefs ist sogar bei der sogenannten nackten Gerste der Fall, wo die Paleae nicht anliegen). Vermöge dessen fndet das Wachsthum des Blattederchens zwischen der Testa und dem Pericarpium und zunächst dem im Endosperm aufgespeicherien Material stath, bis dasselbe schliefslich an dem vom Embryo am Weitesten entfernten Ende des Korns hervorbricht.

Von den in dem Endosperm wāhrend des Wachsthums des Blattfederchens wahrzunehmenden Veranderungen sind 
208 Brown un Horon, Boibrigs aur Geschichte der

folgende die wishtigsten : Die stärkehaltigen Zellen zunächst dem Sculelluin des Embryos verlieren groisentheils ihre protoplastische Wand und werden mehr und meir zerstort. Dieser Proceís geht allmälig dor Lànge des Forns nach fort und ist in allen Fällen an nerikliehsten in den Theilen des Endosperms, welche einer Absorptionsflüche zunächst liegen, d. h. in dem Scutellum oder in den numiltelbar untar dena wachsenden Blattfederchen befindlichen Theilen der Testa.

Der Inhalt der Aleuronzellen änders sich mit dem Wachsthum des Kornes bedeutend, und liat man ein Kurn genommen, dessen Endospern einen zarten Zelletblua aufweist, wie diefs z. B. bei einer feinen, auf leichtem Boden gewachsenen Gerste der Fali ist, so läst sich das Verschwinden und die Absorption der Cellnlose, welche die $W$ ănde der noch zarten stärkebaltigen Zellen bildet, deutlich erkennen *).

Diese Veränderungen machen hauptsūchlich den Malzungsprocefs aus. Der wachsende Embryo bewirkt die Metastase zunächst der neben Stärke vorhandenen Reservestoffe, und erst wenn diese aufgebraucht sind oder anfangen schwer $z u-$ gänglich zu werden, werden die Stärkekörnehen in Milleidenschaft gezogen.

Gerste. - Untersuchen wir zuerst ein Gerstenkorn, dessen Bndosperm Zellen enthält, deren Wände zart gebant und die von dem anhaftenden Protoplasma nur wenig verdickt werden, bei welchen also verhältnifsmälsig leicht eine Diffusion stattfinden kann. In einem derartigen Falle wird keine oder nur eine geringe Eirwirkung zuI die Stärke bemerklich, bevor nicht das Blattfederchen bedeutend ûber die

-) Das Versehwinden der Cellalone whirord des Keimons gowiser Sacnez ist ron Ssch sohon frïher beobachtet worden. Der gröfsere Theil der das Endosperm der Dattal bildenden RuservoEïrpar hesteht aus Collulose, die whinend des Koimens von der wachsendon Pflarae absorbirt wird. 
Spitze des Korns. hinausgewachsen ist. Die Wirkung auf sias Stärkekorn macht sich: wie zo orwartes, anerst in den TheiIen des Endosperms bemerkbar, denen aller andere Biidungsstoff am Yollkommensten entzogen worden, $d$. $h$. in den dein Scutellum des Embryos zonächsł gelegenen. Lärst man das Biattederchen fortwachsen, so sieht man die Wirkung aut die Stärkekörner in der gleichen Richtung sich ausbreiten, in der die Endospermzellen sich zuerst zersetzten, d. b. unraittelbar unterhalb des Federchens und in der Richting, in der dasselbe wăchst.

Ist das Zellgewebe der Gerste stark, und findet sich auf . den Zellenwänden eino dicke Eiweifsschicht, so wird die Metastase der aufser der Stärke vorhandenen Reservekörper bedeutend gestört, und dengemäl's zersetzen sich die Stärkekörner unten am Endosperm bedeutend frūher, als woin der raschen Absurption kein mechanisches Hindernifs entgegensteht.

Weizen. - Beim Weizen beginnt dio Wirkung auf die Stărkekörner lange bevor das Eadosperm vōllig umgewandelt ist. Dieîs hat zwei Gründe : Der erste davon isł die aus der Dicke der Zellevwànde und aus der denselben anhaftenden bedeutenden Menge Protoplasma entspringende relative Zăhigkeit und Fostigkeit des Zellgewebes und die daraus folgende Schwierigkeit der Diffusion, der zweite der Umstand, dafs das, nicht wie bei der Gerste, zwischen Testa und Pericarpiurn festgehaltene Blattfederchen in keinerlei Weise zur Absorption der ReserveLôrper beitrügt, welch' letztere also sämmtlich von der verhältnifsmärsig kleinen Oherfläche des Scutelloms aufgenommen werden müssen. In Folge dieser Art der Absorption werden zunächst den um das Scutellum herumliegenden Regionen des Endosperms alle leicht assimilirbaren Stoffe entzogen, and durch diese entleerten Partieen mússen in der Folge alle ferner gelegenen Bildungsstoffe wandern, bevor dieselben eine absor- 
210 Brown u. Heron, Beiträge aur Qeschichte der

birende Fläche erreichen, und demgemāis kann die weniger assimilirbare Stăke in einem solchen Falle in Angriff genommen werden, wenn auch noch ein Ueberfluifs an anderem Bildungsmaterial ira Bndosperm vorbanden ist.

Bei der Gersto nimmt des Blattfederchen, dicht an der Testa anliegend, seinen Lauf der länge nach durch's Korn, woraus sich klar ergiebt, dafs der längste von einem Stoffpartikelchen bis zur Brreichung einer Absorptionsfläche zu durchlaufende Weg gleich dem kleineren Durchmesser des Korns ist, während beim Weizen dieser Weg gleich der Gesammtlānge des Korns ist. Im Allgeneinen lâfst sich sagen, dafs bei keimenden Cerealien der Zeitpunkt, an welchem die Stärkekörnchen fär den Unterhalt des Entwickelungsprocesses herangezogen werden, von der relativen Leichtigkeit abhångt, mit der die anderen far die Absorption geeigneteren Reservematerialien für diesen $Z_{\text {weck }}$ zugänglich sind.

Die erste Einwirkung auf das Stärkekorn zeigt sich gewöbnlich durch das Erscheinen ron kleinen Grübchen *) auf der Oberfläche des Korns, welche bald in radialer Richtung von Rissen durchzogen werden, wobei die Granulose sich gleichzeitig rasch auföst. In verhältnifsmäfsig kurzer Zeit bleibt vom ursprtnglichen Stärkekorn nichts übrig als ein aus Sterkecellulose bestehendes Skelett, das für einige Zeit noch die Gestalt des Korns beibehält; jedoch auch dieses bricht, allordings in einer viel spateren Periode des Wachsthams der jungen Pflanze, zusammen und verschwindet. Ist die âufsere Hülle des Körnchens einmal durchbrochen, so

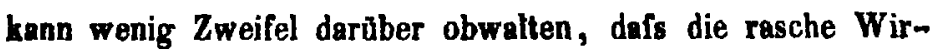
kung auf die Granulose durch die diastatische Wirkung des Zellensaftes verursacht wird. Wir haben uns vielfach be-

-) Das Thrcheinen ron Vertiofungen dieser Art auf den Stirkekömchen unter dorartigen Umstandon hat zuerat C. Nugeli (s. dio Bthrkokbrner) beobuchtet. 
müht, die erwähnte Grübchenbildung auch dadurch zu erzielen, dâfs wir Stärke auĩ verschiedene Weise mit dem wãsserigen Malzextract behandelten, sind jedocb bei gewōhnlicher Temperatur niemals zu einem Ergebnisse gelangt. Wir müssen demgemäfs jene Erscheinung als eine von den Lebensfunctionen der Pflanzenzelle unzertrennliche betrachten. Wie wir gesehen, sind sprechende Anzeichen für eine Absorption der Cellulose durch den Embryo während des Keimens der Cerealien vorhanden, und möglicherweise liegt auch ein Anfang einer gleichen Einwirkung auf die Cellulosenhülle des Ståkkekorns vor, die eine theilweise Blorslegung der Granulose verursacht und damil letztere der auflōsenden Wirkung des Zellenprotoplasmas preisgiebt.

Wirkung de Malzextracts auf zermalmte Stärke. Nachdem nun ermittelt, dafs das Stärkekorn, so lange seine aufsere Hülle unversehrt geblieben ist, der Binwirkung der diastatischen Fermente zu widerstehen vermag, schien es uns von Interesse die Wirkung des Malzextracts auf zermalmte Stärke zu untersuchen. Zu diesem Behufe wurde Stärke mit scharfen Quarzsand oder zerstofsenem Glas zerrieben und etwas Malzextract hinzugethan. Unter solchen Verhāltnissen fanden wir, dafs Stãrke sehr rasch afficirt wird.

Die optische Thäligkeit der sich ergebenden Verwandlungsproducte ist immer sehr niedrig, und in Verbindung mit dem Kupferoxydreducirungsvermögen giebt dieselbe nicht immer Resultate, die mit der Annahme der alleinigen Gegenwart von Maltose und Dextrin verträglich erscheinen. Die Annahme, dafs sich aufserdem noch Dextrose gebildet habe, ist auch nicht gerechtfertigt, da in der Regel jene Lösungen, wenn man sie einige Zeit lang stehen lâfst, in der Wărme digerirt, sich in Bezug auf optische und chemische Eigenschaften einer Mischuog von Dextrin und Maltose mehr und mehr nähern. 
212 Brown u. Heron, Beiträge zur Geschichte der

Die Ursuche lür die erwähnten Abweichungen in den Resultaten suchen wir vielmehr in Yorhandensein von ein wenig Stärketeilulnge in der Lösung, welche sich allmälig in der gleichen Weise, wis gewöhnliche Stärke, in Dextrin und Maltose verwandelt. Sobald wir sahin gelangen, die Wirkung des Malxextracts auf den Stärkekieister in der Kälto zu untersuchen, werden wir einen Bewcis dafür vorfinden, hais dort oin shulicher Körper in Lösung eintritt, und dafs derselbe böchst wahrscheinlich keirierlei optische Thätigkeit besitzt.

Die Stärke wurde bei sümmtlichen Versuchen mit Sund oder Glaspulver zerrieben und mit Normolmalzextract vernischt. Das Malzextrack wurde noch für sich in einer besonderen Probe in gleicher Weise wie die Vorwandlungsfüssigkeit hebandelt.

\section{Gravmo footer}

Suhotanx per

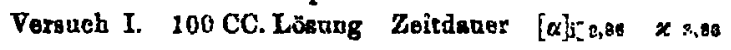
1,7303 20 Stander $152,0^{\circ} \quad 40,0$ Maltose 65,6

Dextrin 24,8

Cellalose $\frac{9,6}{100,0}$

Voxouch II. $\quad 2.8497$

6 Stunden $\quad 152,2^{\circ} \quad 52,7$ Mialtige 86,3

Dextrin 10,5

Collulone $\frac{3,2}{100,0 \text {. }}$

Divselbe Lobngng nacin 20 Stunden in der Kulte

$152,2^{\circ} \quad 68,8$ Meitoso 91,4

Dextrin 7,0

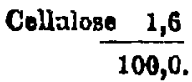

Dieselbe 30 Minuson lang auf $57^{\circ}$ erhitzt 
Stärke und der Verwandlungen derselben.

Grammo fester

Substanz per

Versuch III. 100 CC. Lösung Zeitdauer $[\alpha] 5,8,88 x$ s,8s

3,1554 Stundon $155,4^{0} \quad 51,0$ Maltose 83,6

Dextrin 18,9

Cellulose 2,5

Dieselbo nach 20 stunden in der

Kalte

$152,0^{\circ} \quad 54,4$ Maltose 89,1

Dextrin 8,5

Celluloge $\frac{2,4}{100,0}$

Dieselbe nacin 30 Minaten langem

Digeriren bei $60^{\circ}$

$152,0^{\circ} \quad 53,3$ Maitose 90,6

Dextrin 7,4

Cellulose $\frac{2,0}{100,0}$

Vorsuch IV. $1,308 \quad 6$ Stonden $131,0^{\circ} 43,8$.

Dieselbo nach 24 stïndigem Stehen

in der Kalte

\begin{tabular}{rrr}
$130,6^{\circ} \quad 51,4$ & Maltose & 84,2 \\
& Dextrin & 1,9 \\
& Cellnloge & 13,9 \\
\hline & & 100,0
\end{tabular}

Wirlkung des Maleextracts auf Btärkekleister in der Kältt.

In der Kälte wirkt Malzextract, der allgemeinen Anschauung entgegen, kräftig und rasch auf Stärkekleister.

Wirkung von nicht vorher erhitatem Malzextract. Wenn Normalmalzextract im Verhältnisse von 5 bis 10 CC. auf 100 CC. zu einem, 3 bis 4 pC. feste Masse enthaltenden Stärkekleister hinzutritt, so wird letzterer in 1 bis 3 Minuten völlig dünnfưssig. In diesem Augenblicke hat die Lösung den höchsten Grad von Durchsichtigkeit erreicht, und anmittelbar darauf wird dieselbe von Jod nicht mehr blau gefärbt Die Braunfärbung für Erythrodextrin ist indefs etwas anhaltender und hört selten vor Ablauf von 5 bis 6 Minaten 
214 Brown u. Heron, Beirrüge zur Geschichte der

nach dem Anfange des Yersuchs aul. Wird nun die ungelôste Stärkecellulose von der Lösung durch Filtration getrennt, so findet man, dafs die filtrirte Flüssigkeit eine sehr niedere optische Thătigkeit hat und auch nur ein geringes Kupferoxydredueirungsvermõgen besitzt, was der Annahme widerspricht, dafs aufser Dextrin und Mfaltose nichts anderes aus der Stärke hervorgehe. Die filtrirte Flüssigkeit ist Anfangs vollkommen klar, zeigt aber, nachdein sie einige Zeit gestanden hat, eine Trübung, und diese nimint wätsrend einer halben Stunde, wenn auch nur unbedeutend, fortwährend zu. Die Trübung wird durch eine kleine Menge Stärkecellulose verursacht, welche, wăhrend die Stärkeproducte sich in ibre niederen Modificationen aufgelöst hahen, unlōslich geworden ist.

Die optische Thätigkeit der Lõsung ist am Geringsten zwei bis drei Minuten nachdem volständige Verlüssigung eingetreten ist und bleibt 30 bis $\mathbf{4 0}$ Minuten constant. Nach Ablauf dieser Zeil and stets, wenn die Absetzung der Cellulose vollendet ist, steigt das specifische Drehungsvermōgen und das Kupferreducirungsvermoggen merklich, und beide erreichen nach ungefăhr drei Stunden ihr Maximum. Die respectiven Werthe von $[a]$ und $x$ sind nunmehr mit der Annahme der aileinigen Gegenwart von Dextrin und Maltose vereinbar.

Wir hegen keinen ' $/$ welfel daran, dals die abnorm niederen Werthe von $\lfloor\alpha\rfloor$ und $x$, wie sie nach dem Eintreten der Klärung sich zeigen, von der kleinen in Lösung bleibenden Menge Stärkecelluluse herrühren, und dafs die carauffolgende allmälige Yergrōfserung des Drehungswinkels in dem Zerfallen dieser gelösten Stärkecellulose begründet ist.

Nachstehende, iri Figur 2, Tafel 1 graphisch dargestellte Ergebnisse lassen sich als Typen einer unter den obigen Verhältuissen angesteliten Stärkeverwandlunł̧ betrachten.

3,7 Grm. Sturke und $10 \mathrm{CO}$. Normalmalzextrast aut $100 \mathrm{CC}$. Flïgsigkeit. 
Stärke und der Verwandlungen derselben.

\begin{tabular}{|c|c|c|c|c|}
\hline & $\begin{array}{l}\text { Leuer } \\
\text { inuten }\end{array}$ & $\begin{array}{l}{[\alpha]_{j} s, 86} \\
154,6^{\circ}\end{array}$ & $\begin{array}{c}x_{3, \mathbb{B} 6} \\
-\end{array}$ & $\begin{array}{c}\text { Jodresotion } \\
\text { brynulich }\end{array}$ \\
\hline 15 & . & $154.0^{\circ}$ & - & keino Roaction \\
\hline 30 & 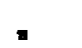 & $154,6^{\circ}$ & - & $n$ \\
\hline 60 & 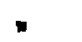 & $157,5^{\circ}$ & 4,1 & n \\
\hline & unden & $161,6^{\circ}$ & 49,7 & $n$ \\
\hline
\end{tabular}

Der Werth von $x$ nach Ablauf von 60 Minuten zeigl das Vorbandenselı von 72,2 pC. Maltose an; wäre das übrige Dextrin, so mūfste der Drehungswinkel $=167,30$, statt des boobachteten $\left(157,5^{\circ}\right)$ sein. Nach Verlauf von 3 Stunden ist der berechnete $W$ inkel $=162,2^{\circ}$, ,egen $161,6^{\circ}$, wie beobuchtet.

Die Abscheidung einer goringen Menge Stürkecellulose, nachdem die Reaction 5 bis 10 Minuten gewāhrh, ist niemals von einem irgend bemerklichen Unterschiedte in der optischen Thātigkeił der Flüssigkeit bepleitet, woruus klar hervorgeht, dafs die Cellulose in der Lōsuug wenig oder gar keine Wirkung auf polarisirtes Licht ausübl. Diels ist bembekenswerth, wenn man die verbāltnifsmāisig hohe optisch Wirkungskraft einer alkalischen Lösung ron Stärkecellulose in Betracht zieht. (Siehe Seite 193.)

Nachstehend die in verschiedenen Fällen erzielte schliefsliche Zusammensetzung der Stārkeverwandlungsproducte :

Dor grofsto

Winkel rrarde

Iir. orriolt noch

1. S Standes

2. Btardon

$261,6^{\circ}$

49,7

$[\alpha]_{j}, 86$

$261,6^{\circ}$

$x_{3,83}$

49,7

Znpemponsotring

Mallose 81,4

Dextrin 18,6

2. Stardon

3. 1 Stunde

161,90

$\$ 9,0$

Maltoge 80,3

Dextrin $\frac{19,7}{100,0}$

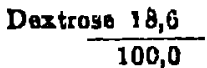

Borochnoter opkinoher Wiakel $162,2^{\circ}$

$168,2^{\circ}$

$163,0^{\prime}$

4. $3 \%$ Stunde 161,90

6. 1 "

b. $3 \%$ n

$162,8^{\circ}$

$162,6^{\circ}$

$\overline{-}$

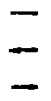


216 Brown u. Heron, Beiträge zur Geschichte der

Wenn die Lōsungen einmal die obige Zusammensetzung erlangt haben, so ändern sich dieselben auch in mehreren Stunden nicht mehr merklich. In etwa 18 Stunden wird gewöhnlich ein geringer Niedergang in der optischen Thätigkeit bemerkbar, was daher rührt, dafs das Malzextract das Dextrin ein wenig angreift.

Nr. 2. zeigte nach 30 Stunden nachfolgende Bestandtheile :

$$
\begin{aligned}
{[\alpha]_{j 3,36} } & =: 59,5^{\circ} & \text { Maltose } 84,4 \\
x_{3,2 e} & =51,5^{\circ} & \text { Dextrin } 15,6 \\
\hline & & 100,0 .
\end{aligned}
$$

Der för diese Zusammensetzung berechnete Winkel beIrügt $[\alpha]_{3,86} 160,2^{0}$. Alle von uns bei der Wirkung des Malzextracts auf Stárkekleister in der Kälte erzielten Resultate sinc่ so überaus gleichförmig gewesen, und die erhaltene Mischung vou Umwandlungsproducten ist in allen Fällen hinsichtlich ihrer Zusammensetzung so vollstandig dieselbe geblieben, dafs wir kein Bedenken tragen, daraus auf eine unter diesen Bedingungen vor sich gehende, bestimmte moleculare Zersetzung der Stärke z.u schlie!sen.

Das Mittel aus den obigen Versuchen ergiebt folgende Werthe :

$$
\begin{aligned}
{[\alpha]_{\mathrm{j} 3,86} } & =162,1^{0} . \\
x_{3,86} & =49,1 .
\end{aligned}
$$

Diefs stimmt mit der Zusammensetzung :

$$
\begin{aligned}
\text { Maltone } & =80,4 \\
\text { Dextria *) } & =\frac{19,6}{100,0 .}
\end{aligned}
$$

Die Gleichung :

$$
\begin{aligned}
& 10 \mathrm{C}_{12} \mathrm{H}_{20} \mathrm{O}_{20}+8 \mathrm{H}_{2} \mathrm{O}=8 \mathrm{C}_{19} \mathrm{H}_{22} \mathrm{O}_{11}+4 \mathrm{C}_{6} \mathrm{H}_{10} \mathrm{O}_{6} \\
& \text { Stärk Maitose Dextrin }
\end{aligned}
$$

erfordert für die Verwondlungsproducte :

*) In dieser getsomiten Abhandlnng ist die optische Thutigkeit des [exting $[\alpha]_{\mathrm{j}} 8,86=216,0^{\circ}$ angenommon worden. 
Stärke und der Ferwandlungen derselben.

$$
\begin{array}{rr}
\text { Maltose } 80,9 & {[\alpha]_{3} 3,86=162,6^{\circ}} \\
\text { Dextrin } 19,1 & x_{3,66}=49,3^{\circ} \\
\hline 100,0 . &
\end{array}
$$

Diese Werthe kommen den in unseren Versucion orzielten sehr nahe. Weiter unten wird nachgewiesen werden, dafs eben auf diese Gleichung alle Verwandlungen hinsteuern und dafs diese es ist, welche die stabilste Form aller durch Malzextract möglichen Zersetzungen der Stärke zum Ausdruck bringt.

Wirkung von vorher erhitztem Maleextract auf Stärkekleister in der Kälte. - Wenn Stärkekleister mit Malzextract versekzt wird, welches vorher erhitzt und dann wieder bis auf die gewōhnliche Temperatur abgekühlt worden ist, so schwächt sich, wie man erwarten konnte, die verwandelnde Kraft bedeutend ab. Rs läfst sich jedoch in der unter solchen veränderten Umstãnden zar Erzielung vollkommener Klarflüssigkeit erforderlichen Zeitdauer nur wenig Unterschied beabachten; je hōher indefs dos Malzextract erhitat worden" desto lãnger lassen sich Stärke und Erythrodextrin in der Flüssigkeit erkennen und desto hōher ist, unter sonst gleichen Umständen, die au irgend ciner bestimmten Zeit beobachtete optische Thătigkeit.

Die in der Kälte durch Malzextract umgewandelten Lōsungen zeigen in den früheren Stadien einon morklichen Unterschied in der relativen Durchsichtigkeit, je nachdem das Malzextract vorher erhitzt gewesen war oder nicht. Ist Malzextract vorgängig bis auf $66^{\circ}$ erhitzt worden, so wird in Folge der verhältnifsmäfsigen Langsamkeit, mit der die lösliche Stärke und die höheren Dextrinarten zerfallen, vorher eine grofse Menge Stärkecellulose durch diese letzteren Körper zur Lösung gebracht. Wird unerhitztes Malzextract verwendet, so werden. die löslichen Stärke- und dì höberen Dextrinarten fast un-mittelbar verwandelt und ü山en demgemäls nur mehr geringe 
218 Brown u. Beron, Beiträge zur Geschichto der

Lōsewirkung auf die Cellulose aus. Aus diesem Grunde zeigen in den ersten Reactionsstadien die mit vorher erhitztem Malzextract behandelten Lösungen eine gröfsere Durchsichtigkeit als diejenigen, welche mit nicht erhitztem Malzextract behandelt worden sind; im ersteren Falle indet dagegen eine stárkere nachtrăgliche Abscheidung der Cellulose statt, als in dem letzteren.

\section{Wirkung des Malzextracts auf Stärkekleister in der Wärme,}

Um die Wirkung des Malzextracts auf Stärkekleister bei hohen Temperaturen untersucben $\mathfrak{w}$ kōnnen, mưste ein Mittel aufgefunden werden, das die Möglichkeit bot in einem Theile der Flüssigkeit bei einem beslinmten Punkte der Reaction jede weitere Verwandlung zu sistiren. Am Nāchsten lag es, die Flüssigkeit auf den Siedopunkı zu bringen. Diefs lieferte jedoch bei raschen Verwandlungen keine günstigen Erg ebnisse, denn wenn auch die Lösung noch so schnell erhitzı wurde, so fand doch Slets eine weitere Vorwandlung der Stärkeproducte statt, ehe noch der Wirkung des diastatischen Gährstoffes durch Gerinnung Einhalt gebolen werden konnte.

Wir erreichten unseren Zweck endlich durch Anwendung von Salicylsäure, welche die weitere Verwandiung der Stärke aufhält. ohne für die analylische Untersuchung der Producte irgend hinderlich zu sein. Unser Verfahren bestand in Folgendem : Proben von der Yerwandlungsflüssigkeit wurden in bestimmten Quantitāten im gewünschten Augemblicke in ein Fläschchen gegossen, in welchem 2 bis 3 Cgrm. Salicylsäure sich betanden. Die Probe wurde heifs mit der Sãure geschüttelt, dann abgekühlt und nachträglich analysirt. Das spec. Gewicht der Lösung wurde stets bei einer anderen Probe ermitielt, die nicht mit der Såure zersetzt, sondern nur herausgenommen und abgekuhlt worden war. Die gesammte, aus dem geringen Grade von Wasserbindung während dieses Pro- 
cesses sich ergebende Zunahme an festen Bestondtheilen ist kaum bemerkbar.

Nachfolgende Versuche veranschaulichen die unverkennbare Fähigkeit geringer Quantitäten Salicylsäure, die Verwandlung der Stärke durch Malzextract auf halten zu können.

$100 \mathrm{CC}$. Starkelsleizttr, $5 \mathrm{Grm}$, Starke entkaltend, Furden boi jedem Verguche verwencet, mit jewsils 5 CC. Normalmalzextract und den nachstehencen Nengen Salicylenture.

Yartrandlaug bei $58^{\circ} \mathrm{C}$.

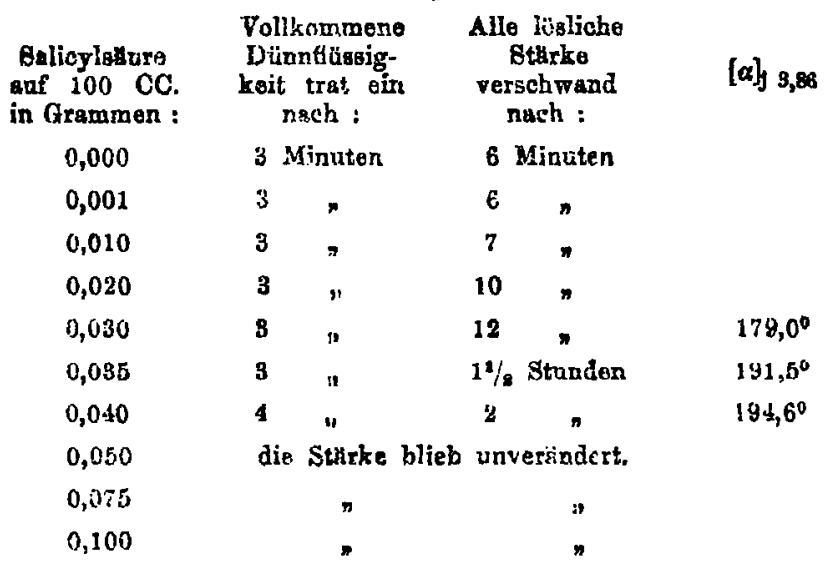

Unter den bei obigen Versuchen vorbandenen Verhältnissen sehen wir, dafs Quantităten von Salicylsāure bis zu $10 \mathrm{Mgrm}$. auf die Reaction nur geringen Einflufs gusüben, während über dieses Quantum hinaus der Verzögerungseffect der Säure rasch steigt. $40 \mathrm{Mgrm}$. heben beinahe gãnzlich die Thäligkeit der in $5 \mathrm{CC}$. Normalmalzextract enthaltenen Diastase auf, während 50 Mgrm. alier Wirkung vollkommen Einhalt thun.

Es ist bemorkenswerth, dais, so lange das Verwandlungsag̣ens irgend welche diastatische Kraft besitzt, es zitemlich gleich lange Lett dauert, bevor der Stärkekleister rollkonmen dünnflüssig wird. 
220 Brown u. Heron, Beiträge zur Geschichte der

Da die zur Sistirung allex Wirkung erforderliche Menge Salicylsāure, wie diefs natürlich, je nach der in Anwendung kommenden Malzart sich ändert, so giebt uns diels ein Mittel an die Hand, das relative Verwandlungsvermögren von Mala, ganz abgesehen von einem anderen, weiter unten erlāuterten Verfahren, abzuschätzen.

Nachdem wir nun ein Verfahren aufgefunden haben, welches gestattet, die Wirkung des Malzextracts zu irgend einer beliebigen Zeit zu sistiren, bedarf es nur einer Reihe von Beobachtungen in kurzen Zeitabstānden von einander, um den Fortgang einer Reaction graphisch darzustellen mittelst einer Curve, deren Punkte durch die respective Länge von rechtwinkeligen Coordinaten bestimmt werden. Die Abscissenlinie wird in gleiche Theile getheilt, welche der Zeildauer der Wirkung in Minuten entsprechen, während auf der Ordinatenlinie das specifische Drehungsvermögen in Winkelgröfsen von $216^{\circ}$ bis auf $150^{\circ}$ herunter verzeichnet wird.

Verändcrung der Wiorkung des Malzextracts durch die Hitze. - Es ist augenscheinlich, dafs die Verschiedenheit der bei verschiedenen Wärmegraden in der Behandlung von Stärke mit Malzextract erzielten Ergebnisse aus einem von zwei von einander ganz verschiedenen Gründen, oder auch aus beiden entspringen kann. Diese Gründe sind : 1) der directe Einflufs der Wärne aứ die Spaltung des Stärkemoleculs, und 2) die durch lie Wärme im Verwandlungsagens hervorgebracinten Veränderungen. O'Sulli y a n herührt diesen Punkt am Ende seiner letzten Abhandlung *) und neigt zu der Annahme, dafs die mannigfaltigen Zersetzungen, welche man beobachtet, allein auf den letztere! Grund zuruckzuführen seien. Unsere Versuche stim.men mit dieser Annalıne vollkommen überein, dẹn wir linden

\#) Journ, ahim. soc. $1876,2,143$. 
in jedem einzelnen Falle, dafs die jeweilige Reactionsphase durch die vorgängige Behandlung des zur Verwendung kommenden Malzextracts bestimmt wird, insofern diese Behandlung bei derselben oder bei einer höheren Temperatur stattgefunden, als die ist, bei welcher die Verwandlung vor sich geht.

Werden die Ergebnisse graphisch dargestellt, so findet sich z. B., dafs die bei 60 und $66^{\circ}$ mit beziehungsweise bis auf diese Temperaturen erwãrmtem Malzextract bewirkten Verwandlungen in zwei ganz verschiedenen, in Figur 4 und 5, Tafel I verzeichneten Curven repräsentirt sind. Ist dagegen das Malzextract vorher einige Minuten lang auf $66^{\circ}$ erwärmt worden, und werden die Verwandlungen nachher mit diesenı Malzextract bei remperaturen von respective 60 und $66^{\circ}$ angestellt, so findet sich, dafs beide Curven identisch sind und der hochgradigeren Verwandlung entsprechen, wie ein Vergleich von Figur 5 und 6, Tafel I diefs ergiebt.

Für alle Temperaturgrade über $50^{\circ}$ läfst sich Obiges in folgende allgemeine Worte fassen :

Wenn zuei gleiche Quantitäten Stärke bei verschiedenon Temperaturen der Einwirkung gleicher Quantitatten Malzextract ausgesetzt werden, welche vorher einige Minuten mindestens ebenso hoch, oder höher, als die höhere der in Anwendung kornmenden Versuchstemperaturen erhitzt wordes sind, so sind die in beiden Fallen vor sich gehenden Umwand. lungen in jeder Beziehung einander gleich *).

Wirkung des Maleextracts bei $40^{\circ}$ C. - Die Wirkung des Malzextracts auf Stärke bei $40^{\circ}$ weicht in mehrtren wesentlichen Punkten von der in der Kälte stattfindenden ab.

-) Der Eintritt vollkommener Dünnfliesigkait im Stbrkekleieter, oder in anderen Worten, dio Verwandlang der Granulose in lösliche Stæretst; soheint durch höhere Warmegrade etwas befordert zu werden, unił zwar gang naabhungig ron dor Behandlung, welche das Maluextract, rorher erfahren bat. 
222 Brown u. Beron: Beiträge aur Qeschichte der

Zuvōrderst isi, wenn der Stärkekleister nicht sehr dick und das zur Verwendung kommende Extractquantum nicht sehr gering ist, beine Atsscheidung von Stārkecelluiose wahrnehmbar, noch auch läfst sich letzterer Körper bei irgend welchem Stadium der Reaction in Lösung vorfinden, da derselbe frúhzeitig vollig verwandelt wird. In Uebereinstimmung mit der Verwandlung der Cellulose sind auch die Werthe von $[a]$; und * auf allen Varwandlungsstufen mit dem alleinigen Vorhandensein von Dexirin und Maltose vollkommen vereinhar. Die Verminderung in der optischen Thätigkeit erreicht ziemlich bald ihre hochste Grenze und bleibt dann auf eine betrāchtliche Zoit vollkommen constant. Die Reactionsgrenze scheint absoluı die gleiche $z u$ sein wie in der Kälte, nämlich $[\alpha]_{3,86}$ $=162,0^{\circ}$ unit $x_{3,86}=4 y, 3$, entsprechend der Zusammensetzung :

$$
\begin{aligned}
\text { Maltose } & =80,9 \\
\text { Dextrin } & =\frac{19,1}{100,0}-
\end{aligned}
$$

Durch die nachfolgenden Zahlenangaben wird ein genaueres Bild einer solchen Verwandiung gegeben. In Figur 3, Tafel I ist dieselbe graphisch dargestellt.

5 Grm. Bohke und 10 CC. Normulnalzextract suf $100 \mathrm{CC}$. Flilssigkeit. Das Malzextract vorher 20 Minuten lang auf $40^{\circ}$ orwormt

\begin{tabular}{|c|c|c|c|}
\hline Zeitdauer & {$[\alpha]_{j} 9,86$} & $x_{8,36}$ & Jodreaction \\
\hline $2_{1 / 8}^{1 /}$ Minuten & $164, x^{0}$ & - & tiof brann \\
\hline 15 & $163,3^{2}$ & - & brsun \\
\hline 30 & $163,3^{\circ}$ & 48,9 & keine Rezction. \\
\hline
\end{tabular}
Vorwandlungstemperatur $40^{\circ}$.

Von diesen Zahlenwerthen ist der nachfolgende Procentsatz der Stärkeproducte in der Mischung herzuleiten :

$$
\begin{aligned}
& \text { Maltose } 80,0 \\
& \text { Dextrin } 20,0 \\
& \hline 100,0,
\end{aligned}
$$

welcher Zusarnmensetzung die Werthe von $[\alpha]_{i 3,95}=163,2^{0}$ und $z$ s,86 $=48,8$ entsprechen. Da das Aufhören der Wir- 
kang in obigem Versuche möglicherweise davon herrührte, dafs das Malzextract zam Theil seine Kraft verloren hatte, so wurde mehr Malzextrach, im Yerhältnifs von $10 \mathrm{CC}$. per 100, hinzugethan und die Lösung weiter digerirt, wobei sich bolgendes Resultat ergab :

Nacb 60 Minuten : $[\alpha]_{3,85}=161,6^{0} \quad x_{9,86}=49,7$.

Die Zusammensetzung :

$$
\begin{array}{r}
\text { Maltose }=81,5 \\
\text { Dextrin }=18,7 \\
\hline 100,0
\end{array}
$$

erforderte die Werthe :

$$
[\alpha]_{j 3,86}=168,8^{\circ} \quad x_{3,86}=49,7 \text {. }
$$

Die Lösung liefs sich nicht sehr lange digeriren, weil sehr bald Gährung eintrat. Doch ersehen wir, dals die weitere Erzeugung von Maltose auf Kosten des Dextrins sehr langsam vor sich geht.

Wirkung des Malzextracts bei $500^{\circ}$ - Wird Malzextract auf $50^{\circ}$ erwärmt und dann auf Stürkekleister bei derselben Temperatur einwirken gelassen, so ist die Wirkung heinahe die glejche, wie jene, wenn auf $40^{\circ}$ erwärmtes Malzexlract auf Stărkekleister bei $40^{\circ}$ einwirkt. Die folgenden sind die bei einem solchen Versuche erzielten Ergebnisse; sie finden sich in Figur 3, Tafel 1 graphisch dargestellt :

5 Grm. Stärko per $100 \mathrm{CC}$.

10 CC. Malrextract (rorher 20 Minuten lang auf $50^{\circ}$ exhitzt) per

\begin{tabular}{|c|c|c|c|c|}
\hline \multicolumn{2}{|c|}{ Zeitdaner } & {$[a]_{3,98}$} & $x_{y, 86}$ & Jodreaction \\
\hline $2^{2} / 9$ & Minnten & $168,1^{\circ}$ & - & tief braun \\
\hline $\boldsymbol{5}$ & त & $168,5^{\circ}$ & - & bratin \\
\hline 15 & 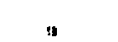 & $166,5^{\circ}$ & - & brann \\
\hline 30 & $"$ & $183,7^{\circ}$ & - & keine Reaction \\
\hline 60 & $"$ & $162,8^{\circ}$ & 49,6 & $n$ \\
\hline
\end{tabular}
$100 \mathrm{CC}$.

Verwandlangstemperatur $60^{\circ}$.

Die Zusammensetzung der Flessigkeit nach Verlauf ron 60 Minufen wax in Proconten : 
224 Brown u. Heron, Beilräge zur Geschichte der

$$
\begin{aligned}
& \text { Msitose }=81,3 \\
& \text { Dextrin }=18,7 \\
& \hline 100,0,
\end{aligned}
$$

woflir $[a]_{3,88}=162,3^{\circ}$ und $x_{3,86}=49,6$ orforderlich.

Es wurde die Lōsung mit einer weiteren Quantitã̆ Malzextract digerirt. Nun trat Anfangs wenig oder gar keine Aenderung ein, nach Ablauf von 16 Stunden jedoch wurden die folgenden Werthe für die berichtigten Stärkeproducte erzielt :

$$
\{a\}_{3,86}=147,7^{\circ} \quad x_{9,86}=60,8 .
$$

Diese Zahlen entsprechen den Eigenschaften der Maltose vollkommen. Bs hat also das gesammte Dextrin eine Wasserbindung erfahren, aber ohne dals Dextrose erzeugt worden wäre.

Wirloung des Malzextracts bei $60^{\circ} \mathrm{C}$. - Wenn Malzextract auf 60 bis $62^{\circ}$ erhitzt wird, so findet man, dafs die Wirkung desselben im Vergleich zu einem gleichen Quantum desselben Extracts, welcher nur auf $50^{\circ}$ erhitzt worden war, etwas abgeschwächt ist.

Bei $60^{\circ}$ soltte der allgemeinen Annahme zufolge die Verwandlung der Stärke nach 0'Sulliv a n's Gleichung A vor sich gehen, d. $h$. es sollton sich Sistirungsanzeichen der Reaction einstellen, wenn der Werth von [a] für die gemischten Verwandlungsproducte auf $170^{\circ}$ heruntergegangen ist und das Kupferoxydreducirungsvermõgen den Werth 44,1 erreicht hal. Es ist diefs jedoch nicht der Fall, wie sich aus Figur 4, Tafel I ergiebt, woselbst $z$ wei Verwandlungen bel $60^{\circ}$ mit auf die gleiche Temperatur erwărmtem Malzexiract graphisch dargestellt sind. Man findet; dafs, wenn $10 \mathrm{CC}$. Malzextract und darüber für eine normale Verwandlung von $5 \mathrm{Grm}$. Stärke auf 100 CC. verwendet werden, der Portgang der Reaction keine Unterbrechung erleidet, bis schliefslich der Winkel von 162 bis $163^{\circ}$ erreicht wird, was annähernd innerhalb eines in 
umgekehrten Verhăltnisse zu dem verwendeten Quantum Malzextract stehenden Zeitraumes statthat. Zwar ist es bei Verwendung von relativ geringen Quantitáten Malzexiract möglich, durch Sistirung der Reaction etwa $\mathrm{z}$ wischen der fünften und zwanzigsten Minute irgend einen Deliebigen Winkel von etwa $178^{\circ}$ bis $164^{\circ}$ zu erlangen, mit entsprechendem Kupferoxydreducirungsvermügen; allein wir besitzen keine Norm für Beurtheilung des richtigen Augenblicks, in dem die Reaction einzustellen ist, noch auch begegnet man innerhalb der beiden genannten Punkte einem åufsern Anzeichen, vielleicht einer Verlangsamung der Reaction, aus dem sich auf den $\mathbf{A b s c h l u f s}$ einer bestimmten molecularen Verwandlung schliefsen liefse.

Die normale Verwandlung des Stärkekleisters bei $60^{\circ}$ ist ähnlich der in der Kälte und bei allen niedrigeren Temperaturen stattfindenden und nähert sich schon der durch die Gleichung :

$$
10 \mathrm{C}_{42} \mathrm{H}_{80} \mathrm{O}_{10}+8 \mathrm{H}_{2} \mathrm{O}=8 \mathrm{C}_{22} \mathrm{H}_{82} \mathrm{O}_{11}+4 \mathrm{C}_{6} \mathrm{H}_{10} \mathrm{O}_{6}
$$

ausgedrūckten Reaction.

Es folgen hier einige von den durch Behandlung der Stărke unter den obigen Verhältnissen erzielten Ergebnissen :

5 Grm. Sttrice in $100 \mathrm{CC}$.

Malzextract vorher 20 Minuten lang auf $60^{\circ}$ erwirmt.

Verwandhragatemperatar $60^{\circ}$.

\begin{tabular}{|c|c|c|c|c|}
\hline $\begin{array}{l}\text { Anzahl der } \\
\text { per } 100 \mathrm{CC} \text {. } \\
\text { Terbrauchtan } \\
\text { CC. Mals- } \\
\text { extract }\end{array}$ & \multicolumn{2}{|c|}{$\begin{array}{c}\text { Zeitdsuer } \\
\text { der } \\
\text { Reaction }\end{array}$} & {$[\alpha]_{j} 3,86$} & $x_{3,86}$ \\
\hline 16,6 & \multicolumn{2}{|c|}{5 Minuten } & $162,0^{\circ}$ & 49,2 \\
\hline 20 & 15 & $n$ & $162,4^{\circ}$ & 49,3 \\
\hline 10 & 20 & $\pi$ & $162,8^{\circ}$ & 49,0 \\
\hline 15 & 20 & $n$ & $163,8^{\circ}$ & 49,3 \\
\hline 10 & 60 & $n$ & $162.9^{\circ}$ & 49,6 \\
\hline 15 & 60 & . & $162,6^{\circ}$ & 60,5 \\
\hline 10 & 15 & $n$ & $162,3^{0}$ & 49,8 \\
\hline $\begin{array}{c}10 \\
\text { Mittel }\end{array}$ & 60 & n & $\frac{163,6^{\circ}}{162,8^{\circ}}$ & $\frac{48,9}{48,8 .}$ \\
\hline
\end{tabular}


226 Brown u. Heron, Beitrüge zur Geschachte der

Der mittlere Werth für $[\alpha]$ und $x$ aus den rorstehenden Reispielen, die auf's Gerathewohl einer grofsen Anzahl van Versuchen entnommen sind, kumut dem theoretiscten sehr nahe; letzterer ist nãmlich

$$
[a]_{j 3,86}=162,6^{6} \quad x_{3,86}=49,3 .
$$

Hier anschliefsend geben wir noch in ihren Einzelheiten einige Versuche, welche den Fortgang der Vurwandlung als eine Function der Zeitdauer erkennen lassen. In jedern einzelnen dieser Fălı ist die Wirkang: wie oben beschrieben, mittelst Salicylsäure sistirt worden. Auch diese Ergebnisse finden sich in Figur 4, Tafel I graphisch dargestellt.

Versuch 26 Grm. Starke und 5 CC. Malzextrant (vorher aus $60^{\circ}$ orhitzt) per $100 \mathrm{CC}$. Filtagigkeit.

Vorwandlungstemperatur $60^{\circ}$.

\begin{tabular}{|c|c|c|c|}
\hline \multicolumn{2}{|c|}{ Zejtdauor } & {$[\alpha]_{j, a, a n s}$} & Jouruaction \\
\hline 11 & inutes & - & blax \\
\hline 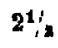 & Misnten & $189,6^{\circ}$ & riolett \\
\hline 5 & n & $178,7^{\circ}$ & tiet braun \\
\hline 16 & » & $166,8^{\circ}$ & sehr hollbraun \\
\hline 30 & 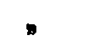 & $164,1^{\circ}$ & keino Resction \\
\hline 60 & $\pi$ & $163,4^{\circ}$ & $\pi$ \\
\hline
\end{tabular}

Boi diesom Punkt wurden 5 CC. per 100 mehr Malzextract hinzagefügt :

90 Minuten $\quad 1822,2^{\circ} \quad$ keins Reaction

Dann weitere $5 \mathrm{CC}$. Malzextract per $10 \mathrm{CC}$. :

120 Minuten

$161,7^{8}$

Noch 4 CC. Maizoxtract por 100 CC. :

185 Minutev $161,2^{\circ}$ $n$

Versuch $U$. In 100 CC. Flüszigkeit kamen sur Verwendung 5 Grw. Stkrke and 10 CC. Malzextract, vorher auf $60^{\circ}$ orwlismt. Vorwandlungstsmperatur $60^{\circ}$.

\begin{tabular}{|c|c|c|c|}
\hline Zeitcaner & {$[\alpha]_{3,3,86}$} & $x_{3,86}$ & Jodreaction \\
\hline 1 Minute & $191,7^{\circ}$ & - & roin blau \\
\hline $2 \% / 2$ Minntan & $175,6^{\circ}$ & $\cdots$ & braun \\
\hline 5 & $166,8^{\circ}$ & - & sehr kellbra's \\
\hline 15 & $185,7^{\circ}$ & - & keine Reaction \\
\hline
\end{tabular}


Stärke und der Verwandlungen derselben.

$\begin{array}{lccc}\text { Zeitdauer } & {[\alpha\}_{3,89}} & x_{3,86} & \begin{array}{c}\text { Jodresotion } \\ 30 \text { Minutes }\end{array} \\ 163,7^{\circ} & - & \text { keine Reaction } \\ 60 \quad & 162,9^{\prime \prime} & 49,6 & *\end{array}$

Fier wurden noch 4,5 CC Malzextract per $100 \mathrm{CC}$. hinzugethan : 90 Minuten $169.3^{\circ} \quad-\quad$ keine Rerction

Weiters 4,2 CC. Malzextract per 100 CC. -

120 Minuten $\quad 160,1^{\text {p }} \quad 52,0$

Bei obigen Versuchen ist die optische Thätigkeit durch Fortdigeriren und Hinzutritt ron weiterem Malzextract nur wenig unter den der theoretischen Verwandlung entsprechenden Punkt herabgedrückt worden, was kigr dafür spricht, dafs die Reaction keineswegs in Folge der Abschwächung der diastatischen Kraft des Malzextracts zu Ende kommt. Andererseits schreibt sich dieses Auf hören auch nicht davon her, dafs etwa dem Verwandlungsagens durch den Ueberschufs von erzeugter Maltose entgegengewirkt wird; denn am Schlusse einer solchen Verwandlung finden wir, dafs die Flüssigkeit sehr wohl ein weiteres Quantum Stärke bis zu den niedrigst möglichen Producten der Einwirkung - Dextrin und Maltose - umzusetzen vermag.

Wirkung des auf $66^{\circ}$ erwärmten Malrextracts. - Wird Malzextract rasch bis auf $66^{\circ}$ erwärmt und alsbald zu Stërkekleister von derselben Temperatur hinzugethan, so weicht die Reaction in den ersten Stadien nur wenig von der bei beiderseitiger Erwärmung auf $60^{\circ}$ orzielten ab. Wird jedoch das vorganngige Errwärmen des Malzextracts auf einige Minuten fortgeset2l, so ändert diefs die Wirkung bedeutend. 10 bis 15 Minuten langes Forterwärmen bei $66^{\circ}$ genügt, um in dieser Beziehung die Maximaländerung herbeizuführen; über diesen Punkt hinaus tritt durch Forterwärmen bei gleicher Temperatur nur geringe Aenderung ein. 
Brown u. Heron, Beiträge zur Geschichte der ...

In Taf. II, Fig. $7^{*}$ ) sind drei verschiedene Verwandlangen von Stärkekleister bei $66^{\circ}$ mit vorher bezichlingsweise 20, 40 uni 60 Minuten lang uuf $66^{\circ}$ erhitztem Malzextract graphisch dargestellt. Es zeigt sich, dafs die Zeit der Erwärmung des Extracts über 20 Minuten hinaus auf die Ergebnisse so gut wie keinen Einflufs ausübt. Bei Stärkeverwandlungen mit auf $66^{\circ}$ erwärmtem Malzextract macht sich im Allgemeinen eine weit langsanere Reaction im Vergleiche zu Verwandlungen bei $60^{\circ}$ bemerkbar; die Abnahme des Winkels zu irgend einer gegebenen Zeit giebt das Mafs der Schnelligkeit der Wirkung ab. Indefs findet die Yerwandlung von Granulose in lösliche Stärke, wie sie sich durch Eintreten von vollkommener Dünnfüssigkeit kund giebt, ganz eben so rasch bei $66^{\circ}$, wie bei $60^{\circ}$ statt, und sogar weit rascher, als bei 40 bis $50^{\circ}$.

Vergleicht man die Jodreactionen aus den Verwandlungen bei $66^{\circ}$ und bei $60^{\circ}$ miteinander, so ist auch bei denjenigen, welche in beiden Fällen gleicher optischer Thätig keit entsprechen, keine Uebereinstimmung zu bemerken.

In Verwandlungen bei $66^{\circ}$ tritt vollstāndiges Verschwinden der Jodreaction ein, wenn das specifische Drehungsvermögen der Stärkeproducte auf 188 bis $189^{\circ}$ gesunken ist; wogegen in Verwandlungen bei $60^{\circ} \mathrm{Jod}$ selır häufig eine auf Erythrodextrin oder sogar auf lösliche Stärke hindeutende Färbung ergiebt, wenn der Winkel bis auf 165 bis $166^{\circ}$ herabgegangen ist. Dieser Mangel an Uebereinstimmung entspririgt unserer Anschauung nach aus einer Verschiedenartig-

*) In den tiber Fig. 7 stehenden Erkulurangen sind die Znichen für dis Linien 12 und 12 mit einander verwechselt. Die punktirte Linie ist Nr. 13 (60 Min. orhitzt), dio aus sonkrecht za einander stehenden Strichen gebildete int Nr. 12 (40 Min. erhitzt). 
keit in der Wirkung der im Malzextract enthaltenen verschiedenen Verwandlungsagentien auf Dextrin. So sind z. B. einige von den im Malzextract enthaltewen Verwandlungsegentien bei dessen Erwãrmung auf nur $60^{\circ}$ in Stande, die höheren A.chroodextrine rascher zo spalten und in einfachere zn zerlegen, als das Erythrodextrin gebildet oder in diese höheren Achroodextrine verwandelt werden kann, und wir können demgemärs unter diesen Umstánden eine sehr niedere ộtische Thātigkeit erlangen und dabei doch etwas Stărke oder Erythrodextrin vorfinden. Wenn andererseits Malzextract auf $66^{\circ}$ erhitzt wird, so nimmt die Thătigkreit des die höheren Achroodextrine zerlegenden Verwandlungsagens bedeutend ab, wăhrend das Agens, welches die Verwandlung von lösticher Stärke in Erythrodextrin und von Erytbrodextrin in die hüheren Arten von Achroodextrin herbeiführt, seine Thätigkeit beibehält oder sogar etwas erhöht. In dem letzteren Falle ist es leicht ersichtlich, dafs das Verschwinden des Erythrodextrins und der löslichen Stärke von einer weit höheren optischen Thãtigkeit hegleitet ist, als in dem früheren Falle.

In Verwandlungen bei $66^{\circ}$, gerade so wie bei den niedereren Temperaturen, findet keine Unterbrechung im Fortgange der Reaction statt, und folglich lärst sich jeder beliebige Winkel dadurch erzielen, dafs man die Verwandlung beim richtigen Punkte sistirt, wobei natürlich die analytischen Ergebnisse je nach der Dauer der Reaction variiren. Zu dem Zeitpunkt, wo das Jod aufhōrt eine Braunfärbung der Lōsuing zu verursachen, beträgt der Winkel immer sehr annähernd 188 bis $189^{\circ}$.

Die Höhe der für das Kupferoxydreducirungsvermôgen and das specifische Drehungsvermögen der Verwandlungsproducte erlangten Werthe ist in allen Stadien der Reaction mit der Annahme des alleinigen Vorhandenseins von Dexirin 
230 Brown u. Heron, Beitröge zur Geschichte der

und Maltose vollionimen im Einklang. Es erhellt diers aus den rachfolgenden Ergebnissen :

\begin{tabular}{|c|c|c|c|c|c|c|}
\hline 1. & $\begin{array}{l}{[\alpha]_{\sharp 3,80}} \\
188,3^{\circ}\end{array}$ & $\begin{array}{r}x_{3,86} \\
25,9\end{array}$ & $\begin{array}{c}\text { Maltose } \\
\text { pC. } \\
\mathbf{4 2 , 4}\end{array}$ & $\begin{array}{c}\text { Dextrin } \\
\text { pC. } \\
57,5\end{array}$ & nach & $\begin{array}{l}\{\alpha]_{j} 3,8 i \\
\text { Berechnuag } \\
185,6^{\circ}\end{array}$ \\
\hline 2. & $193,4^{n}$ & 19,2 & 31,4 & $C 8,6$ & & $195,2^{\circ}$ \\
\hline 3, & $182,2^{0}$ & 33,5 & 55,7 & 44,3 & & $179,3^{\circ}$ \\
\hline 4 & $192,6^{2}$ & 22,6 & 37,0 & 68,0 & & $191,0^{\circ}$ \\
\hline & $190,3^{\circ}$ & 23,4 & 89,3 & 61,7 & & $190,7^{\circ}$ \\
\hline
\end{tabular}

Nachfolgende Versuche veranschaulichen den Fortgang der Reaction hei $66^{\circ}$ mit Malzextract, welches vorher auf die gleiche Temperatur erwärmt worden war. Ditselben sind nelst anderen gleichartigen Versuchen in Taf. I und II, Fig. 5,6 und 7 graphisch dargestellt. Diese Versuche fanden in der üblichen Weise statt; der Reaction wurde an den bezeichneten Punkten init Salicylsäure Einhait gethan.

Versuch $I$.

anf $100 \mathrm{CC}$. Flüssigkeit kamen $6 \mathrm{Grm}$. Stiaks und $8,9 \% \mathrm{CC}$. auf $66^{\circ}$ erhitzien Malzextracts.

\begin{tabular}{|c|c|c|c|}
\hline \multicolumn{4}{|c|}{ Verwandlungstemperatur $=65^{\circ}$. } \\
\hline & auer & {$[\alpha]_{\mathrm{j}} \mathrm{g,46}$} & Jodreaction \\
\hline $2^{1}$ & nuten & $2 \cap 4,0^{\circ}$ & tiof braun, \\
\hline 5 & $"$ & $20:, 2^{0}$ & braan, \\
\hline 10 & * & $195,5^{\circ}$ & hellbraun, \\
\hline 20 & $n$ & $191,8^{\circ}$ & suhr hellbraun, \\
\hline 30 & ๓ & $188,2^{0}$ & kaine Reactio \\
\hline 60 & $n$ & $185,0^{\circ}$ & $x$ \\
\hline
\end{tabular}

Zusalz vun \$,3 CC. Malzextract per 100 CC. :

90 Niusten $\quad 178,0^{0} \quad$ keine Resction.

Zusstz ron weiteren 4,3 CC. Malzextract per $100 \mathrm{CC}$. :

120 Minuten $173,0^{\circ} \quad$ keine Roaction.

Tersuch $I I$.

18,04 CC. Malzextruck (auf $66^{\circ}$ erbitzt) per $100 \mathrm{CC}$ :

\begin{tabular}{|c|c|c|c|}
\hline \multicolumn{2}{|c|}{$\begin{array}{l}\text { Zaitdauer } \\
\text { 21/2 Minuten }\end{array}$} & $\begin{array}{r}{[a]_{\mathrm{j}} 9,85} \\
205,4^{0}\end{array}$ & $\begin{array}{l}\text { Jodreaction } \\
\text { tief braun, }\end{array}$ \\
\hline 5 & 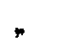 & $199,5^{\circ}$ & hellbreun, \\
\hline & $n$ & $195,2^{\circ}$ & sehr hellbraun, \\
\hline & n & $191,0^{\circ}$ & \\
\hline & " & $187,0^{\circ}$ & keine Reaction, \\
\hline & . & $181,2^{n}$ & $n$ \\
\hline
\end{tabular}


Stärke und der Verwandlungen derselben.

Zusatz ron 6,4 CC. Malzextract per 100 CC. :

90 Minuter $176,9^{\circ}$ keine Reaction.

Zueatz ron weiteren o CC. Malzoxtract per 100 CC. :

120 Minuten $171,8^{\circ}$ ksine Resction.

Versuch $I I I$.

25 CC. Malzextract per 100 CC. :

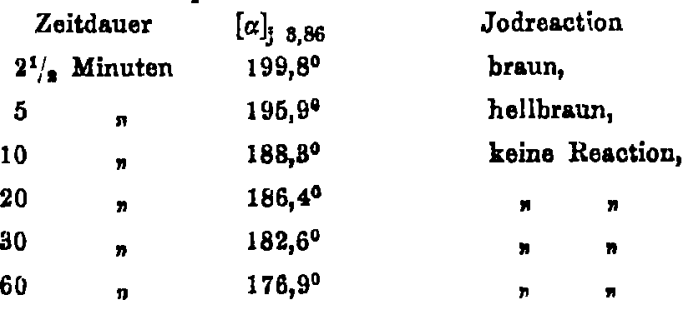

Zuestz won 9,7 CC. Malzextract per 100 CC. :

90 Minuten $170,7^{\circ}$ keine Resction.

Zueatz von weiteren 8,2 CC. Malzeztract per $100 \mathrm{CC}$. :

120 Minuten $\quad 165,5^{\circ} \quad$ kaino Resction.

Zusatz ron weiteren 7,2 CC. Malwextract per $100 \mathrm{CC}$. :

150 Minuten $163,9^{\circ} \quad$ keine Reaction.

Wirkung des Malzextracts bei mehr als $66^{\circ}$ Wärme. Wenn Malzextract über $66^{\circ}$ erwärmt wird, so ändert sich die Wirkung desselben auf die Stärke noch mehr. Diese Aenderung erreicht ihr Maximum bei ungefähr 75 bis $76^{\circ}$. Läfst man 20 bis 30 CC. Malzextract, das vorher auf diese Temperatur erhitzt worden, auf einen 5 bis $6 \mathrm{Grm}$. Stärke per 100 CC. enthaltenden Stärkekleister einwirken, so geht die Abnahme in der optischen Thätigkeit 10 bis 12 Minuten lang mit grofser Regelmäfsigkeit und ziemlicher Schnelligkeit von Statten, am Ende dieses Zeitraums jedoch wird die Reaction überaus langsam oder aber hört gãnzlich auf.

Der niedrigste Drehungswinkel, der hierbei erreicht wird, beträgt selten weniger als $195^{\circ}$, und in der Regel wird die optische Thătigkeit durch Hinzuthun eines weiteren Quantums Malzextract, ähnlich dem zuerst verwendeten, nur unbedeutend geringer, auch wenn die Digestion lange fortdauert. 
232 Brown u. Heron, Beiträge zur Geschichte der

Nachstehendes sind die bei einigen in dieser Weise angestellten Versuchen erzielten Ergebnisse :

Verauch $I$.

Auf 100 CC. 5 Grm. Sthrke.

30 CC. Malgextract anf $76^{\circ}$ erw\&rmt.

Verwandlung bei $75^{\circ}$.

\begin{tabular}{|c|c|c|c|c|}
\hline \multicolumn{2}{|c|}{$\begin{array}{c}\text { Zeitdener } \\
21 / 8 \text { Minuten }\end{array}$} & $\begin{array}{l}{[\alpha]_{\}} 3,86} \\
205,0^{\circ}\end{array}$ & $\boldsymbol{x}_{3,86}$ & $\begin{array}{l}\text { Jodroaction } \\
\text { viol Erytbrodextrin, }\end{array}$ \\
\hline 5 & $n$ & $200,8^{\circ}$ & - & $n$ \\
\hline 10 & * & $196,5^{0}$ & - & geringe Fürbung, \\
\hline 20 & $n$ & $195,5^{\circ}$ & - & keine Reaction, \\
\hline 30 & - & $195,5^{\circ}$ & - & $n$ \\
\hline 45 & $n$ & $194,6^{0}$ & - & $n$ \\
\hline 60 & & $184,6^{\circ}$ & 23,0 & $n$ \\
\hline
\end{tabular}

Zasatz ron 15 CC. des gleichen Malzeztraots per 100 CC. :

70 Minuten

$194,4^{0}$

keine Reaclion,

90 n

$194,0^{\circ}$

Versuch $I I$.

Per 100 CC. 5 Grm. Sturke.

25 CC. Malrextract auf $76^{\circ}$ erhitzt.

Verwandlung bei $75^{\circ}$.

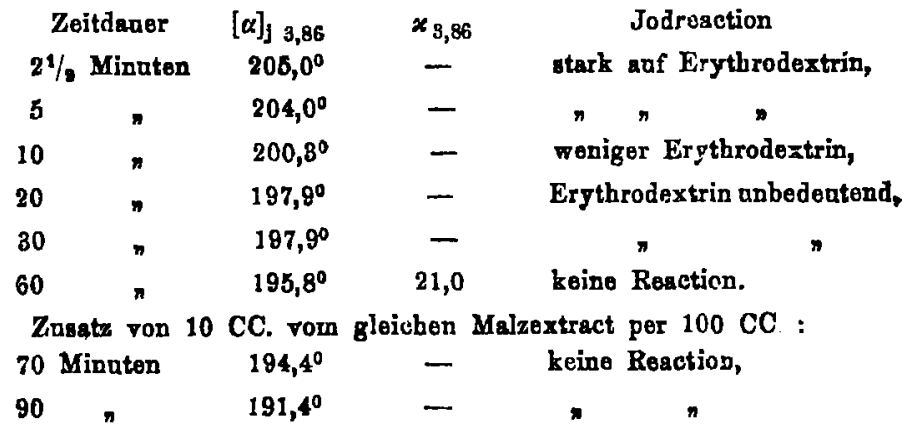

Diese Versuche sind nebst einigen anderen in Taf. II, Fig. 8 nnd 9 graphisch dargestellt. War das Malzextract nicht genügend erwãrmt, so trat zuweilen, wenn weitere Quantităten hinzugethon wurden, eine plötzliche Abnahme des Winkels ein, wie diefs aus Fig. 9, Nr. 18 ersichtlich ist. 
Unter den obigen Verhältnissen wird der Stärkekleister sehr bajd dünnflüssig, und die das Vorhandensein von Stärke verrathende blaue oder violette Jodreaction verschwindet durchgehends nach Verlauf von nicht ganz zwei Minuten, vom Anfange des Versuchs an gerechnet; in der That treten diese Veränderungen eben so rasch, wenn nicht sogar etwas rascher ein, als bei niedereren Temperaturen. Die Jodreaction auf Erythrodextrin ist indefs sehr anhaltend. Die volle braune Furbe, welche anzeigt, dafs die Bildung dieses Körpers in quantitativer Beziehung ihren höchst möglichen Grad erreicht hat, wird erzielt, wenn die optische Thätigkeit der Lōsung auf 202 bis $203^{\circ}$ gesunken ist, wogegen die Reaction erst bei $194^{\circ}$ oder etwas darunter verschwindet.

Nach O'Sullivan liefert die Stärke bei Temperaturen von $68^{\circ}$ bis $4 c_{-}$dem Grade, bei dem das Verwandlungsagens zerstört wird, untor dem Einflusse von Malzextract ein Dextrin, das von Jod nicht gefärbt wird und das für die Gesammtverwandlungsproducte einem Drehungswinkel von 202,8 entspricht. Wir haben wieder und wieder versucht, uns von dem Vorhandensein eines solchen Dextrins durch den Augenschein zu überzeugen, und haben dabei jeden mōglichen Versuchsweg betreten, doch ohne allen Erfolg. Wenn ein Winkel von 202 bis $203^{0}$ erzielt wird, so ergiebt die Lōsung stets die stärkstmögliche bräunlichrothe Jodreaction und die höchste Färbung findet zwischen diesen beiden Graden stati. Daraus lōnnen wir nur schliefsen, dafs das Dextrin in $\mathbf{O}^{\prime} \mathrm{S}$ ullivan's Formel (C) ein Erythro- und kein Achroodextrin ist. Daher ist das Erythrodextrin oder $\alpha$-Dextrin nach der Bezeichnung von Bo ildor:neau und von O'Sullivan eines der gewöhnlichen, durch Abbau der löslichen Stärke sich ergebenden Dexirine und nicht blofs eine isomere Modification jenes Kôrpers, wis allgemein angenommen worden. In dieser Ansicht werden wir durch die foigenden Betrachtungen bestärkt. Is leuchtet 
234 Brown u. Heron, Beiträge zur Geschichte der

ein, dafs, wenn Brythrodextrin nur eine isomere Modification der lőslichen Stårke wãre, es sich aus löslicher Stärke ohne gleichzeitige Erzeugung von Maltose mürste gewinnen lassen. Thatsächlich ist jedoch bei allen Reactionen, die wir untersucht, das Abweichen der Jodreaction von dem reinen Blau der Stärke, wodurch das Erscheinen einer Spur van Erythrodextrin bekundet wird, jederzcit von dem Auftreten eines Kupferoxydreducirungsvermőgens in der Flüssigkeił begleitet, auf welche zuvor Fohling'sche Lösung keinerlei Wirkung hervorbrachte.

Während des ganzen Verlaufs der Stärkeverwandlungen bei $76^{\circ}$ finden sich keine Anzeichen von der Erzeugung irgend eines anderen Körpers als Dextrin und Maltose, und der nach dem Kupferoxydreducirungsvermögen berechnete Winkel stimmt jederzeit annähernd mit dem aus der Beobachtung sich ergebenden specifischen Drehungsvermögen überein. Diese Uebereinstimmung ist jedoch nicht ganz so vollstāndig, wie bei den niedereren Temperaturen, und diefs sind wir geneigt dem Umstande zuzuschreiben, dafs die höheren Dextrine durch die Wirkung der Fehling'schen Lösung zum Theil in niedrigere Modificationen übergeführt werden und demgemärs etwas zu viel Maltose erzeugt wird.

Es folgen hier einige Beispieie von zu verschiedenen Zeitpunkten sistirten Verwandlungen bei $76^{0}$ :

\begin{tabular}{|c|c|c|c|}
\hline & {$[\alpha]_{j, 3,86}$} & $x_{3,86}$ & $\begin{array}{c}{[\alpha]_{j} 3,86} \\
\text { nach } \boldsymbol{x} \text { berechnet }\end{array}$ \\
\hline 1. & $204,1^{\circ}$ & 0,4 & $205,8^{\circ}$ \\
\hline 2. & $198,7^{\circ}$ & 17,9 & $196,6^{\circ}$ \\
\hline 8. & $195,9^{\circ}$ & 20,5 & $193,8^{3}$ \\
\hline 4. & $194,1^{\circ}$ & 22,8 & $191,8^{\circ}$ \\
\hline 5. & $194,6^{\circ}$ & 29,0 & $191,1^{\circ}$ \\
\hline 6. & $19 B, 4^{\circ}$ & 18,7 & $195,8^{\circ}$ \\
\hline 7. & $192,1^{0}$ & 28,8 & $190,2^{\circ}$ \\
\hline
\end{tabular}




\section{Jodrsactionen.}

Es dürfte hier der geeignete Ort sein, auf die in Jer Jodreaction bei der Verwandlung der Stärke mit Malzextract beobachteten Veränderungen etwas näher einzugehen. Diese Veränderungen lassen sich am besten in Reactionen, welche bei $66^{\circ}$ eingeleitet werden, beobachten.

Im Augenhlicke der vollkommenen Dünnfüssigkeit liefert Jod eine dunkel-indigoblaue Reaction, welche bein Fortgange der Verwandlung allmälig violett und dann dunkel-röthlichbraun wird. Diese letztere Reaction ist zuerst sehr stark, dann aher verschwienmt sie nach und nach, bis schilefslich das Jod gar keine Färbung mebr erzeugt.

Wir haben uns davon aberzeugt, defs dieser Farbenwechsel von Blau bis Bräunlichroth von der Mischung der beiden Körper, lösliche Stärke und Erythrodextrin, herrührt. Wenn diese Stoffe isolirt und deren Lösungen in verschiedenen Verhältnissen gemischt werden, so können beim Versetzen mit Jod alle bei einer Stärkeverwandlung beobachteten Farbenunterschiede erzielt werden.

Iie Jodverbindungen dieser beiden Körper ergeben im Spectroskop keine Absorptionsstreifen, sondern schneiden gegenüber liegende Enden des Spectrums ab.

Erkennung von löslicher Sturke oder von Aahroodextrin neben Eirythrodextrin. - Vermöge der gröfseren Verwandtschaft der lōslichen Stärke zu Jod lä́lst sich eià Spur dieses Körpers neben einem Ueberschusse von Erythrodextrin dadurch ontdecken, dafs man ein sehr geringes Quantum Jod binzuthut. Die violette oder blaue Reaction erscheint unter solchen Úmstănden vor der braunen des Erythrodextrins. Andererseits ist die Verwandtschaft des Erythrodextrins zu Jod aich geringer, als die des Achroodextrins. Fǚgi man mümlich soenig Jod zu einem Gemenge von Acircio- und Eryjurodextrin, so 
236 Brown u. Heron, Beiträgo zur Geschichte der

verschwindet die im ersten Augenblicke uuftretende rothbraune Forbe fast sofort wieder, zufolge der Bildung der farblosen Jodverbindung des Achroodextrins. Erst ein Ueberschurs von Jod bewirkt dauernde Färbung.

\section{Einfuls der Neutralisirung auf die Wirkung des Malz- extracts.}

a) Baryumhydrat. - Wird Malzextract nach einige Minuten langem Erhitzen auf $66^{\circ}$ mittelst Baryumbydrat neutralisirt und von dem sich ergebenden Niederschlage abfiltrirt, so findet sich, dafs seine Wirkung auf Stärkekleister etwas abgeschwächt ist, wenn auch im Allgemeinen die Form der Verwandlungscurve nicht wesentlich von derjenigen abweicht, welche bei nichtneutralisirtem Malzextracte erhalten wird. Es erhellt diefs aus einem Vergleiche der Curve Nr. 19 auf Taf. Il, Fig. 10 mit der in Taf. I, Fig. 6 für einen Fall aufgezeichneten, in welchem ungefähr ein gleiches Quantum nichtneutralisirten Extracts zur Verwendung kam.

b) Natriumcarbonat. - Wenn man statt mit Baryumhydrat das Malzextrat nách dem Erhilzen auf $66^{\circ}$ mittelst kohlensaurein Natrium schwach alkalisch macht und dan! wochmals einen Augenblick auf $66^{\circ}$ erhitzt, so ist das Verwandlungsagens immer noch fähig, das specifische Drehungsvtrmögen der Stärkeproducte rasch, jedoch nicht weiter, als his auf 194 bis $196^{\circ}$ herabzubringen, und zwar auch dann nicht, wenn man wiederholt frische Quantitāten von demselhen Malxexiract hinzufügs. Das auf diese Weise behandelte Malzextract verhält sich der Stärke gegenüber thatsächlich genau sol, wje das auf 75 bis $76^{0}$ erwärmte Malzextract.

Nachstehende Versuche erläutern das eben gekennzeichnete Verhalten. Die Ergebnissis sind in Taf. II, Fig. 10 graphiseh dargestellt. 
Stärke und der Verwandlungen derselben.

Tersuch $r$.

Par 100 CC. 5 Grm. Sthrke, 16 CC. Malzextract enf $66^{\circ}$ erwlirmt und mit $\mathrm{Na}_{3} \mathrm{CO}_{3}$ neutralisirt.

Temperatur whrend der Resction 65\%.

\begin{tabular}{cccc}
\multicolumn{2}{c}{ Zeitdauer } & {$[\alpha]_{\mathrm{J}} 8,86$} & Jodreaction \\
$21 / 2$ & Minuten & $214,0^{\circ}$ & blau \\
6 & $n$ & $201,0^{\circ}$ & braun \\
10 & $n$ & $200,0^{\circ}$ & \multicolumn{2}{c}{ n } \\
20 & $n$ & $198,9^{\circ}$ & keine Resction \\
30 & $n$ & $193,9^{\circ}$ & $n$ \\
60 & $*$ & $198,9^{\circ}$ & $n$
\end{tabular}

Zusatz ron 8,4 CC, rom gleichon Malzextract per 100 CC. :

90 Minuten $194,0^{\circ}$ koine Resction.

Zusatz ron weiteren 8 CC. des gleichen Msuextracts per 100 CC.: 120 Minuten $194,0^{\circ}$ keine Raction.

Versuch IL

Per 100 CC, 5 Grm. Starkt, 19,8 CC. Malzextract, wie zuror, mit $\mathrm{Na}_{\mathrm{a}} \mathrm{CO}_{\mathrm{a}}$ behandelt.

Resctionstemperatur $\approx 65,0^{\circ}$.

\begin{tabular}{|c|c|c|c|}
\hline \multicolumn{2}{|c|}{ Zoitdauer } & $[\alpha]] 8,88$ & Jodreaction \\
\hline $21 / 2$ & Minuten & $205,3^{0}$ & röllig brans \\
\hline 5 & $n$ & $201,0^{0}$ & $n$ \\
\hline 10 & $n$ & $197,8^{\circ}$ & hellbraun \\
\hline 20 & $n$ & $196,0^{\circ}$ & $n$ \\
\hline 80 & $\nabla$ & $195,6^{\circ}$ & koine Reaction \\
\hline 60 & n & $194,7^{\circ}$ & 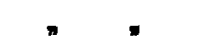 \\
\hline
\end{tabular}

Zusate von 10 CC. vom gleichen Malzextract per 100 CC.:

90 Minuten $1942^{\circ}$ keine Resction.

Zusate ron 8,7 CC. rom gleishen Malrextract per 100 CC. :

120 Minuten $192,3^{\circ} \quad$ keino Reaction.

Natriumhydrat. - Wird Maizextract auf $66^{\circ}$ erhitzt und mit Natriumhydrat ganz schwacn alkalisch gemacht, so geht der schliefsliche Drehungswinkel der Stärkeproducte nicht unter $202^{\circ}$ herunter; es ist diefs derjenige Winkel, welcher dem Maximum der Jodreaction auf Erythrodextrin bei allen Verwandlungen mit bis auf 66 bis $76^{\circ}$ erhitztem Malzextract 
238 Brown u. Heran, Beiträge zur Geschichte der

entspricht. Spatteres wiederholtes Hinzufügen vom gieichen Malzextract drückt die Grörse des Winkels nicht weiter herab, wie aus dem nachiolgenden, in Fig. 11, Tafel Il graphisch dargestellten Versuche hervorgeht.

Por 100 CC. 5 Grm. Btarke, 25 CC. Malzextract anf $66^{\circ}$ erwärmt und mit NaHO gans schroach alkslisch gemacht.

\begin{tabular}{|c|c|c|c|c|c|}
\hline & dauer & $\{\alpha\}], 8,8$ & Jnd & reastion & \\
\hline $2^{2}$ & Minuten & $207,8^{\circ}$ & violett, & viei si & thene \\
\hline 5 & $n$ & $204,8^{\circ}$ & tierbreun, & pधuig & Stärke \\
\hline 10 & " & $204,0^{\circ}$ & tiefbrann, & keine & Stärko \\
\hline 20 & $n$ & $202,0^{\circ}$ & " & 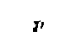 & . \\
\hline 80 & n & $202,0^{\circ}$ & $"$ & $;$ & $"$ \\
\hline 60 & " & $202,0^{c}$ & " & $"$ & " \\
\hline
\end{tabular}

Zusatz von 9,3 CC. rom gleichen Malzectract per 100 CC. :

90 Minuter $203,0^{\circ}$ tiefbrau:i, keine Sthrike.

Zusatz von 8,2 CC. rom gleicben Mrizextract per $100 \mathrm{CC}$. : 120 Minuten 203,0 $0^{\circ}$ tigfbraur, keino Starke.

Wird Malzextract mit Soda etwas stärker alkalisch gemacht, so erlischt die diastatische Kraft desselben vollstündig. Bei allen Versuchen mit neutralisirtem Malzextract auf Stärke war die fortschrcitende Wirkung von einem merkbarca Niederschlage von Albuminoïden begleitet.

Die moleculen Verwandlungen der Stärke.

Die oben beschriebenen Versuche erweisen unserer Ansicht nach die Möglichkeit von mindestens vier bestimmten Verwandlungen, welche die Stärke einzugehen vermag. Die weitaus bestimmteste, gewöhnlichste und stabilste von diesen ist die schliefsliche Reaction, die überaus leicht zu erzielen ist mittelst nicht ũber $60^{\circ}$ hinaus erwärmtem Malzextract, und welche $162,6^{\circ} \mathrm{znm}$ specifischen Drehungsvermbgen ihrer Producte und 49,3 zum Kupferoxydreducirungsvermoggen hat.

Den nächstfolgenden ausgezeichneten Punkt bildet das Verschwinden der Jodreaction anf Erythrodextrin, wenn die Stärke 
mit auf $66^{\circ}$ erwärmtem Malzextract behandelt wird. Diese Verwandlung findet bei $[a]_{3,86}=188,5^{\circ}$ and $x=25,0$ (ungefähr) statt und ändert sich bei verschiedenen Quantitäten Malzextract nur überaus wenig.

Die nächste scharf markirte Reaction wird erzielt mit auf $75^{\circ}$ erhitztem Halzextract, sowie auch mit auf $66^{\circ}$ erhitztem und mit kohiensaurem Natron alkalisch gemachten Malzextract; dabei sind die erlangten Werthe $[\alpha]_{\mathrm{j}, 86}=195$ bis $196^{3}$ und $x_{8,86}=18,9$.

Die höchste durch unsere Versuche festgestellte, scharf markirte Verwandlang wird erzielt durch die Wirkung des auf $66^{\circ}$ erwärmten und mittelst Soda sehr schwach alkalisch gemachten Malzxtracis, wobei die gleiche Reaction bei allen Verwandlungen über $66^{\circ}$ sich durch das Erscheinen der höchsten Färbung durch Jod auf Erythrodextrin kenntlich macht. Die Werthe for die Verwandlung, d. h. $[\alpha]_{j, 8,86}=202$ bis $203^{\circ}$ und $x=12,7$, kommen denen von $0^{\prime}$ 'Sullivan's Formel beinahe gleich, doch ist das Dextrin ein Erythrodextrin.

Umwandlung der höheren Spaltungsproducte in niederere. - Werden die Producte einer Stārkeverwandlung mit optischer Thätigkeit von $u$ uber $162,5^{\circ}$ mit etwas unerhitztem Malzextract bei 50 bis $60^{\circ}$ behandelt, so sinkt das sperifische Drehungsvermögen des in Lösung befindlichen Körpers selur rasch bis auf $162,5^{\circ}$ herunter, und gleichzeitig steigt das Kupferoxydreducirungsvermögen bis auf ungefähr 49,3. Auf dieser Stufe angelangt, verbleiben gedachte Factoren eine Zeit lang constint. Unter gūnstigen Umständen tritt jener Werìsel plötzlich ein and nicht durch eine allmälige und langseme Wasseraddition, wie sich aus den nachfolgenden Versuchen ersenen läfst.

Die Verwandlung der Stärke mit vorgüngig bis auf $65^{\circ}$ erhitztem Malzextracte fand auf dem gewöhnlichen Wege stalt; 
die Reaction wurde ungefähr 10 Minuten nach Beginn durch Kochen sistirt. Die Stärkeproducte ergaben in der Analyse nach der Correction folgende Werthe :

$$
[\alpha]_{3,80}=187,8^{\circ} \text { and } \times 8,80=28,9 \text {, }
$$

was dem folgeriden Procentsatze der Bestandtheile entspricht :

$\begin{array}{lr}\text { Maltose } & 47,3 \\ \text { Dextrin } \quad \begin{array}{r}52,7 \\ \hline 100,0 .\end{array}\end{array}$

Zu 100 CC. dieser Lösung, mit einem Gehalte von 5 Grm. fester Bestandtheile, wurden 5 CC. unerhitzten Malzextracts bei einer Temperatur von $60^{\circ}$ hinzugethan. Nach Ablauf von zwei Minuten fanden sich die Coëfficienten für die Stärkeproducte wie folgt :

$$
[\alpha]_{j, 86}=162,6^{\circ} \text { und } x=49,3 \text {, }
$$

was einem Procentgehalt von

$$
\begin{array}{rr}
\text { Maltose } & 80,8 \\
\text { Dextrin } & 19,2 \\
\hline 100,0
\end{array}
$$

entspricht. Dieses Verhältnifs wurde durch fernere 15 Minuten lange Digestion nicht weiter alterirt.

Bei einem anderen ähnlichen Versuche, bei dem die Werthe für die gekochte Lõsung

$$
\text { [a] } 8,86=184,2^{\circ} \text { und } x 3,86=81,8
$$

betrogen, wurden dieselben durch 2 Minuten langes Einwirken von 5 CC. unerwärmten Malzextracts bei $50^{\circ}$ auf

$$
[\alpha]_{j} 3,86=164,4^{\circ} \text { und } x 3,86=48,9
$$

gebracht, worauf dieselben einige Zeit lang constant blieben.

Nehmen wir an, dafs die Achroodextrine aus den höheren und niederen Verwandlungen identisch sind, so scheint kein ausreichender Grund dazu vorhanden zu sein, warum die Wasserbindungen derselben bis zu einem gewissen Grade so rascly stattiuder und dann plōtzìch stillı stehen sollten. Diese Erscheinung kann nicht etwa eine durch das Vorhandensein eines grorsen Ueberschusses von Maltose herbeigtführte $\mathbf{A b}-$ 
schwächung der diastatischen Kraft des Verwandlungsagens zum Grunde haben, da eine solche Flüssigkeit fähig ist, ein weiteres Quantum Stärke bis zu der gleichen Hōhe zu reduciren.

Die natürlichste Ërklärung hierfür besteht nun darin, dafs die Dextrine keine metameren, sondern polymere Kōrper sind, indem diejenigen, welche Verwandlungen von höherer optischer Thätigkeit entsprechen, ein grörseres Molecul besitzen, als die aus Verwandlungen mit niedererer optischer Thătigkeit sich ergebenden, und dafs die letzteren aus den ersteren durch eine theilweise Wasserbindung mit darauf folgender Eliminirung von Maltose erzeugt werden.

Durch Abscheiden und Prüfen der Dextrine sind wir in dieser Ansicht bestätigt worden.

Seildem wir zu obigen Schlüssen gelangt, haben M u s c ul us und Graber*) eine gleiche Theorie vorgebracht zur Erklärung gewisser Thatsachen, die dieselben in Verbindung mit der Wirkung von gefällter Diastase auf die Stärke beobachtet hatten. Sie betrachten die Stärke als ein Polysaccharid mit der Formel $n\left(\mathrm{C}_{19} \mathrm{H}_{20} \mathrm{O}_{10}\right)$, das unter dem Einflusse von Diastase und Säuren Wasser aufnimmt und darauf Zersetzung orleidet **).

Diese Anschauung über die Constitution der Stārke oder richtiger gesagt der lōslichen Stārke ist unserer Ansicht

*) Bull. soc. chim. 80, 69.

-) Dr. Armstrong, der eben mit der Bearbeitung einer neuen Ansgabe ron Miller's organisober Chemie beschäftigt ist, bat uns einen vor dem Erscheinen der Musculas' und Graber'schen $\Delta$ rbeit gefortigten Druckhogen zur Eineioht thergeben, worin ausgeftihrt ist, dafs aus den Untersuchungen ron O'Sullivan notiwendigerwaiso auf ein seltr bohes Molecala'gewicht der Sthrtat za schliefsen sei, so zwar, dafo das Stłrkemolecul, jo nachdem das Dextrin der Formel $\mathrm{C}_{28} \mathrm{H}_{80} \mathrm{O}_{10}$ odor $\mathrm{C}_{24} \mathrm{H}_{40} \mathrm{O}_{20}$ ontspreche, 72 berw. 144 Atome Koblenstoff enthsilten milsse. 
nach vollkommen correct und stimmt mit uuseren Versucher durchaus überein.

Bei aufmerksamem Betrachten unserer Ergebnisse findet man, dafs die einfachste Formel, die sich für lösliche Stärke annehmen läßst,

$$
10\left(\mathrm{C}_{12} \mathrm{H}_{20} \mathrm{O}_{10}\right)
$$

ist.

Die erste Wirkung der Verwandlungsagens in Malzextract auf dieses complicirte und wandelbare Molecul äufsert sich in der durch Wasseraddition bedingten Abtrennung einer von diesen 10 Gruppen und Umwandlung derselben in Maltose, während die übrig bleibenden 9 Gruppen sich zu dem ersten Dextrin der Reihe, dem Erythrodextrin $\alpha$, constituiren.

Dieses Dextrin wird durch weitere Wasseraddition wieder in ein Molecul Maltose und in das Erythrodextrin $\beta$, welches aus 8 Gruppen $\mathrm{C}_{22} \mathrm{H}_{20} \mathrm{O}_{10}$ besteht, gespalten, und dieses geht seinerseits wieder in ein Molecul Maltosp und ein Dextrin, welches nunmehr aus sieben solcher Gruppen besteht und das erste Achroodextrin genannt wird, über.

In dieser Weise geht, können wir sagen, die weitere Differenzirung oder der Abbau des ursprünglichen Moleculs voran, bis durch immer wieder erneute Wasserbindung schliefslich die vollständige Umwandlung in Maltose erreicht worden ist.

Die Anzahl der einzelnen Dextrine, welche nach dieser Hypothese mōglich sind, hängt von dem Molecularge wicht des niedrigst möglichen Dextrins ab. Unter der Voraussetzung, dafs ein Dextrin existenzfăbig ist, welches in seinem Molecul ebensoviel Kohlenstoffatome wie die Maltose enthält, würde man neun verschiedene Stufen bis zur vollständigen Umwandlung in Maltose zu gewärtigen haben, jedoch nur acht, im Falle das niedrigste Dextrin doppelt so viele Kohlenstoffatome als die Maltose enthaiten sollte. 
In der folgenden Tabelle sind mit Zugrundelegung der yorstebenden Hypothese die Werthe von $[\alpha]_{j} s, 86$ und $x_{9,86}$ für die den verschiedenen theoretischen Verwandlungsstufen entsprechenden Producte aufgezeichnet.

\begin{tabular}{|c|c|c|c|}
\hline Nr. der Verwardlungen & $\{\alpha\}_{j}, 3,9 \pi$ & $x_{3,88}$ & Resultirende Dextri \\
\hline Lösliche Stžrke & $218: 0^{\circ}$ & 0 & - \\
\hline 1 & $209,0^{\circ}$ & 6,4 & Erythrodextrin \\
\hline 2 & $202,2^{2}$ & 12,7 & $n$ \\
\hline 8 & $196,4^{\circ}$ & 18,9 & Achroodextrin \\
\hline 4 & $188,7^{0}$ & 25.2 & $n$ \\
\hline 5 & $182,1^{\circ}$ & 51,3 & » \\
\hline 6 & $175,6^{\circ}$ & 37,3 & $n$ \\
\hline 7 & $169,0^{0}$ & 43,3 & n \\
\hline 8 & $162,6^{\circ}$ & 49.8 & $n$ \\
\hline 9 & $1: t, 3^{c}$ & 56,1 & $n$ \\
\hline Meltose & $150,0^{\circ}$ & 61,0 & - \\
\hline
\end{tabular}

Unter diesen möglichen Verwandlungen haben unsere Versuche ganz unverkennbar die Existenz von Nr. 2, 3, 4 und 8 festgestellt, während Anzeichen von 5 und 6 sich häufig in verschiedenerlei Weise bemerklich gemacht haben, jedoch nicht mit derselben Sicherheit, wie in den anderen Fällen.

Die $\mathrm{Nr} .1$ and 2 entsprechenden Dextrinarten sind Erythrodextrine, wogegen die übrigen Achroodextrine sind.

Das beständigste Dextrin ist jenes der Umwandlung 8. Zwischen dieser Stufe und der vollständigen Verwandlung in Maltose haben wir kein Anzeichen einer Abschwächung der Reaction wahrnehmen kõnnen. Dit Verwandhung 9 kann allerdings dadurch erzielt werden, dafs man 8 auf einige Zeit mit unerwärıntem Malzextract fortdigerirt, allein die Abnahme des Winkels ist stetig und regelmärsig bis zum Erscheinen der Maltose.

Durch die ganze Reihe der mit Malzextract unter den verschiedenartigsten Umständen bewerkstelligten Stärkeverwandlungen sind die erzielten Ergebnisse stets mit der 
Hypothese vereinbar gewesen, dafs die Wasseranziehung und Spaltung *) des löslichen Stärkemoleculs von der Erzengung

1) eines kryutallisirbaren Körpers, der Maltose, mit specifischem Drehungavermögen $[\alpha]]=160^{\circ}$ und einem Kupieroxydreducirungsvermbgen $=61$, und

2) einer Beihe nicht krygtallsisirbarar Körper, Dextrine genannt, welche alimmtlich ein und dasselbe specifuohe Drehungsvermögen $[\alpha] ;=216$, aber kein Reductionsvermögen haben,

begleitet ist.

M uscul us hat angegeben, dars die verschiedenen Dextrinarten sich dem polarisirten Lichte gegenüber verschiedenartig verhalten und sämmtlich in verschiedenem Grado fähig sind, Kupferoxyd zu redueiren. Wird diese Angabe als richtig angenommen, so leuchtet es ein, dafs die Werthe von $[\alpha]_{3}$ und $x$ für die Dextrine auf den sãmmtlichen Stufen der Reihe in umgekehrtem Verbältnisse wochseln müssen, und zwar derart, dafs diese Körper als Mischungen oder Verbindungen von Maltose mit einem Dextrin von $[\alpha]_{j}=216^{\circ}$ und ohne Reductionsvermögen zu betrachten sind.

Diese Anschauung haben wir in gegenwärtiger Abhandlung durchgãngig vertreten.

Augenblicklich befassen wir uns mit der lsolirung und Untersuchung der verschiedenen Dextrinarten; diese Arbeit verspricht überaus interessurte Ergebnisse zu liefern und wir hoffen in nicht allzulanger Zeit in Stande zu sein, die Resultate unserer diefsbezüglichen Versuche veröffentlichen zu kònnen.

-) Dr. Armitrong hat fur diesen chemisoben Vorgang, d. h. fur eine Hydratbildung mit gleicheitiger oder daranffolgender Spaltung des Moleculs, die Bezeichnung "Hydrolyse" vorgeschlagon. Die Verwandlang der Starke in Maltose und Dextrin, die Invertirang des Rohrzuckers aind Beispiele einer solohen hydrolytischen Wrirkung, wogegen bekanntlich z. B. die Umwendlang des Aethylenoxyda in Glywil nur einer einfachen Bydratbildung gleichkommt. 


\section{Ist die Dextrose ein Product der Einwoirkung des Malo- extracts auf Starke?}

Um auf diese wichtige Frage eine Antwort zu finden, haben wir das Ergebnifs der anhaltenden Einwirkung von betrăchtlichen Mengen Malzextract auf eine Lösung von DextrinMaltose von bekannter Zusammensetzung untersucht.

Bei diesen Untersuchungen wurde auf's Fleilsigste dafür Sorge getragen, dafs Duplicatsspecimina von Malzextract in absolut der gleichen Weise behandelt wurden, wie die Verwandlungsflüssigkeiten selber.

Veroush $I$.

Es warde anf gewbhnlichom Wege eine Loonng von Verwandiungsproducton dargestellt, welcho folgende Worthe ergab :

$$
\begin{array}{lll}
{[\alpha]_{8,36}=163,6^{\circ}} & \text { Maltose } & 80,1 \\
x y, 88=48,9 & \text { Dextrin } & \frac{19,9}{100,0 .}
\end{array}
$$

Zu 76 CC. dieser Ibaung warden 25 CC. vorglngig bis anf $62^{\circ}$ orhitaten Malzextracts hinrugethan. Die Mischung warde 16 Stunden lang bei $65^{\circ}$ digerirt; die Stkrkeproducte ergaben hioranf folgende corrigirto Daten :

$$
\begin{array}{llr}
{[a] \text { s,e }=162,1^{\circ}} & \text { Maltowe } & 97,8 \\
* a, \infty)=58,6 & \text { Dextrin } & 2,2 \\
\hline & & 100,0 .
\end{array}
$$

\section{Verruch $I L$}

Btizkorerwandlung bei $60^{\circ}$ C. mit anf $62^{\circ}$ erwarmtem Malsextract. Zoitdauer der Verwandlung : 1 stunde.

$$
\text { [a] } 0,88=164,0^{\circ} \quad x 8,88=49,57 \text {. }
$$

Diese Lösung wurde nach $\Delta$ blochung in drai Theila, A, B and C gotheilt

A. 74,5 CC. mit 25,5 CC. unerbitzten Malzextractes 16 Stunden bei $53^{\circ} \mathrm{C}$. digerirt.

Stikrkeproducto corrigirt :

$$
[x] \mathrm{s,86}=147,0^{\circ} \quad \approx 8,88=61,5 \text {. }
$$

B. 74,6 CO. mit 25,4 CC. vorher anf $62^{\circ}$ erhitaten Malzextractes 16 Stunden lang bei $63^{\circ} \mathrm{C}$. digerirt.

StArkeproducte corrigirt :

$$
[a]]_{3,86}=150,5 \quad x 9,86=68,3 \text {. }
$$


246 Broton u. Beron, Beiträge zur Geschichte der
C. 74,5 CC. mit 25,5 CC. yekochten Misisortracts 16 Stupden jagg bei $53^{u}$ digerirt.
Stkxkeproducto corrigirt :

$$
[\alpha] 3,86=166,0^{\circ} . \quad x: 3,86=49,3 .
$$

Bei diesem letzleren. Versuche II mulste, urn alle ans dem: Malzextract nöthig werdenden Correctionen zu erzielen, eine hesondere Analyse angestellt werden :

1) ron dem duf $62^{\circ}$ erwshrmten and eine Stunde lang bei $60^{\circ}$ digerirten Malzextract;

2) ron Nr. 1, nachiom die Lösung auf den Siedepunkt gebracht worcien;

8) Ton unorwärmtem Mslzextract nach 16 stündiger Digestion bei $53^{\circ}$;

4. run auf $62^{\circ}$ orwhirntom und 16 stunden lang bei $53^{\circ}$ digerirtem Maizextract;

5) ron getochtem nnd 16 Stunden lang bei $53^{\circ}$ digerirtem Maiz. extract.

Nur unit Hülfe dieser Vorsichtsmafsregeln beim Behandeln eines so veränderlichen Körpers wie Malzextract konnen irgend genaue Ergebnisse erzielt werden.

Bei den nachfolgenden Versuchen wurde nicht die ganze Menge des Malaextracts am Anfange auf einmal zugefügt, sunilern sie wurde, ans mehrere Portionen vertheilt, in auf cinander folgenden Zeilräumen zugegeben.

Versuch IIL

Fs wurde eive Löaung ron V8rwandlungsproducten bereitet, welehe nach der Corraction :

$$
[\alpha]_{; 3,86}=162,3^{0} \quad x_{8,86}=49,6
$$

orgab. Vore dieser Lösurig purden $75 \mathrm{CC}$. bei $60^{\circ} \mathrm{C} .16$ Stunden lang mit 24,7 CC. Malzeztract digerirt, die 20 drei verschiedenen Perioden hinzigethan warden. Für die Strurkeproduete urgaben sich die corrigirten Werthe :

$$
[\alpha]_{3,56}=147,7^{\circ} \quad x_{3,86}=60,8
$$

Fereuch IV.

Ursprtingliche Sthrkeproducto :

$$
[\alpha]_{\mathrm{j} 3,36}=164,3^{0} \quad x_{3,86}=48,5 .
$$

Von dieser Löøung wurden 66 CC. 28 Standen lang mí 34 CC. Malzextract digerirt; letateres war in vier verschiedeven Portionen zugefügt worden. 
Stïrke und der Verwoandlungen derselben.

$$
\begin{gathered}
\text { Stirkeproducte, corrigirt : } \\
\left\{\alpha_{j}^{j}=148,2^{\circ} \quad x=58,6 .\right.
\end{gathered}
$$

Aus den saimmtlichen hier angegebenen Versuchen ergiebt sich ganz klar, dafs auch durch eine anbaltende Einwirkung von Malzextract auf Stärke keine Dextrose gebildet woird. Das Enuproduot der Reuction ist Maltose, welche, wie wir schon oben usuhgewiesen, woder darch das Verwandlungsagens sulber, noch durch das geringe in Malzextract enthaltene Quantum Säure eine weitere Wasseraddition erleidet. Die von anderen Seiten behauptete Bitdung von Dextrose mag theils durch Thatsachen begrundet sein, und es sind dann ohne Zweilel die ron uns als so nothwendig erkannten Vorsichtsmalsregeln nicht genügend beobachtet worden, oder sie beruht auf einem Irrthum, zu dem der bisher angenommene zo hohe Werth des Kupferoxydreducirnngsvermögens Varanlassung gegeben hat.

\section{Das Wesen der Diastase.}

Wird Malzextract allmálig erwärmt, so wird ein Gerinnen zuerst bei ungefähr $46^{\circ}$ bemerkbar. Wird diese Tenperatur beibehaiten, so findet der hòchste unter diesen Yorhältnissen mögliche Grad ron Fällung in 15 bis 20 Minuten statt, and das Forterwärmen hat keinen weiteren Einflufs. Wird jedoch die Temperatur um ein Paar Grade erhõht, so tritt ein weiteres Gerinnen ein, welches hinwiederum ziemlich bald seinen Höhepunkt erreicht. Diese Zunahme des Gerinnens mit der Temperatur geht bis auf ungefähr $95^{\circ} \mathrm{C}$. fort.

Die bei irgend einer Temperatur sich ergebende Menge an geronnener Substanz aus demselben Quantum Normalmalzextract findet sich in der nachfolgenden Tabelle verzeichnet. In der dritten Spalte sind hier die absoluten Werthe des Eiweifsniederschlags in Procenten auf die bei $100^{\circ}$ erhaltene Yällung bezogen. 
248 Brown u. Horon, Beitrüge zur Geschichte der

\begin{tabular}{|c|c|c|}
\hline Temperatur & $\begin{array}{l}\text { Geronnenss Eiweiss } \\
\text { in Arammon }\end{array}$ & $\begin{array}{l}\text { Procentgatz des } \\
\text { Gegammtbotrags }\end{array}$ \\
\hline $50^{\circ}$ & 0,044 & 19,1 \\
\hline $60^{\circ}$ & 0,123 & 53,5 \\
\hline $66^{\circ}$ & 0,165 & 67,4 \\
\hline $76^{\circ}$ & 0,186 & 80,8 \\
\hline $100^{\circ}$ & 0,230 & 100,0 \\
\hline
\end{tabular}

Eine jede Stufe in dein dorch die Wärme herbeigeführten Gerinnen des Malzextracts ist von einer bestimmten Aenderung in dessen Stärkeverwandlungsvermögen begieitet; und unigekehrt haben wir niemals eine Aenderung in Stärkeverwandlurigsvermögen entdecken können, welche nicht mit deutlich wahrnehmbaren Gerinnungserscheinungen verbunden gewesen wäre.

Hierzu kommt noch, dafs bei 80 bis $81^{\circ}$, wo die diastatische Kraft des Malzextracts erlischt, fast sämmtliche dem Gerinnen ausgesetzte Albuminoïde niedergeschlagen sinó. Hieraus folgern wir, dafs die diastatische Kraft eine Function der gerinnungsfähigen Albuminoide selber ist und sich nicht, wie bisher allgemein angenommen, vom Vorhandensein eines bestiminten Verwandlungsagens herschreibt.

Diese Anschauung gewinnt noch ferneren Halt durch die nachfolgenden Betrachtungen. Wird Malzextract ein- oder zweimal unter einem geringen Drucke durch eine dünne Thonzelle, wie z. B. eine Batteriezelle mil sehr engen Poren filtrirt, so stellt sich heraus, dafs das bis zum Kochen erhitzte Filtrat keine Albuminoìde, sondern nur eine Spur von phosphorsaurem Kalk falien läfst. Diese Erscheinung schreibt sich zweifelsohne von der gleichen Ursache her, wie wir sie beschrieben haben, als wir auf die Eigenschuften der in gleicher Weise behardelten lösiichen Stärke aufmerksam machten. Da dio Albuminoide höchst colloïdal sind und ein grofses „Lõsungsmolecul" besitzen, so lassen sie sich nicht durch die gedachte 
Wand durchfiltriren *). Abgesehen von diesem Verluste an Albuminoiden haben wir keinerlei Aenderung in der Zusammensetzing des so behandelten Malzextracts zu entdecken vermocht; alierdings nimmt das Rechtsdrehungsvermögen der Flüssigkeit etwas zu, allein diefs rührt ganz ausschliefslich von der Abscheidung des linksdrehenden Eiweifses her.

Wird das Verhalten der filtrirten Flüssigkeit gegen Stärkekleister einer Prüfung unterzogen, so findet man, dafs dieselbe absolut keine Verwandlungskraft besitzt. Dieselbe hat alle diastatische Wirlsamilieit eben so vollkommen verloren, als wenn sie auf ihron Siedepunkt erhitzt vorden wodre.

In diesem Falle ist hinwiederum, ohne dafs Wärme zur Anwendurg gekonmen wäre, die Entfernung der gerinnungsfähigen Albuaninoide mit dem Verluste des Verwandlungsvermögens verbunden. Die diastatische Wirkung scheint ron den gerinnungsfăhigen Albuminoìden eben so antrennbar zu

*) Diese Ergebnisse sind ron besonderem Werthe fur dio Beurtheilung eines von Dr. W. Roberta besohriobenen Vorsuchs, ron dem hüufig behanptet wird, daf derselbe olne mllohtige Waffo gegen dio Lobre von der leblosen Zangang (Abiogenesie) bilde. Dieser Benbachter fand, dafs beim Filtriron eines ron Bactetien wiamelnden Pfanzenaufgusses durch eine poröse irdene Wand die filtrirte Flüssigkeit, wenn diesolbe anch in, die Erreugung ron Organiamen begünstigende Temperaturverhkltninse gebracht wurde, unfruchtbar und anverdndort bliob, wolohes Ergebnif ansuchliefs. lioh der Trennung der Bactorion und ihrer Koime von der Flutssigkeit zugesehrieben wurds. Nun sehen wir eber, defi anch die Flissigkait duroh eine solche Behandlang sehr bedentend gellendert werden kanu, indem die Albuminoïdo oder plastischen Krorper, auf wolohou die Heterogenisten ibre Lohro von der spontanen Erzeitgung ron Leben grtinden, theilwoise oder ghtnzlich ontfornt worlea.

Wir woilen liur aurohans nicht all Verfuchter der Abioganesis wagesehen werden, wolohe naoh unserer Ansicht sogar Vielea gogea sich bal; wir woller nur darkuf uufuerksam gemacht haben, dal's dieser sogenannts Fuudamentalversuch ron Dr. Roberts keines. wege den ihn zugeschrie'oeneni Worth besitst. 
250 Brown u. Heron, Beiträge zur Geschich te der

sein, wie die Erzengang von Weingeisi es von der actenzelle ist, mindestens halten wir die Thatsachen, welche tür die erstere Annahme sprechen, sind eben so beweiserd, wie diejenigen, welche zur Begründung des Causalnexus zwischen Hefe und Weingeist vorgebracht werder.

Die Gerste enthält vor ihrer Keimung mehr löshare, csagulirungsfähige Albuminoide, als nach Yolterdung des Malzprocesses. Nachfolgende Tabelle stelit die Ergetnisse dar, die durch Coagulirung gleicher Mengen normaten wässerigen Gerstenextracts bei verschiedenen Temperaiuren erzielt worden sind. Die Gerste war dieselbe, wie die, welche beim letzten derartigen Versuche nach der Keimung verwendet worden war, and es wurden $100 \mathrm{Th}$. Gerste siatt $80 \mathrm{mh}$. Malz zur Hersteliung des Extracts gebraucht.

\begin{tabular}{|c|c|c|}
\hline Temperatur & $\begin{array}{l}\text { Gegronnenes } \\
\text { Eiweifs in } \\
\text { Crammen }\end{array}$ & $\begin{array}{l}\text { Procentsatz, bezcgen auf } \\
\text { das gesemmote bei } 100^{\circ} \mathrm{C} \text {. } \\
\text { gerlitie Qtautum }\end{array}$ \\
\hline $50^{\circ}$ & 0,063 & 18,3 \\
\hline $60^{\circ}$ & 0,194 & 56,6 \\
\hline $66^{\circ}$ & $0 ; 233$ & 67,9 \\
\hline $76^{0}$ & 0,311 & 90,6 \\
\hline $100^{0}$ & 0,343 & 100,0 \\
\hline
\end{tabular}

Obgleich das absolute Quantum von cosugulirbayem Eiweifs in der Gerste bedeutend grôfser ist, als im Halz. so ist doch der Procentsatz des gesammten bei der gleichen Temperstur gefältten Quantums in beiden Fâllen ziemlich gleich.

Die gerinnungsfäbigen Albuminoìde des frischen Gerstenextracts sind allem Anscheine nach von denell res Malzextracts wenig verschieden, doch aber besitzen dieselben nur eine beschränkte diastatische Kraft. Die erst ¿ei Temperaturen über $66^{\circ}$ geronnenen Theile üben uuf Stärbckeister keine Wirkung aus, während die unter $60^{\circ}$ gefallten eine schwach $\theta$ Wirkungskraft besitzen, die jedoch wahrscheinlich nur den fünfzigsten oder hundertsten Theil der Intensităt der bei der- 
Skärke und der Verwandlungen dersellien.

selben Temperatur im Malzextracl in Lösung befindlichen Theile beträgt.

Wăhrend des Keimungsprocesses müssen die gerinmungsfähigen Albaminoide offenbar einige Veränderung erleiden, welche, ohne auf deren physikalische Eigenschaften einen grofsen Einfluf́s auszuüben, denselben eine bedeutende potentielle Energie ertheilt.

Möglich ist, dafs diese Körper aus Theilen des Zellenprotoplasmas (welches noch einige von den Eigenschaften des lebenden Protoplasmas zurũckbehailen hat) bestehen, die sich in einem Zustand schwankender Molecularspannung befinden, während sie die für die Bedürfnisse des wachsenden Embryos erforderlichen Aenderungen erleiden. Diese Aenderangen gehen wahrscheinlich von der äufsersten Colloïdalform bis ziu einem Zustande, bei welchem ein leichteres Durchdringen der Zellenwände möglich ist.

Durch die eigenthưmliche Molecularspannung erlangen die Albuininoìde eine gewisse Labilităt in ihrer Zusammensetzung und dadurch wiederum werden sio befähigt, unter günstigen Umständen die Hydrolyse der Starke herbeiführen zu können.

Bis jetzt ist es uns nicht möglich gewesen, irgend einen charakteristischen Wechsel in dem Zustande des Verwandlungsagens zu entdecken, welcher mit der Freigebung einer so bedeutenden Energie im Zusammenhang stände; eine solche Veränderung mufs aber auf alle Fälle vor sich gehen.

Das Verwandlungsvermögen der vethâltnilsmäfsig wenig activen Gerstealbuminoïdo lâfst sich auch nach deren Trennung vom Korne und demgemáfs ohne Hülfe von Keimung erhöhen. Ein auf einige Stunden bei $30^{\circ} \mathrm{C}$. der Wirkung von gewõhnlicher Hefe uusgesetzter Gcrstenextract gewinnt durch eine solche Behandlung bedentend an Fähigkeit, die Stärke zu verwandeln. Bine genan dem gleichen Processe ausgesetzte 
Mischang von Hefe und reinem Rohrzacker liefert eine Flüssigkeil, welche nicht die geringste Einwirkungskraft auf die Störke besitzt. Es leuchtet ein, dafs das Wachsthum der Hefenzelle gewisse Aenderungen in den Albuminoiden herbeizuführen vernag, welche beim gewöhnlichen Keinungsprocesse durch die Wirkung der lebenden Pfianzenzelle selber erzengt werden. Diese bemerkenswerthe Wirkung scheint sich auf die Saccharomyces zu beschränken. Wenn nur Schizomyceten im Gerstenextract vorhanden sind, so gewinnt der Aufgufs durchaus nicht an diastatischem Yermögen, sondern veriiert im Gegentheil noch rasch dasjenige, weishes er ursprünglich besafs.

Unserer Anschaliung nach dürfte sich durch eine Combination der Grundzüge von Liehig's Gährungstheorie mit einem Theile von Frémy's, Hemiorganisations"-Hypothese (S. sur la génération des ferments) eine rationelle Erklärung aller auf die sogenannte diastatische Gährung bezüglichen Thatsachen gewinnen lassen.

Mit der obigen Hypothese wird der Einflufs der Wärme auf die nachfolgende Wirkung des Malzextracts auf die Stärke verständlicher, als or es bisher gewesen.

Die erste Wirkung der Wärme besteht darin, dafs durch "Gerinnung 4 die Modificationen des Zellenprotoplasmas zerstört werden, welche während ihrer Wirksamkeit eine hinreichende Kraft freigaben, um die Hydrolyse der kleineren und weniger schwankenden Molecule der in der Reihe am Niedersten stehenden Dextrinarten herbeizuführen. Während nun. die Quautität dieser thätigeren Körper durch die Erhöhurg der Temperatur nach una nach abnimmt, verbleiben diejenigen Albuminoide uncongulirt, welche eine verhältnifsmabsig geringe Kraftmeng freizugeben fähig sind; letzture genthis allerdings, um die zusammengesetzteren und schwankenderen Molecule der höheren Daxirinarten zu hydrolysiren, nicht 
aber, um irgend eine Aenderung in den weniger schwankenden Moleculen der niedereren Dextrinarten herbeizuführen.

Dic diastatischen Gährstoffe, unähnlich den organisirten, besitzen kcinerlei Wiedererzeugungsvermōgen, und demgemäls ist deren Verwandlangswirkung beschrãnkt und steht in genauem Verhältnisse zu dem vorhandenen Verwandlungsagens. Unter so bewandten Umständen läfst sicb die relative Verwandlungsfähigkeit von zwei Malzaufgüssen leicht dadurch ermitteln, dafs unan zwei Stärkeverwandlungen unter sbsolut den gleichen Verbältnissen vor sich gehen lärst und eine den im Obigen beschriehenen ähnliche Zeitcurve errichtet. Das relative Verwandlungsvermögen läfst sich danach bemessen, wie weit die Stärke in einer bestimmten Zeit reducirt wird. Burion on Trent, Juli 1879.

\section{Zur Kenntnifs einiger Ultramarinverbin- dungen ;}

von Karl Heumann.

(Eingelsufen den 27. Angust*1879.)

Erste A b ha nd lung.

Seit Gmelin's Verfahren zur kūnstlichen Darstellung der dem Lasurstein zu Grunde liegenden blauen Substanz un die Oeffentlichkeit gelangte, sind von verschiedenen Chemikurn zahlreiche, aber vergebliche Versuche zur Gewinnung solcher Ultramarine angestellt worden, welche Katium oder andere Metalle stati des Natriums enthalten. 